University of South Florida

DIGITAL COMMONS

Digital Commons @ University of

@ UNIVERSITY OF SOUTH FLORIDA

South Florida

USF Tampa Graduate Theses and Dissertations

USF Graduate Theses and Dissertations

3-25-2015

\title{
An analysis of technology applications in the restaurant industry
}

Muhittin Cavusoglu

University of South Florida, muhittin@mcavusoglu.com

Follow this and additional works at: https://digitalcommons.usf.edu/etd

Part of the Hospitality Administration and Management Commons

\section{Scholar Commons Citation}

Cavusoglu, Muhittin, "An analysis of technology applications in the restaurant industry" (2015). USF Tampa Graduate Theses and Dissertations.

https://digitalcommons.usf.edu/etd/5456

This Thesis is brought to you for free and open access by the USF Graduate Theses and Dissertations at Digital Commons @ University of South Florida. It has been accepted for inclusion in USF Tampa Graduate Theses and Dissertations by an authorized administrator of Digital Commons @ University of South Florida. For more information, please contact digitalcommons@usf.edu. 
An Analysis of Technology Applications in the Restaurant Industry

by

\begin{abstract}
Muhittin Cavusoglu
A thesis submitted in partial fulfillment

of the requirements for the degree of Master of Science

Department of Hospitality Management

College of Hospitality and Technology Leadership

University of South Florida
\end{abstract}

Major Professor: Cihan Cobanoglu, Ph.D.

Katerina Berezina, Ph.D.

Serdar Ongan, Ph.D.

Date of Approval:

March 25, 2014

Keywords: Restaurant technology, Front of house applications, Back of house technologies, Mobile POS, PCI DSS

Copyright $@$ 2015, Muhittin Cavusoglu 


\section{Acknowledgments}

I would like to express my gratitude to my major advisor, Dr. Cihan Cobanoglu for his great support of my master's thesis. I am very thankful to him for his continues motivation, feedback, and patience.

I am also grateful to the other members of my committee members, Dr. Katerina

Berezina and Dr. Serdar Ongan, for their valuable guidance, feedback, and encouragement.

Besides the major advisor and committee members, I would like to thank my family, all my teachers and professors throughout my education for their support and attention on me.

Last but not least, I take this opportunity to express gratitude to Republic of Turkey Ministry of National Education for providing scholarship for me to study at U.S. 


\section{TABLE OF CONTENTS}

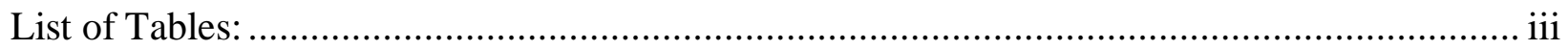

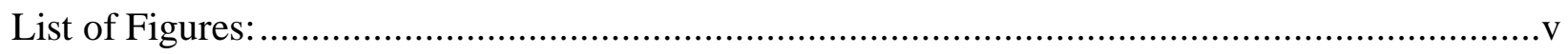

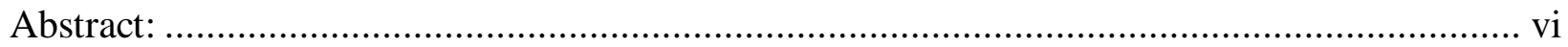

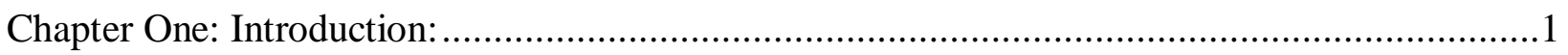

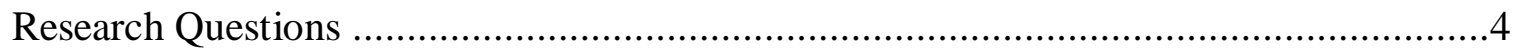

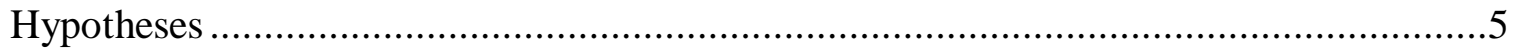

Limitations and Assumption ...........................................................................

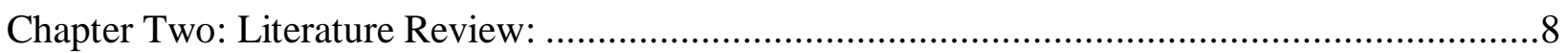

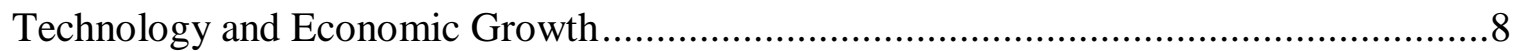

The Relationship between Technology and Economic Growth .............................9

The Relationship between Information Technology and Business .......................10

The Information Technology Paradox ...............................................................12

The Economic Impact of Food Industry on Total U.S. Economy ....................................13

Economic Impact of the Restaurant Industry ..............................................................15

Food Eaten Away from Home.......................................................................

Hospitality Industry and Information Technology ......................................................18

The Relationship between Information Technology and the Restaurant Industry 19

Technology Systems / Applications in the Restaurant Industry .....................................22

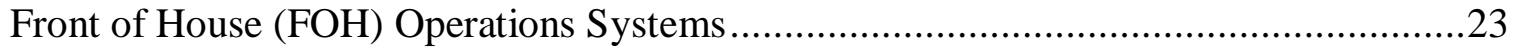

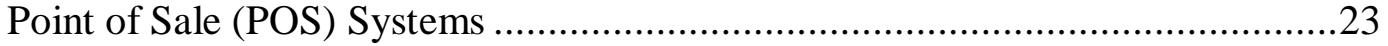

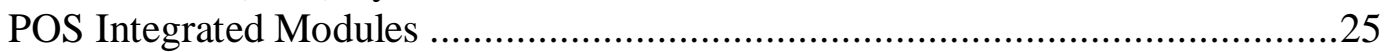

POS Integrated Payment Applications.......................................................29

Emerging FOH Operation Technologies............................................................32

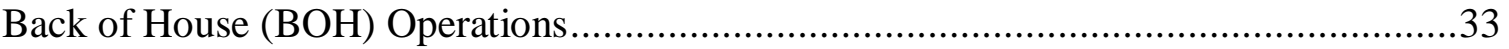

Accounting / Financial Software ......................................................................34

Labor Management System /Labor Screening and Recruitment Tool ..................34

Customer Relationship Management System.....................................................35

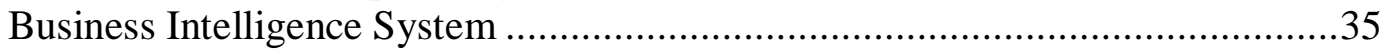

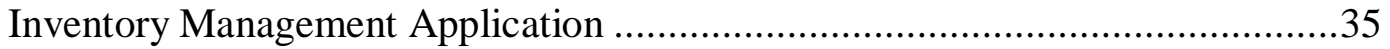

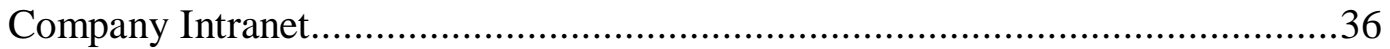

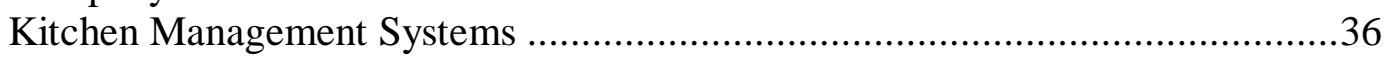

Integrated Cost Control System.........................................................................

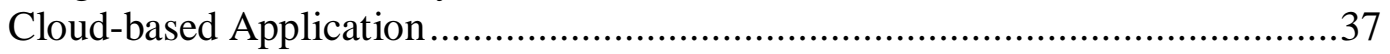

Enterprise Management System (EMS) .........................................................38

Enterprise Reporting System (ERS) and Real-Time based Reporting .................38

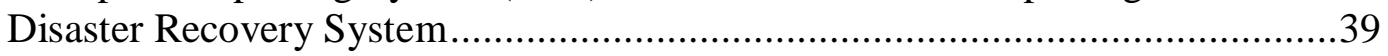




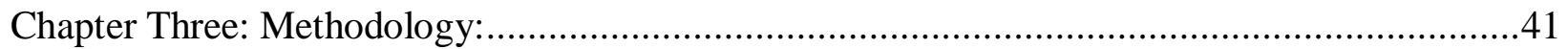

Research Design and Instrument ................................................................. 41

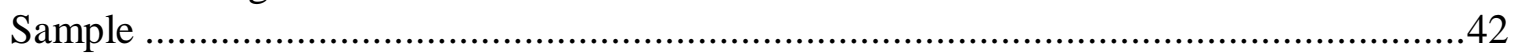

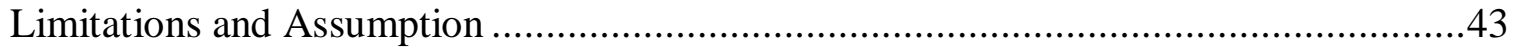

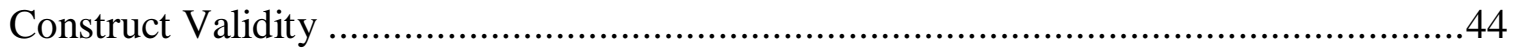

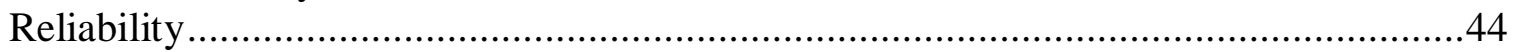

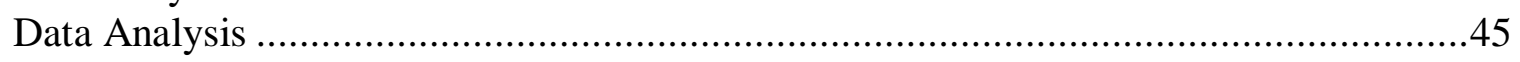

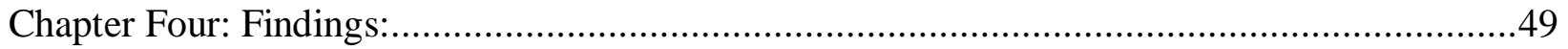

Company Characteristics, IT Budgets and Strategies .......................................49

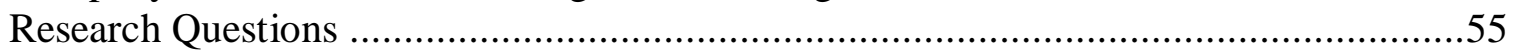

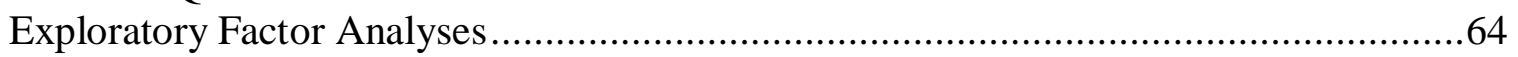

Hypotheses Testing .............................................................................. 74

Hypotheses Related to POS FOH Technology Features .................................75

Hypotheses Related to POS BOH Technology Features .................................77

Hypotheses Related to Mobile POS Perspectives......................................... 80

Hypotheses Related to PCI DSS Compliance ....................................... 82

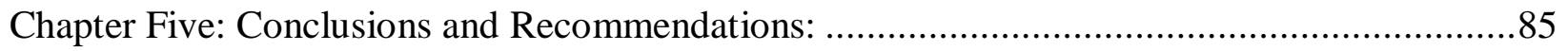

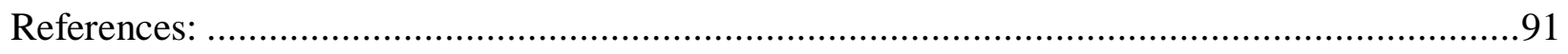

Appendix A: Letter of Permission from the Current Holder of the Data:.............................. 100 


\section{LIST OF TABLES}

Table 1: Summary of Kondratiev Waves …………………............................................................

Table 2: U.S. Personal Consumption Expenditures by Type of Product (Billions of dollars) 13

Table 3: Expenditures for Travel, Consumer Expenditure Interview Survey, 2005-2011....19

Table 4: Job Function of the Respondents ......................................................................................50

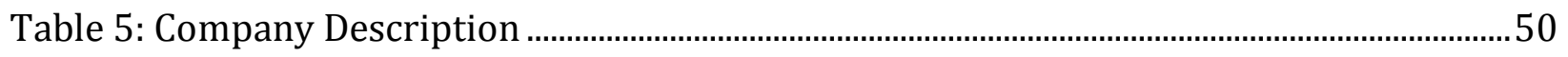

Table 6: Type of the Restaurant.........................................................................................................51

Table 7: Business Metrics Comparison Current Year and Previous Year........................................51

Table 8: Organization Preferences: Business Leadership versus Technology Leadership....52

Table 9: IT Budged Projection for Today and in Three Years as a Percentage of Sales............52

Table 10: Corporate Annual IT Budget in Dollars for 2013 ………..................................................53

Table 11: Comparison between Capital Expenditures versus Operating Expenditures ..........53

Table 12: Reference to IT Strategic Planning in the Mission Statement of Company................54

Table 13: Level of IT Decision Making at the Company …………………………………………...54

Table 14: IT Steering Committee

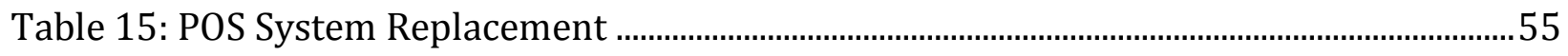

Table 16: IT Budget Distribution at the Restaurant Companies.....................................................56

Table 17: Technology Area IT Budget Distribution...........................................................................56

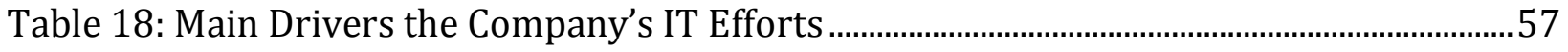

Table 19: Top Challenges for the Restaurant Technology Departments ......................................58

Table 20: POS FOH Technology Software/Hardware Utilization and Their Importance .......59 iii 
Table 21: POS BOH Technology Software/Hardware Utilization and Their Importance.......60

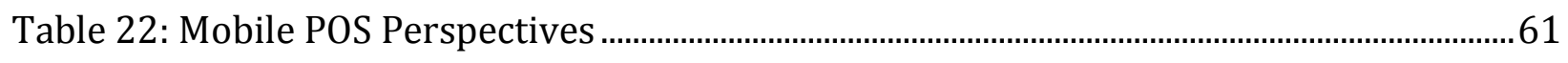

Table 23: PCI Compliance Trends and Challenges .................................................................................62

Table 24: Payment Card Industry Data Security Standards ...............................................................63

Table 25: Level of Payment Card Industry Compliance ..................................................................64

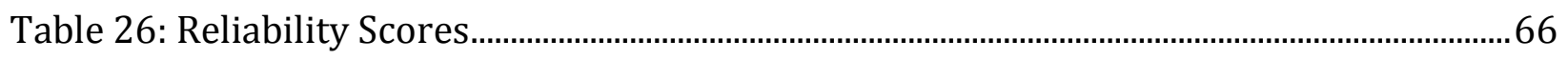

Table 27: Bartlett's Test of Sphericity and the Kaiser-Meyer-Olkin Measure of Sampling

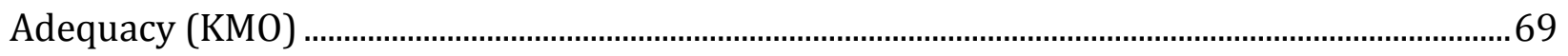

Table 28: Rotated Component Matrix for POS FOH Operation Features ..........................................70

Table 29: Rotated Component Matrix for POS BOH Operation Features .........................................71

Table 30: Rotated Component Matrix for Mobile POS Perspectives ................................................72

Table 31: Rotated Component Matrix for PCI DSS Compliance.............................................................73

Table 32: Hypothesis Testing for POS FOH Technology Features ....................................................76

Table 33: Hypothesis Testing for POS BOH Technology Features ...................................................78

Table 34: Hypothesis Testing for Mobile POS Perspectives..............................................................81

Table 35: Hypothesis Testing for PCI DSS Compliance ………………………………………….....83 


\section{LIST OF FIGURES}

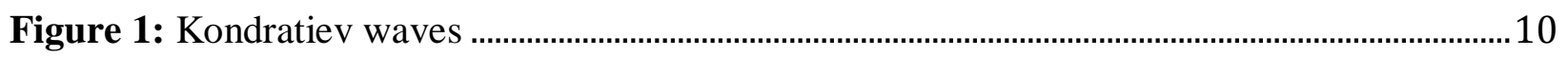

Figure 2: Comparison of personal consumption expenditures for the year $2013 * \ldots \ldots \ldots \ldots \ldots \ldots \ldots \ldots . . . .14$

Figure 3: Multiplier effect graph of some important sectors ……...................................................16

Figure 4: Food away from home (FAFH) as a share of household food expenditures ...................17 


\begin{abstract}
The purpose of this study was to examine the utilization of Front of House and Back of House technology applications by U.S. restaurants across different types of restaurants along with their level of IT management style, and the importance of these technology applications to the restaurants' operations. This study used secondary data. The survey data collected from 500 randomly selected restaurant technology managers who are current subscribers of Hospitality Technology Magazine as of January 2013. Response rate was $27.2 \%$ and these sample groups represented 67,299 restaurant units. The data analysis was organized into 3 parts (descriptive, factor analysis and independent samples t-test). The data analyzed with The Statistical Packages for Social Sciences (SPSS, version 21). In the descriptive part of the data analysis, the information about respondents' job functions, company characteristics and companies' IT perspectives are evaluated. In the second part, factor analysis was used. Since the factor analysis is a data reduction technique, factor analysis is used to create correlated variable composites and to reduce variables for better interpretation. The third and final stage of the data analysis included testing hypotheses based on factor analysis outcomes by using an independent samples t-test. The main purpose of using an independent samples t-test is to determine whether position (IT versus Non-IT), types of restaurant (Chain versus Independent), business leadership and technology leadership (Innovator versus Follower) differ on the factor attributes.
\end{abstract}




\section{CHAPTER ONE:}

\section{INTRODUCTION}

The service industry is one of the most important industries in the United States (U.S. Bureau of Economic Analysis, 2014a). Similarly, restaurant industry is one of the biggest components of the service industry. The National Restaurant Association (2015a) stated that restaurant industry sales are predicted to be more than $\$ 709.2$ Billion in 2015 . Moreover, expenditures in food services and accommodations have increased steadily from 2010 to 2013 rising from $\$ 617.7, \$ 649.5$, and $\$ 685.0$ to $\$ 714.7$ Billion respectively (U.S. Bureau of Economic Analysis, 2014a). The proportion of the food services and accommodations in the total personal consumption expenditures was 6.22\% (U.S. Bureau of Economic Analysis, 2014a), whereas it was $4.18 \%$ of the total U.S. Gross Domestic Product in 2013 (U.S. Bureau of Economic Analysis, 2015). As a result, the restaurant industry is one of the growing industries in the U.S.

The restaurant industry is divided into two main categories: Chain restaurants and independent restaurants (DeMicco et al., 2015). Chain restaurants are defined as "two or more eating establishments at separate locations under common ownership or related through other legal entities which as dominant activity provide prepared food for consumption on or off premises" (Wyckoff and Sasser, 1978, p. xxiii); whereas independent restaurants are the owneroperated restaurants having no partnership with any national or international restaurants (Pizam, 2005). Based on the level of service, these restaurants are divided into several main categories. 
According to DeMicco et al. (2015), these categories are: quick service restaurants, casual restaurants and fine dining restaurants. Each category is further defined below.

Quick service restaurants: Quick service restaurants provide a limited number of food items to customers in a very short window of time, and generally customers order their food at a counter or through a drive-through and pay for their food before consuming it (DeMicco et al., 2015).

Casual restaurants: "Casual restaurant were initially created to cater to the needs and wants of the middle class who were looking to enjoy the activity of going out to eat and being served without the high price tag associated with upscale or fine dining restaurants" (DeMicco et al., 2015 p. 5).

Fine dining restaurants: Fine dining restaurants are also known as white tablecloth restaurants. "A high level of service is delivered and expected by the patron. The restaurant décor itself helps to deliver the feeling that a superior dining experience is about to be delivered by the staff and experienced by the customers" (DeMicco et al., 2015 p. 5). Therefore, a high level of service delivery results in a high price tag in the fine dining restaurants (DeMicco et al., 2015).

Across all these levels of restaurant types, technological advancements in the world have influenced the restaurant business. Technology has become a major factor in the operation of restaurant businesses with the blossoming of the telecommunications industry, advancements in computer capabilities, and the development of sophisticated software to support delivery of services (Buhalis, 1998; Olsen and Connoloy, 2000). The restaurant industry is no exception (Collins, Cobanoglu, and Malik, 2003). Previous studies have also shown that investing in information technology (IT) companies were able to achieve revenue growth as well as cost 
savings (Kauffman and Walden, 2001; Kulatilaka and Venkatraman, 2001; Patil and Wongsurawat, and Irani, 2015; Ruth, Brush, and Ryu, 2015; Sambamurthy, Bharadwaj and Grover, 2003). As a result, "with the advent of new technology and its impact on restaurant operations, one would believe that most firms in the restaurant industry would be IT oriented in the production and delivery of goods and services" (Oronsky and Chathoth, 2007, p. 942). Despite this, IT may not be seen as a major function in restaurants. Less than half of the IT managers in restaurants are solely responsible for IT, while the rest have a main function (e.g., accounting manager, restaurant manager etc.) within the restaurant and secondarily have IT management responsibilities (Cobanoglu, 2007). Cobanoglu (2007) stated that "this simple fact indicates a potential problem within the restaurant industry wherein managers who have a core responsibility in an area other than technology would be unable to spend sufficient time on technology management...” (p. 40).

All restaurant technology may be divided into two major categories: Front of House (FOH) and Back of House (BOH) technologies that respectively support $\mathrm{FOH}$ and $\mathrm{BOH}$ operations (American Hotel \& Lodging Association [AH\&LA], 2006; Walker, 2014). Therefore, the main technology system used in these operations in a restaurant is the point of sale system (POS) which is "a network of cashiers and server terminals that typically handles food and beverage orders, transmission of orders to the kitchen and bar, guest-check settlement, timekeeping, and interactive charge posting to guest folios" (Collins and Cobanoglu, 2008, p. 245). Another version of POS used in the restaurant industry is the handheld POS terminal, which is also known as a mobile POS device or tableside ordering device. A handheld POS terminal is a portable device which has all the capability of the main functions of a pre-check POS system, as well as integrated tableside ordering and payment devices (Kasavana, 2011). All 
of these restaurant technologies which accept, process, store or transmit credit card payments must comply with a set of security standards known as the Payment Card Industry Data Security Standards (PCI Security Standards Council, 2013). The existence of these technology-based systems in restaurants and how they are used in restaurants are the main focus of this study. Restaurants may have different approaches to the management of technology based on their level of receptivity of innovation (i.e., whether they are innovators vs. followers) from the business and technology perspective (Collins and Cobanoglu, 2008).

Restaurant managers are continuously facing a problem of selecting technologies for their establishments. However, a fast growth and development of restaurant technology makes it difficult to follow those technology solutions that are important for the industry. This study will close this gap. Therefore, the purpose of this study was to examine the utilization of Front of House and Back of House technology applications by U.S. restaurants across different types of restaurants along with their level of IT management style, and the importance of these technology applications to the restaurants' operations.

\section{Research Questions}

The following research questions are proposed in this study:

1. What are the main drivers for IT investments in restaurants?

2. What are the main drivers for restaurants' IT efforts?

3. What is the top challenge facing restaurants' technology departments?

4. What are the point of sale (POS) Front of House (FOH) technology features used in restaurants? 
5. What is the importance of POS FOH technology features to the restaurants' operations by IT managers?

6. What are the point of sale (POS) Back of House (BOH) technology features used in restaurants?

7. What is the importance of POS BOH technology features to the restaurants' operations by IT managers?

8. What are the perceptions of restaurant IT managers on mobile POS systems?

9. What are the perceptions of restaurant IT managers on Payment Card Industry Data Security Standards (PCI DSS) practices in restaurants?

10. To what extent are U.S. restaurants compliant with PCI DSS requirements?

11. What is the level of PCI DSS compliance in restaurants?

\section{Hypotheses}

Based on the research questions listed above the following hypotheses are developed:

1. $\mathrm{H}_{\mathrm{A} 1}=$ There is a significant difference in POS FOH technology features between chain restaurants and independent restaurants.

2. $\mathrm{H}_{\mathrm{A} 2}=$ There is a significant difference in POS FOH technology features between restaurants which identify themselves as innovators versus followers from a business perspective.

3. $\mathrm{H}_{\mathrm{A} 3}=$ There is a significant difference in POS FOH technology features between restaurants which identify themselves as innovators versus followers from a technology perspective. 
4. $\mathrm{H}_{\mathrm{A} 4}=$ There is a significant difference in POS FOH technology features between restaurants with IT educated IT managers versus non-IT educated IT managers.

5. $\mathrm{H}_{\mathrm{B} 1}=$ There is a significant difference in $\mathrm{POS} \mathrm{BOH}$ technology features between chain restaurants versus independent restaurants.

6. $\mathrm{H}_{\mathrm{B} 2}=$ There is a significant difference in POS $\mathrm{BOH}$ technology features between restaurants which identify themselves as innovators versus followers from a business perspective.

7. $\mathrm{H}_{\mathrm{B} 3}=$ There is a significant difference in $\mathrm{POS} \mathrm{BOH}$ technology features between restaurants which identify themselves as innovators versus followers from a technology perspective.

8. $\mathrm{H}_{\mathrm{B} 4}=$ There is a significant difference in POS BOH technology features between restaurants with IT educated IT managers versus non-IT educated IT managers.

9. $\mathrm{H}_{\mathrm{Cl}}=$ There is a significant difference in mobile POS perspectives between chain restaurants versus independent restaurants.

10. $\mathrm{H}_{\mathrm{C} 2}=$ There is a significant difference in mobile POS perspectives between restaurants which identify themselves as innovators versus followers from a business perspective.

11. $\mathrm{H}_{\mathrm{C} 3}=$ There is a significant difference in mobile POS perspectives between restaurants which identify themselves as innovators versus followers from a technology perspective.

12. $\mathrm{H}_{\mathrm{C} 4}=$ There is a significant difference in mobile POS perspectives between restaurants with IT educated IT managers versus non-IT educated IT managers. 
13. $\mathrm{H}_{\mathrm{D} 1}=$ There is a significant difference in PCI DSS compliance between chain restaurants versus independent restaurants.

14. $\mathrm{H}_{\mathrm{D} 2}=$ There is a significant difference in PCI DSS compliance between restaurants which identify themselves as innovators versus followers from a business perspective.

15. $\mathrm{H}_{\mathrm{D} 3}=$ There is a significant difference in PCI DSS compliance between restaurants which identify themselves as innovators versus followers from a technology perspective.

16. $\mathrm{H}_{\mathrm{D} 4}=$ There is a significant difference in PCI DSS compliance between restaurants with IT educated IT managers versus non-IT educated IT managers.

\section{Limitations and Assumption}

The limitations of this study are the sampling procedure and sample size. The sample consisted of the IT managers of restaurants who subscribe to Hospitality Technology Magazine; therefore, the results may not able to be generalized beyond this population. Additionally, it was assumed that the respondents had the responsibility for their restaurant companies, including multi-units, and their answers represented the technology outlook of the entire enterprise. 


\section{CHAPTER TWO:}

\section{LITERATURE REVIEW}

\section{Technology and Economic Growth}

The literature reviewed shows a positive and significant relationship between improvements made in technology, and economic growth. Study of the relationship between technology and economic growth goes back to the early 1900s to the work of Joseph Alois Schumpeter. He is considered to be one of the leading economists in the twentieth century (Hospers, 2005; Sledzik, 2013; Tichy, 2011). There are also many current studies focusing on technology and economic growth. Search of the literature reveals a wealth of studies, such as: Bosworth and Triplett (2001), What's new about the new economy? IT, economic growth and productivity; Brynjolfsson and Hitt (2000), Beyond computation: Information technology, organizational transformation and business performance; Debackere, Verbeek, Luwel, and Zimmermann (2002), Measuring progress and evolution in science and technology-II: The multiple uses of technometric indicators; Dedrick (2003), Information technology and economic performance: A critical review of the empirical evidence; Hospers (2005), Joseph Schumpeter and his legacy in innovation studies; Jorgenson (2001), Information technology and the U.S. economy, Jorgenson and $\mathrm{Vu}$ (2005), Information Technology and the World Economy and Sood and Tellis (2005), Technological Evolution and Radical Innovation. 


\section{The Relationship between Technology and Economic Growth}

According to Sledzik (2013) and Tichy (2011), Schumpeter's main contribution to economics was showing the role of technological innovation in economic growth. Schumpeter argues in his book The theory of economic development (1934) that technological innovation is one of the main engines or dynamics of economic growth. Furthermore, in another book, Business cycles: A theoretical, historical, and statistical analysis of the capitalist process (1939), he studied the correlation between economic upswings and technological innovation. As a result of that study, he concluded that one of the most important reasons for economic upswings is technological innovation (Schumpeter, 1939).

Schumpeter defined the effect of technological innovation on economic growth through Kondratiev waves, which are 50-year cycles (Rosenberg and Frischtak, 1984; Tichy, 2011). The idea of Kondratiev waves belongs to Russian Nikolai Kondratiev; however, it was kept alive and further developed by Schumpeter in the first half of the 1900s (Tanning and Tanning, 2013).

Table 1 summarizes the Kondratiev waves (Tichy, 2011, p. 16).

Table 1: Summary of Kondratiev Waves

\begin{tabular}{|l|l|l|}
\hline Kondratiev wave & Period & Innovation \\
\hline 1st & 1780 s-1842 & Industrial revolution \\
\hline 2nd & $1842-1897$ & The age of steam and steel Railroad, cement, telegraph, photos \\
\hline 3rd & $1898-1950$ & Electricity, chemistry, motors, automobile industry Aluminum, plane, cinema \\
\hline 4th & $1950-2000$ & Electronics, TV, nuclear energy, plastic, cosmonautic, computers \\
\hline 5th & $2000->>>$ & $? ? ?$ \\
\hline
\end{tabular}

Source: Tanning and Tanning (2013) and Czesany (2006).

In the research cited in Schumpeterian business cycles: Past, present and future (2011), Tichy reported that although there are many signs of the fifth Kondratiev wave (such as "information and communication technologies, renewable resources, biotechnologies, and 
innovative materials (like nano-materials) studies" (p. 1073)), many researchers are persuaded by the idea of information and communication technologies as being the fifth Kondratiev wave.

The graph below (Tanning, Saat, and Tanning, 2013, p. 6) shows that the relationship between economic growth/upswings and the technological innovation/developments occur on average every 50-year period from the Schumpeterian approach of Kondratiev theory.

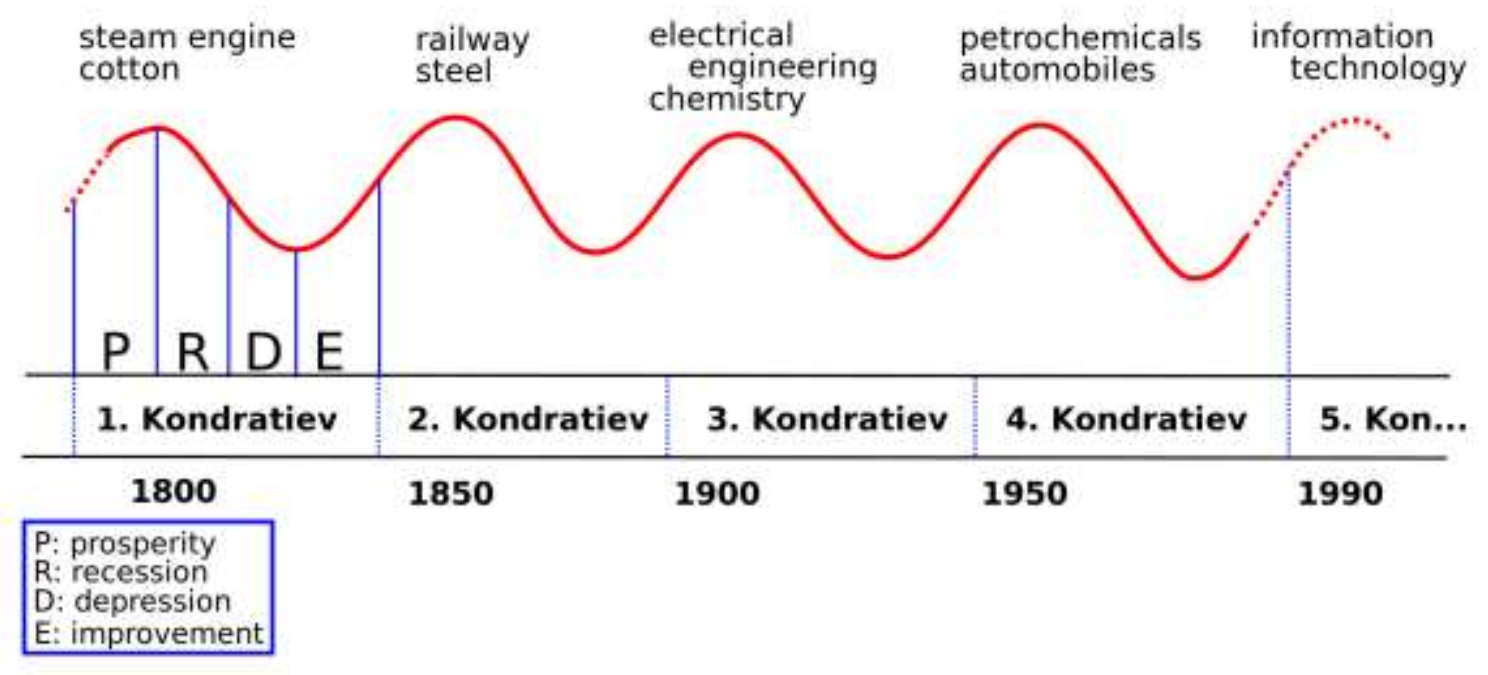

Figure 1: Kondratiev waves

Source: Korotayev and Tsirel (2010) and Tanning et al., (2013).

\section{The Relationship between Information Technology and Business}

Brynjolfsson and Hitt (2000) defined information technology (IT) as "computers as well as related digital communication technology [that have] the broad power to reduce the costs of coordination, communications, and information processing” (p. 24). Advancement in information technology has entirely changed the way business is done in many industries (Ansel and Dyer, 1999; Brynjolfsson and Hitt, 2000; Buhalis, 2003; Jorgenson and Stiroh, 2000). Melville, Kraemer and Gurbahani (2004) concluded that information technology is valuable 
because it provides broad benefits, such as "flexibility, quality improvement, cost reduction, productivity enhancement" (p. 54) and much more in the business industry. Additionally, Mithas, Tafti, Bardhan and Goh (2012) found out in their study (conducted with a sample of over 400 international companies between the years 1998 to 2003) that investment in information technology has a positive effect on profitability and revenue growth. Previous studies also showed that through the investment in information technology, companies were able to achieve revenue growth as well as cost savings (Kauffman and Walden, 2001; Kulatilaka and Venkatraman, 2001; Patil and Wongsurawat, and Irani, 2015; Ruth, Brush, and Ryu, 2015; Sambamurthy, Bharadwaj and Grover, 2003). Moreover, information technology offers competitive advantages to firms (Barney, 2015; Bienstock, Stafford and Stafford, 2015; Cho and Olsen, 1998; Clemons, 1986; Law, Leung and Buhalis, 2009; Madhavaram and Appan, 2015; McFarlan, 1984; Melville et al., 2004; Porter, 1985). Liang and Tang (1992) reported that there are two strategies (proactive or reactive) when evaluating competitive advantages: "The proactive strategy requires the firm to be an innovator; whereas, the reactive strategy suggests the firm to be a follower..." (p. 29). To gain an early competitive advantage from the technology, innovator companies have proactive information technology strategies, leading them to benefit from the technology first; on the other hand, followers avoid the innovation risks but as a result follower companies also benefit from technology later (Liang and Tang, 1992). Lastly, since information technology is adopted in areas such as operational efficiency, customer relationship, cost control, and strategic decision-making, it becomes an integral part of each and every one of these operations (Laudon and Laudon 2010; Law et al., 2009; Nyheim, McFadden, and Connolly, 2005). 


\section{The Information Technology Paradox}

Literature reviewed on this issue demonstrates that a series of studies on the effects of information technology on company performance and productivity show a significant relationship between information technology and productivity and company's key performance indicators (revenue growth, profitability, cost savings etc.). However, this positive effect is not universal. For instance, Barua, Kriebel and Mukhopadhyay (1995), Brynjolfsson and Hitt (1998), and Weill (1992) reject these findings. Moreover, Robert Solow, a Nobel awarded economist (as quoted in Mogotlhwane, Khosrowshahi, and Underwood, 2006) stated that "[w]e see the computer age everywhere except in the productivity statistics" (p. 270).

Researchers who reject the positive relationship between information technology and productivity and company performance, named their theory the "productivity paradox" or "information technology productivity paradox" (Oz, 2005; Xiong and Luo, 2012). Additionally, some of the studies conclude that there might not be a direct effect of information technology on productivity and company performance, and therefore the advantages of information technology should be measured in other ways than company increased performance and productivity (David, Grabski and Kasavana, 1996).

As a result, the latest studies have shown that either there is no information technology paradox (Xiong and Luo, 2012) or that there has been an indirect effect of information technology on company productivity and performance in the hospitality industry (Mihalic and Buhalis, 2013). Moreover, Kimes (2008) stressed that "correctly implemented, technology can more than offset its cost with increased revenue" (p. 298). 


\section{The Economic Impact of Food Industry on Total U.S. Economy}

According to the U.S. Bureau of Economic Analysis (2014a), personal consumption expenditures by type of product reached \$11,484.3 Billion, whereas Gross Domestic Product was $\$ 17,078.3$ Billion in the U.S. Economy in 2013 (U.S. Bureau of Economic Analysis, 2015).

Table 2 below shows the U.S. personal consumption expenditures by type of product from 2010 to 2013 (U.S. Bureau of Economic Analysis, 2014a).

Table 2: U.S. Personal Consumption Expenditures by Type of Product (Billions of dollars)

\begin{tabular}{|c|c|c|c|c|c|c|}
\hline \multirow[b]{2}{*}{ Main Categories } & \multirow[b]{2}{*}{2010} & \multirow[b]{2}{*}{2011} & \multirow[b]{2}{*}{2012} & \multirow[b]{2}{*}{2013} & 2013 & \multirow{2}{*}{$\begin{array}{c}2013 \\
\text { GDP \% }\end{array}$} \\
\hline & & & & & $\begin{array}{c}\text { Total } \\
\text { Exp. \% }\end{array}$ & \\
\hline \multicolumn{7}{|l|}{ Goods } \\
\hline Motor vehicles and parts & 342 & 363.5 & 395.1 & 417.7 & 3.64 & 2.45 \\
\hline $\begin{array}{l}\text { Furnishings and durable household } \\
\text { equipment }\end{array}$ & 250.4 & 260.7 & 271.1 & 280.9 & 2.45 & 1.64 \\
\hline Recreational goods and vehicles & 312.7 & 321 & 334.8 & 348.7 & 3.04 & 2.04 \\
\hline Other durable goods & 165.6 & 180.2 & 191.1 & 202 & 1.76 & 1.18 \\
\hline $\begin{array}{l}\text { Food and beverages purchased for } \\
\text { off-premises consumption }\end{array}$ & 788.9 & 829.1 & 854.9 & 872.2 & 7.59 & 5.11 \\
\hline Clothing and footwear & 320.6 & 338.9 & 353.7 & 360.7 & 3.14 & 2.11 \\
\hline Gasoline and other energy goods & 333.4 & 409.6 & 415.5 & 408.3 & 3.56 & 2.39 \\
\hline Other nondurable goods & 849.2 & 893.5 & 925.7 & 960.7 & 8.37 & 5.63 \\
\hline \multicolumn{7}{|l|}{ Services } \\
\hline Housing and utilities & 1909 & 1959.9 & 2009 & 2086.3 & 18.17 & 12.22 \\
\hline Health care & 1690.7 & 1764.7 & 1854.7 & 1920.3 & 16.72 & 11.24 \\
\hline Transportation services & 292.9 & 308.1 & 319.9 & 332.6 & 2.90 & 1.95 \\
\hline Recreation services & 385.1 & 400.6 & 418.4 & 436 & 3.80 & 2.55 \\
\hline Food services and accommodations & 617.7 & 649.5 & 685 & 714.7 & 6.22 & 4.18 \\
\hline Food services* & 532.2 & 558.7 & 588.1 & 611.4 & 5.32 & 3.58 \\
\hline Accommodations* & 85.5 & 90.8 & 96.8 & 103.3 & 0.90 & 0.60 \\
\hline Financial services and insurance & 763.2 & 795.8 & 788.4 & 826.7 & 7.20 & 4.84 \\
\hline Other services & 905.4 & 939.3 & 977.4 & 1010.9 & 8.80 & 5.92 \\
\hline $\begin{array}{l}\text { Final consumption expenditures of } \\
\text { nonprofit institutions serving households }\end{array}$ & 275.4 & 275 & 288.5 & 305.6 & 2.66 & 1.79 \\
\hline $\begin{array}{l}\text { Total Personal consumption } \\
\text { expenditures }\end{array}$ & 10202.2 & 10689.3 & 11083.1 & 11484.3 & 100 & \\
\hline Gross Domestic Product & & & & 17078.3 & & 100 \\
\hline
\end{tabular}

*Sub-categories of food services and accommodations

Source: U.S. Bureau of Economic Analysis (2014a).

According to Table 2, expenditures in food services and accommodations categories have 
increased steadily (\$617.7, \$649.5, \$685.0 and \$714.7 Billion, respectively) from 2010 to 2013 . The proportion of the food services and accommodations in the total personal consumption expenditures was $6.22 \%$, whereas it was $4.18 \%$ of the total US GDP in 2013. When food and beverages purchased for off-premises consumption is taken into consideration for the year 2013, total food industry expenditures was calculated at $12.91 \%$ (food services, $5.32 \%+$ food and beverages purchased for off-premises consumption 7.59\%) of the total personal consumption expenditures in the U.S. Additionally, the total food industry has $8.69 \%$ (food services, $3.58 \%+$ food and beverages purchased for off-premises consumption 5.11\%) of the total U.S. GDP in 2013.

The chart below (U.S. Bureau of Economic Analysis, 2014a) shows the personal consumption expenditures by type of product and the comparison with only food and beverages services in 2013.

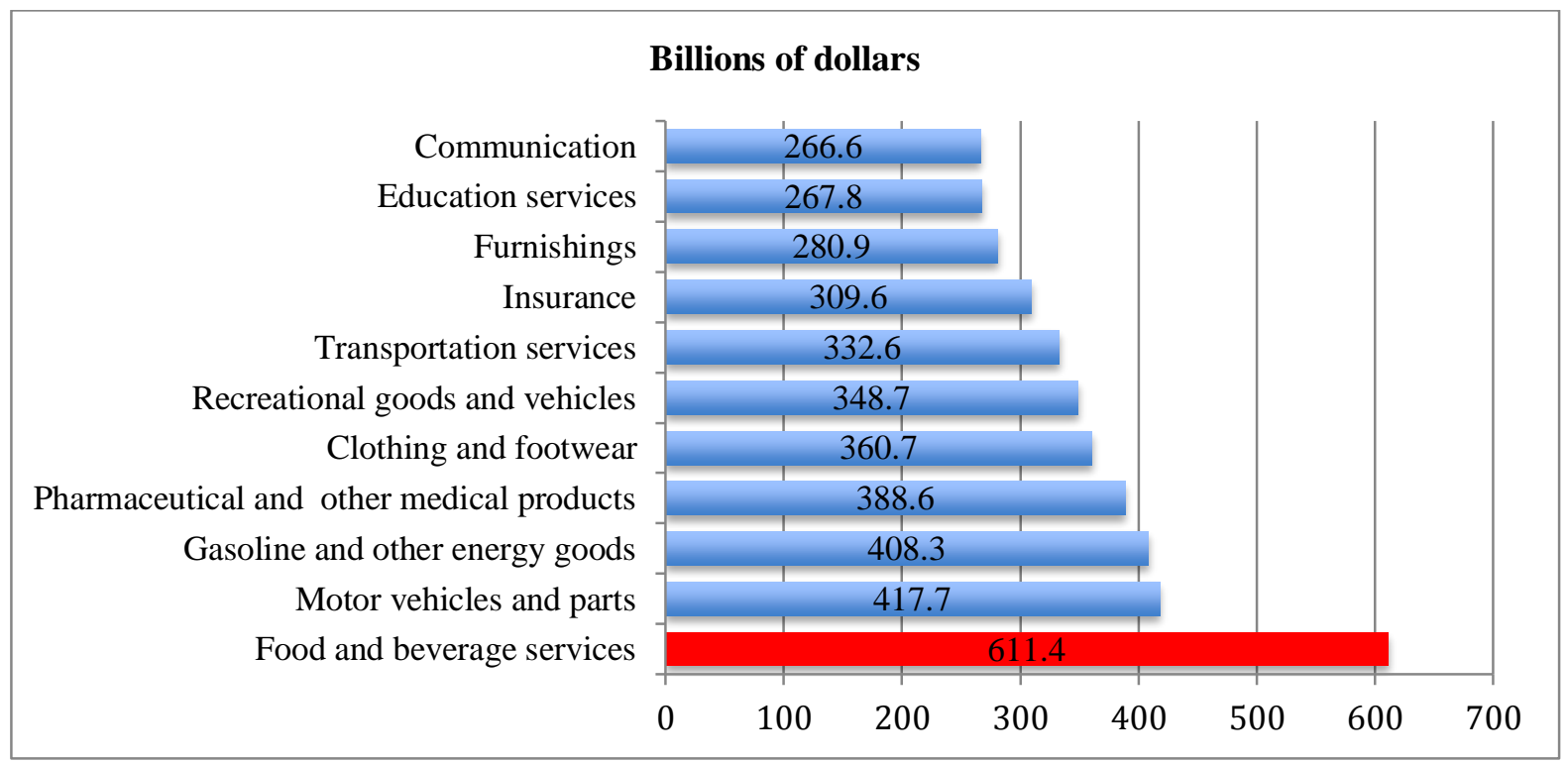

Figure 2: Comparison of personal consumption expenditures for the year 2013*

*Some of the main categories and sub-categories were chosen. Based on data from U.S. Bureau of Economic Analysis (2014a). 
According to the above "comparison of personal consumption expenditures" chart, expenditures in food and beverage services were more than some of the main U.S. services such as communication, education, insurance, transportation as well as goods such as furnishings, recreational goods and vehicles, clothing and footwear, pharmaceutical and other medical products, gasoline and other energy goods and motor vehicles and parts. There is a difference of approximately $\$ 200$ Million between food and beverage services, and gasoline and other energy goods and motor vehicles and parts. The total proportion of food and beverage services in the U.S. total personal consumption expenditures were calculated at $5.32 \%$, whereas that same sector was 3.58\% of the total U.S. GDP in 2013.

\section{Economic Impact of the Restaurant Industry}

Since the total food industry comprises an important proportion of the U.S. total personal consumption even when compared with other important services and goods, it is creating an important economic impact all over the U.S. economy (Kim and Gu, 2003). According to the National Restaurant Association (2015a), the restaurant industry had a 47\% sales share of the total food industry in 2014, while it was $25 \%$ in 1955 . In other words, as of 2014, the restaurant business has gained approximately half of the sales of the total food industry. Therefore, the restaurant industry is one of the main branches of the food industry. Moreover, total sales are estimated at $\$ 709.2$ Billion in 2015, a dramatic increase over the $\$ 42.8$ Billion realized in 1970 (National Restaurant Association, 2015a). Furthermore, the economic impact of the restaurant business is projected to total $\$ 1.8$ Trillion and "each $\$ 1$ spent in restaurants generates an extra $\$ 2$ in sales for other industries" (National Restaurant Association, 2015b). In other words, the 
economic multiplier effect of the restaurant industry is 2 to 1 in the U.S. economy and higher than some other important industries (U.S. Bureau of Economic Analysis, 2014b).

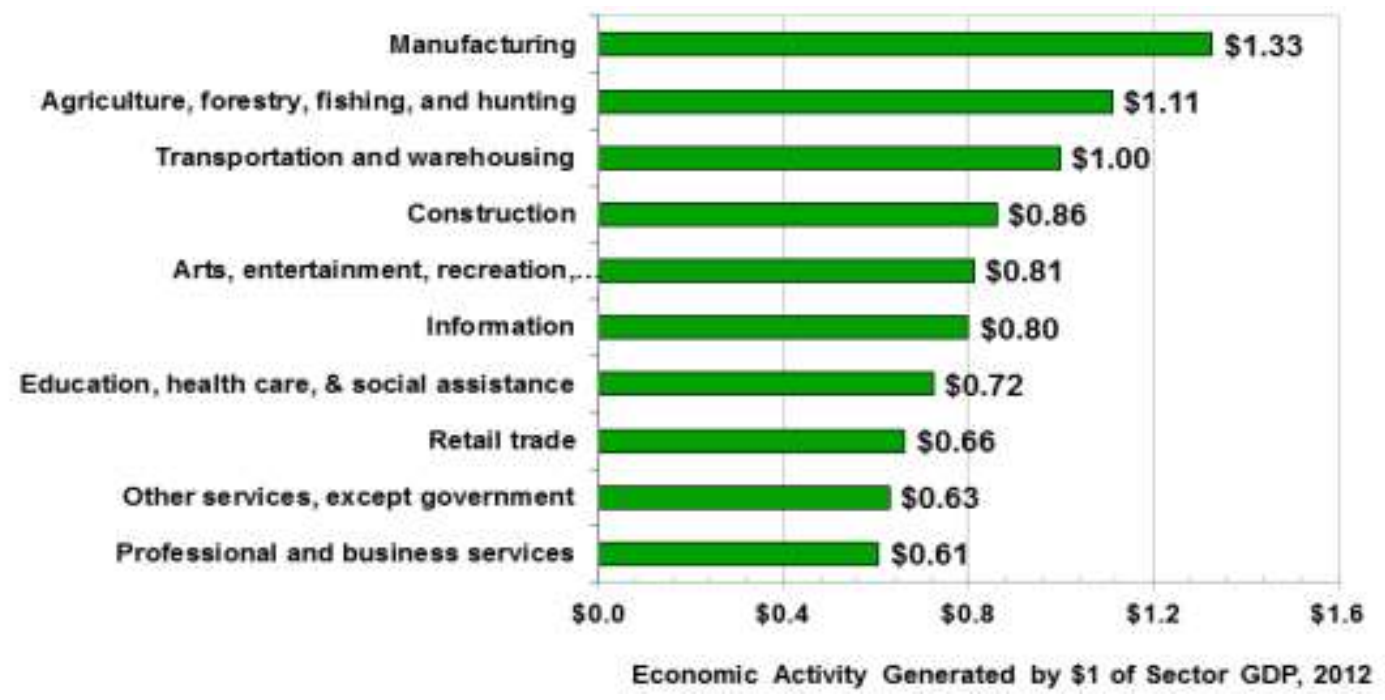

Figure 3: Multiplier effect graph of some important sectors

Source: U.S. Bureau of Economic Analysis (2014b), Annual Input-Output Tables

The restaurant industry provides a variety of products and services and accesses almost every household in one-way or another (Andaleeb and Conway, 2006). Hua and Templeton (2010) reported from Kim and Gu (2003) and the National Restaurant Association (2007) that “consumers spending was 53 cents out of every dollar on food away from home, compared to 45 cents in 1999" (p. 56). Besides the economic impact, in terms of employment capacity the restaurant industry is the second largest private industry with 14 Million employees and is expected to reach 15.7 Million by 2025 (National Restaurant Association, 2015a). For these reasons, according to Hua and Templeton (2010) and Kim and Gu (2003), the restaurant industry contributes significantly to the U.S. economy. 


\section{Food Eaten Away from Home}

In recent decades, there has been a great tendency to dine out in the U.S. According to Binkley (2006), food eaten away from home (FAFH) is one of the main changes in American dining habits. FAFH as a proportion of household food expenditures has increased steadily from $1970(25.9 \%)$ to 2012 (43.1\%) (U.S. Department of Agriculture, 2014).

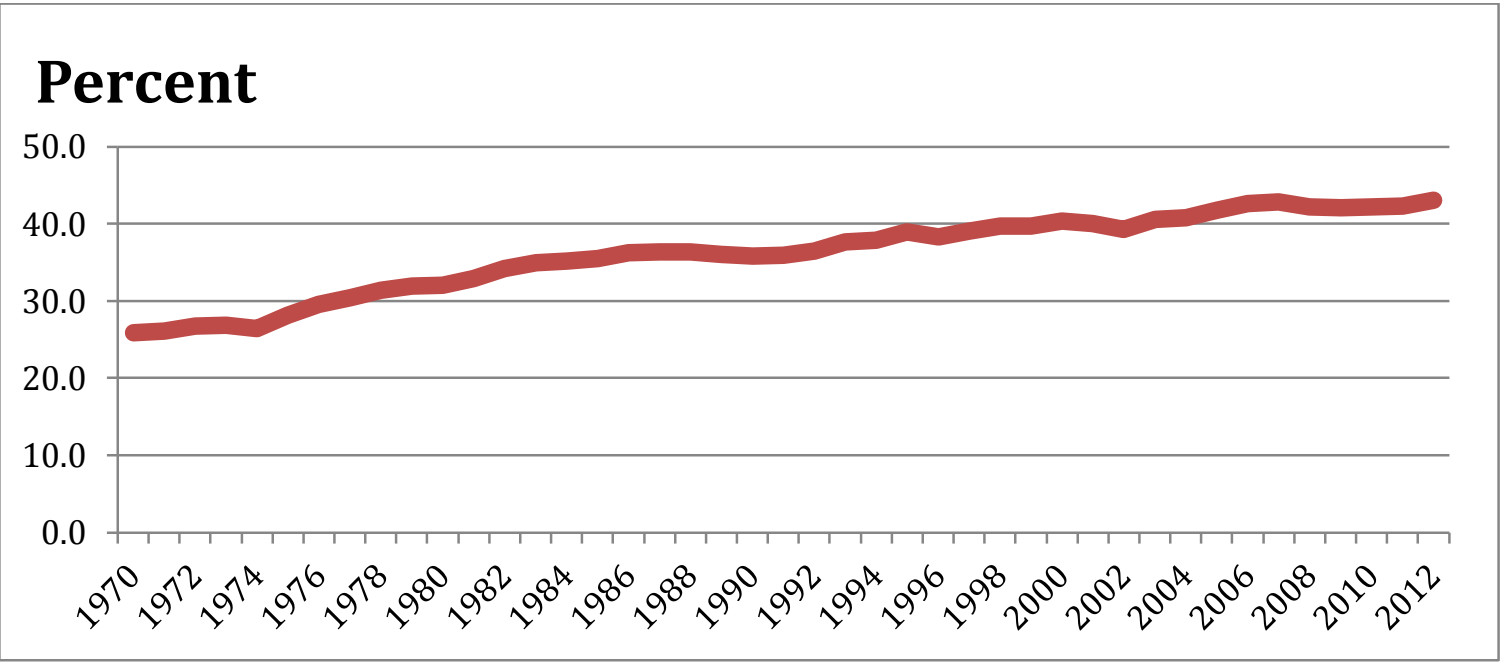

Figure 4: Food away from home (FAFH) as a share of household food expenditures

Source: Based on data from U.S Department of Agriculture (2014).

There have been numerous studies which have addressed the reasons for this growth, such as: the increased value of household time as well as increased household income (Binkley, 2006; Byrne, Capps and Saha, 1998; Kinsey, 1983; McCracken and Brandt, 1987; Prochaska and Schrimper, 1973; Redman, 1980; Yen 1993). According to Goch (1999), the employment rates of married women have almost tripled since 1950. Additionally, the U.S. Department of Labor (2014) has reported that the participation rate of married women is $59.5 \%$ in the workforce compared to $57.7 \%$ of the total female population overall. 
Since married women are increasingly participating the U.S. labor force, they have not had much time to prepare meals at home, and more importantly they have increased household income (Binkley, 2006). Moreover, according to Mogelonsky (1998), dining out becomes more frequent and ordinary instead of as a planned occasion. As result of lack of time to cook at home and increased household income, people now prefer to dine out. All these factors have led to our current "booming restaurant industry" (Andaleeb and Conway, 2006, p. 3). Because the American people have been dining out more and the way of life has changed in the U.S., the restaurant industry now has a huge economic impact on the U.S. economy (Andaleeb and Conway, 2006).

\section{Hospitality Industry and Information Technology}

According to Leung and Law (2013), information technology is playing a crucial role as one of the most important tools in the hospitality industry. Cobanoglu and Collins (2008) claim that information technology is an inseparable part of the hospitality industry.

A large amount of capital has been invested on information technology in the hospitality industry to increase revenues, to decrease the costs and to improve service quality for its customers (Huo, 1998; Siguaw, Enz and Namasivayam, 2000). Furthermore, by implementing information technology, hospitality businesses have realized a positive and significant correlation between the use of information technology and the development of a competitive advantage (Barney, 2015, Cho and Olson, 1998; Clemons, 1986; Madhavaram and Appan 2015; McFarlan, 1984; Porter, 1985). Additionally, researchers from academia as well as industry professionals have highlighted the valuable impact which information technology has had and they have paid attention to the more effective contributions to the hospitality industry (Ham, Kim 
and Jeong, 2005; Hua, Morasan, and DeFranco, 2015; Law, Buhalis, and Cobanoglu, 2014

Siguaw et al., 2000).

\section{The Relationship between Information Technology and the Restaurant Industry}

According to the U.S. Bureau of Labor Statistics as reported by Paulin (2012), on average, a traveler spent $\$ 1372$ per trip in 2011. Table 3 below has been prepared based on surveys collected by the U.S. Bureau of Labor Statistics (2012), from the year 2005 to 2011.

Table 3: Expenditures for Travel, Consumer Expenditure Interview Survey, 2005-2011

\begin{tabular}{|l|r|r|r|r|r|r|r|r|}
\hline \multicolumn{1}{|c|}{ Total trip spending } & $\mathbf{2 0 0 5}$ & $\mathbf{2 0 0 6}$ & $\mathbf{2 0 0 7}$ & $\mathbf{2 0 0 8}$ & $\mathbf{2 0 0 9}$ & $\mathbf{2 0 1 0}$ & $\mathbf{2 0 1 1}$ & \multicolumn{1}{c|}{$\mathbf{2 0 1 1}$} \\
\hline & $\begin{array}{c}\mathbf{\$ 1 , 2 9} \\
\mathbf{3}\end{array}$ & $\begin{array}{c}\mathbf{\$ 1 , 4 0} \\
\mathbf{8}\end{array}$ & $\begin{array}{c}\mathbf{\$ 1 , 4 6} \\
\mathbf{2}\end{array}$ & $\begin{array}{c}\mathbf{\$ 1 , 4 1} \\
\mathbf{1}\end{array}$ & $\begin{array}{c}\mathbf{\$ 1 , 2 7} \\
\mathbf{3}\end{array}$ & $\mathbf{\$ 1 , 3 0 0}$ & $\mathbf{\$ 1 , 3 7 2}$ & Share \% \\
\hline Food and beverages & 320 & 329 & 332 & 327 & 313 & 309 & 329 & 23.98 \\
\hline $\begin{array}{l}\text { Food prepared by consumer } \\
\text { unit on out-of-town trips }\end{array}$ & 41 & 43 & 43 & 49 & 49 & 43 & 48 & 3.50 \\
\hline Food away from home & 236 & 243 & 246 & 238 & 223 & 223 & 236 & 17.20 \\
\hline Alcoholic beverages & 42 & 43 & 44 & 40 & 42 & 43 & 45 & 3.28 \\
\hline Lodging & 294 & 321 & 343 & 329 & 300 & 299 & 315 & 22.96 \\
\hline Transportation & 538 & 610 & 643 & 622 & 543 & 570 & 603 & 43.95 \\
\hline Airfare & 285 & 335 & 360 & 343 & 301 & 325 & 342 & 24.93 \\
\hline Train, bus, ship fare & 73 & 83 & 84 & 71 & 72 & 65 & 62 & 4.52 \\
\hline Car and truck rental & 27 & 28 & 28 & 27 & 25 & 26 & 23 & 1.68 \\
\hline Other vehicle rental* & & & & & & & & \\
\hline $\begin{array}{l}\text { Local transportation (taxi, } \\
\text { etc.) }\end{array}$ & 18 & 21 & 21 & 20 & 17 & 17 & 20 & 1.46 \\
\hline Gasoline and motor oil & 121 & 129 & 132 & 146 & 110 & 119 & 141 & 10.28 \\
\hline Parking fees and tolls & 10 & 10 & 10 & 10 & 11 & 11 & 10 & 0.73 \\
\hline Recreational vehicles & 4 & 5 & 7 & 4 & 6 & 7 & 5 & 0.36 \\
\hline Fees and admissions & 141 & 148 & 145 & 134 & 116 & 122 & 125 & 9.11 \\
\hline
\end{tabular}

*Expenditure is positive, but less than $\$ 0.50$.

Source: U.S. Bureau of Labor Statistics, (2012).

As can be seen in Table 3, total trip spending was categorized into four main groups which are food and beverages, lodging, transportation and fees and admissions. Shares for these categories were $23.98 \%, 22.96 \%, 43.95 \%$ and $9.11 \%$ respectively. Among the four major 
components of total trip spending, food and beverages came in second place with a $23.98 \%$ share, after transportation expenditure (43.95\%). As a result, all of the above figures also show the importance and economic impact of the food and beverages industry on the total hospitality industry, in addition to total U.S. personal consumption expenditures and U.S. GDP.

The World Travel Organization Tourism Highlights (2014) reported that total international tourism receipts across the Americas (including North, Central, and South America and the Caribbean) were \$229.2 Billion in 2013. Additionally, STR Analytics’ Hotel Operating Statistics Almanac (2014) reported that the revenue in the hotel industry has reached on estimated \$163 Billion in 2013. When international tourism receipts and projected hotel industry revenue are added to each other, they still could not reach the restaurant sales which totaled \$660.5 Billion in the U.S. (National Restaurant Association, 2013).

In addition to its impact on the U.S. economy and the food industry, the restaurant industry is also one of the main branches of the hospitality industry. So the fact that information technology is commonly used in the hospitality industry, it brings many benefits to the restaurant industry. Therefore, Information technology creates a large difference (Hayes, 2002) and strongly affects the restaurants' performance (Devaraj and Kohli, 2003). According to Kimes (2008), convenient technology can bring many benefits to the restaurant industry.

Kimes (2008) points out that the benefits of technology include: shortening time spent in the ordering process (e.g., handheld terminals), enhancing processing in food production (e.g., kitchen technology), speeding up the service time (e.g., table management systems), providing faster payment (e.g., handheld terminals), shortening seat turnover or turnaround time (e.g., near field communications and/or table management systems), and decreasing labor cost (e.g., labor management systems, online reservation systems and POS integration into online ordering). In 
addition to these benefits, other improvements that technology may provide competitive advantage, enhanced productivity, higher profitability (Kasavana, 2011), and cost minimization (Thompson, Ekman, Selby, and Whitaker, 2014), better employee management and customization of customer preferences in the restaurant industry (Ansel and Dyer, 1999). Moreover, "restaurant technology provides management with the right information at the right time resulting in fewer costly mistakes, better forecasting, higher productivity, and improved marketing know-how" (Collins and Cobanoglu, 2008, p. 245).

Supporting these points, Brian Sill, president and co-founder of Deterministic, a restaurant management consulting company, is quoted in Collins and Cobanoglu (2008) as stating:

To compete effectively in the markets of today, and tomorrow, all stages of the restaurant production and service chain must act in concert, so as to ultimately deliver quality products at the right prices to the right guests at the right times. Failure to do so can result in excess inventory, poor food quality, poor guest service, underutilized capacity, and unnecessary cost. Restaurant technology helps management monitor and coordinate these activities in a more timely and focused manner (p. 245).

Oronsky and Chathoth (2007) state "IT has played some role in changing a customer's dining experience over the years - the way in which the meal is prepared, the speed at which it is delivered, the way an order is received..."(p. 941). In addition to Oronsky and Chathoth, Buhalis (2003) stressed that information technology has been changing the main dynamics of the industry and reshaping it. Moreover, Liddle (2002) claimed that "nearly half of the "sure-thing" 
changes that will reshape foodservice by 2010 will involve technology" (p.4).

According to Oronsky and Chathoth (2007), recent trends of information technology in the restaurant industry are customer feedback systems (e.g., customer relationship management (CRM), social media activity integrated into CRM platform, and real-time, web-based reporting), repeat business management applications (e.g., e-reservation systems, point of sale (POS) integration into online ordering), marketing management systems (e.g., POS software and handheld terminals), operational restaurant systems (e.g., wireless credit card authorization or mobile POS and revenue management system, accounting/financial software, and integrated cost control software or inventory management tools), human resources management systems (e.g., labor management systems, labor screening and recruitment systems, and company intranet), and Back of House management systems (e.g., kitchen technologies, kitchen management systems, kitchen displays, and kitchen printers).

As a result, based on all the above information, the role which technology is playing in the restaurant industry is an important one.

\section{Technology Systems / Applications in the Restaurant Industry}

There are many technology systems used in the restaurant industry. However, a review of literature demonstrated that there have not been studies on restaurant technology as much as on other fields in the hospitality industry (Huo, 1998; Lam, Cho and Qu, 2007; Kim, Lee and Law, 2008). According to AH\&LA, "Food and Beverage Systems Report" (2006), technologies used in restaurants are divided into two main groups: systems/applications that are used in Front of House $(\mathrm{FOH})$ operations, and those used in Back of House $(\mathrm{BOH})$ operations. 


\section{Front of House (FOH) Operations Systems}

FOH operations can be defined as the process starting with taking orders and delivering food to guests and completing with payment process (AH\&LA, 2006). There are many technology applications that used in this process. Most of the important technologies that are used in Front of House are: point of sale systems, POS integrated modules, POS integrated payment applications and some emerging technologies used in $\mathrm{FOH}$ operations.

\section{Point of Sale (POS) Systems}

POS system is "a network of cashiers and server terminals that typically handles food and beverage orders, transmission of orders to the kitchen and bar, guest-check settlement, timekeeping, and interactive charge posting to guest folios" (Collins and Cobanoglu, 2008, p. 245). According to AH\&LA (2006), "the POS system is the core system for F\&B operations...”(p. 3). POS systems date back to the early 1980s (Ansel and Dyer, 1999). They make it possible to update prices, change menu items, and track sales data through POS systems, all in a simple and quick way (Ansel and Dyer, 1999). A POS system has mainly two components, which are POS hardware and POS software (Kasavana, 2011).

The POS hardware systems are installed on computers and provide the capability of connecting any piece of equipment or device to the POS such as: touch screen terminal, integrated credit card swipe device and table side ordering devices such as handheld terminals (Collins and Cobanoglu, 2008). The POS hardware is meaningless itself and cannot work for the purpose of the restaurants, so there should be some POS applications installed into POS hardware "to instruct to what to do, how to do it and when to do it"(Kasavana, 2011, p. 131). Advancement in POS technology results in user-friendly POS hardware such as touch 
screen terminals which are very informative and easy to use (DeMicco et al., 2015). A touchscreen terminal is made of a flat screen and microprocessor to control it (Kasavana, 2011). It is a flexible device providing ease to data entry and meal selections, and eliminating incomplete orders (Kasavana, 2011). Additionally, Ansel and Dyer (1999) state that touch screen terminals decrease the number of staff working on the front line and decrease customers' wait time. Moreover, advanced touch screen terminals reduce the burden of employee training and increase employee effectiveness and efficiency (DeMicco et al, 2015).

Credit card payments have become a common habit in the U.S. society (McCall and Belmont, 1996). In 2012, $81 \%$ of the bill payments in fine dining restaurants were processed through credit, debit and/or pre-paid cards (Satran, 2013). Therefore, an integrated credit card swipe device is now an inseparable part of the advanced POS systems (Kasavana, 2011). This is an integrated device to the main POS system, made of magnetic stripe readers, which are used for credit card authorization and printing receipts to be signed (Collins and Cobanoglu, 2008). According to Mastroberte (2014), integrating credit card payment into POS has increased the efficiency of the employee.

Another piece of user-friendly POS hardware is the handhelds POS terminal, which is also known as mobile POS device or tableside ordering device. A handheld POS terminal is a portable device which has all the capability of the main functions of a pre-check POS system, as well as integrated tableside ordering and payment devices (Kasavana, 2011). Although the handheld terminals date back to the late 1970s (Collins and Cobanoglu, 2008), updated versions are still commonly used and are increasing in popularity in the restaurant industry (Manion and DeMicco, 2005). However, a hotly debated discussion about the advantages and disadvantages is still ongoing even into the present. 
Advantages of mobile POS devices include: serving guests more quickly, delighting guests (DeMicco et al., 2015), increasing guest satisfaction (Kasavana, 2011) and reducing credit card skimming (Cobanoglu, Erdem, Nusair, and Berezina, 2012). In contrast to these advantages of mobile POS devices, however, there are also some drawbacks, such as: they are easy to lose, and easy to damage (Collins and Cobanoglu, 2008), the devices are expensive (Manion and DeMicco, 2005), and they are not a secure method of payment due to the possibility of data interception through wireless technology so some managers do not want to invest in mobile POS devices (Lucas, 2003). Besides the mobile POS devices, customers are willing to try new technologies; therefore, mobile POS applications and mobile optimized websites are gaining popularity among restaurant customers (DeMicco et al., 2015).

Other than POS hardware, there are many modules or programs compatible with POS systems, such as: gift card modules, POS integration into online ordering, social media activity integrated into POS, table management systems, reservation systems, menu management systems, and take-out/delivery systems used in the restaurant industry. Furthermore, POS systems provide some payment applications, such as: wireless credit card authorization, tableside payment devices, near field communication, and bill pay via customers' mobile phones. In addition to payment applications, the advanced POS systems integrate some emerging FOH operation technologies, which are: digital signage devices, energy efficient POS, barcode scanners, and biometric readers.

\section{POS Integrated Modules}

POS systems are becoming more powerful, with the ability to connect different modules (Collins and Cobanoglu, 2008). Gift card integration, POS integration into online ordering, 
social media activity integrated into POS, table management systems, reservation systems, takeout/delivery systems, and menu management systems are some commonly used modules in the restaurant industry.

A gift card module is a piece of integrated POS software that tracks the gift cards sales and redemption (Collins and Cobanoglu, 2008). According to Kasavana (2011), a gift card program helps to increase customer loyalty, attracts new customers, and provides advanced cash flow. Moreover, other benefits of gift card programs are "increased sales, the frequency and nature of customers' transactions are tracked, a higher profit margin because not all gift cards are redeemed, and the refilling and reusing of them by customers" (DeMicco et al., 2015, p. 137). According to Collins and Cobanoglu (2008), 10\% of the all transactions in Starbucks are done through gift cards which provided the company a great benefit.

POS integration into online ordering is another beneficial module for the restaurant industry. It is another type of distribution channel for the restaurant industry to increase sales, and also decrease labor costs (Kimes, 2008). Since it is connected to a POS system, it provides quick food delivery and reduces the waiting time (Kimes, 2008). According to Creamer and Lorden (2014), most of the POS companies are offering an integrated online ordering module as part of a POS system.

Social media activity integration into POS is another interface that enables restaurant to advertise their menus online and receive orders through social media (Riggs, 2013). According Creamer and Lorden (2014), 33\% of the restaurant customers are expecting social media integration into the POS. In the same reports, it was clearly seen that some of the important POS systems providers are seeking to integrate online ordering and/or social media activity with the POS systems (Creamer and Lorden, 2014). 
There are some POS modules that help restaurateurs to organize and to handle table management, reservations and menu management much better. Table management systems are one of the most efficient modules for organizing and handling table status and reservations (DeMicco et al., 2015). Ansel and Dyer (1999) state that "table management systems are designed to track table status to improve timeliness of service and speed turns" (p. 2). Table management system can be a function or an integrated mechanism of the POS system which provides better communication among servers and guests, decreases waiting time, keeps tracks of reservations and distributes the tables equally among the servers (Collins and Cobanoglu, 2008; Kimes, 2008). Through a computer screen, seating area as a whole can be graphically displayed, vacant, occupied and reserved tables can be checked, and whether a guest check is paid or still open can be controlled (DeMicco et al., 2015). Additionally, a particular table status can be checked and guests informed as to when it might become available (Collins and Cobanoglu, 2008). As a result, table management systems can increase effectiveness and efficiency of the restaurants (DeMicco et al., 2015).

To be able to keep track of reservations, table management systems require reservation modules. The reservation module is a part of the table management system and monitors the call-in and walk-in reservations, shows the current status of the tables and forecasts seat turnover or turnaround time (Collins and Cobanoglu, 2008). According to Kimes (2008), reservation systems also keep track of online reservations and provide guest records as well as changes to reservations. Some of the restaurant companies have reported that online reservations accounted for $30 \%$ of the all reservations (Ruggless, 2003). Consequently, reservation systems bring many benefits to restaurants.

Nowadays, instead of having reservations and dining at a restaurant, some people prefer 
to order food online for both take out or home delivery; therefore, online ordering attracts more customers to the restaurants and increases the popularity of this method (Kimes, 2008). Moreover, according to Lang (2006), there has been an increase in restaurant sales after implementing online ordering and reservations into the restaurants' technology. DeMicco et al. (2015) state that home delivery has been growing in popularity among the table service restaurants. Therefore, the take-out/delivery system is addressed to the people who demand online ordering. The take-out/delivery system is an order placement system which includes restaurant customers' addresses, map directions to the customers, phone number, and previous preferences for delivering food their address (Collins and Cobanoglu, 2008). Take-out/delivery systems bring important benefits to the restaurants industry. These benefits include: enhancing delivery timing, increasing driver productivity, providing efficient routing to the drivers, and offering maps with highlighted routes, and optional step-by-step directions (DeMicco et al., 2015).

Another effective POS module is menu management. Monitoring the entire menu is as important as monitoring the reservations. It helps the restaurants to assign prices, keeps track of entire menu items, provides detailed recipes and nutritional information, and also gives management the opportunity to control inventory usage and cost of the items (Collins and Cobanoglu, 2008; Kasavana, 2011). Menu management systems can provide a detailed menu item analysis report which includes the quantity of each menu item sold, cost control performance, the ideal cost of food for each item, and the contribution margin of each menu item (DeMicco et al., 2015). Therefore DeMicco et al. (2015) stressed that "this information is helpful in analyzing profitability, food costs, customer preference, menu structure, trends, promotion effectiveness, product performance and contribution” (p. 145). 


\section{POS Integrated Payment Applications}

Customer-facing payment technologies (which are basically tableside payment devices, mobile wallets, and mobile remote payment/wireless credit card authorization) have been increasing in popularity among the both restaurants and consumers (Kimes and Collier, 2014). According to Horovitz (2012), 44\% of the casual restaurant consumers now prefer to use tableside payment.

A tableside payment device allows customers to make their payment on-site by using their credit or debit cards and retaining their credit card information during the payment process. Since the tableside payment device requires credit card authorization, it needs to be connected with the POS system. Wireless credit card authorization is an integrated module on the POS, which accepts the payments through tableside payment devices or personal digital assistants (Tesone, 2005). According to Scornavacca, Prasad, and Lehmann (2006), it provides higher efficiency, quicker service, increased preciseness and is more user friendly. Moreover, according to Kimes and Collier (2014), tableside payment devices decrease the payment time in restaurants; therefore they increase customer satisfaction by providing faster payment.

Another popular customer-facing payment technology is mobile payment. Horovitz (2012) reported that $33 \%$ of the casual restaurants' and $25 \%$ of the quick service restaurants' customers would like to use mobile payment. For example, in a two-year period mobile payment transactions have reached $20 \%$ of the total transactions in Starbucks (Wester, 2013). The mobile payment system is a module integrated into the POS system for helping the customers to pay their bills through smart phones (Rehman and Coughlan, 2013). According to Creamer and Lorden (2014), 59\% of the POS technology upgrades will be on mobile wallet or bill pay via customers' mobile phone. Additionally, in 2015, most of the POS vendors interviewed have 
planned to add mobile wallet module on the POS systems (Creamer and Lorden, 2014).

Since there is an increasing demand for mobile payment, some institutes are working on mobile payment to offer a secure and faster mobile payment system (Rehman and Coughlan, 2013). Therefore, near field communication technology is beginning to replace current radio frequency identification (RFID) usage in the mobile devices with a secure PIN for faster authorization and transaction, as this provides wider connectivity and provisioning via mobile devices (Kasavana, 2011). Additionally, "the use of near field communications (NFC) means that the smartphone or mobile device never leaves the customers' hands when they scan their payment" (Kimes and Collier, 2014, p. 8). As a result, since the customers do not give their phones to the servers, mobile payment technology can be thought more secure. This is supported by Cobanoglu et al. (2012) when they state "mobile POS technology reduces credit card skimming" (p. 15).

Although Cobanoglu et al. (2012) state that "mobile POS technology reduces credit card skimming" (p. 15), they also stress that network protection is itself a serious concern. According to the 2014 Trustwave Global Security Report, 59\% of the credit card fraud in 2013 came from the U.S. Additionally, $18 \%$ of the fraud came from the food and beverage industry, whereas $11 \%$ of the fraud came from the hospitality industry in 2013 (Trustwave Global Security Report, 2014). Furthermore, in 2013, 1,165,090 complaints were recorded with regard to fraud, and $17 \%$ of the fraud complaints came from credit card holders (Federal Trade Commission, 2014). Since the network security and fraud issues have increased in the last decade, the Payment Card Industry Data Security Standards (PCI DSS) were established in 2006 by global payment brands including: American Express, Discover Financial Services, JCB International, MasterCard, and Visa Inc. (Berezina, Cobanoglu, Miller and Kwansa, 2012). As a result, all companies that 
accept credit cards must abide by the set of standards or requirements initiated by PCI DSS (Connolly and Haley, 2008). PCI data security standards (version 3.0) with which all companies which are processing, storing or transmitting credit card information must comply, are provided below (PCI Security Standards Council, 2013):

- Install and maintain a firewall configuration to protect cardholder data.

- Do not use vendor-supplied defaults for system passwords and other security parameters.

- Protect stored cardholder data.

- Encrypt transmission of cardholder data across open, public networks.

- Use and regularly update anti-virus software or programs.

- Develop and maintain secure systems and applications.

- Restrict access to cardholder data by business need-to-know.

- Assign a unique ID to each person with computer access.

- Restrict physical access to cardholder data.

- Track and monitor all access to network resources and cardholder data.

- Regularly test security systems and processes.

- Maintain a policy that addresses information security for all personnel.

Besides the requirements above, there are some practices that may improve the credit card transaction's security. These practices can be "Use of point-to-point encryption (P2PE)", "Outsource PCI compliance efforts", and "Use of tokenization at the card swipe". (PCI Security Standards Council, 2011, 2012, 2013). Additionally, researchers identified several issues and barriers to PCI DSS compliance in restaurants (Collins and Cobanoglu, 2008; Collins, 
Cobanoglu, and Bilgihan, 2013). They are: lack of budget, brand responsibility, the high burden of PCI DSS compliance on merchants, lack of knowledgeable staff, complexity of PCI DSS, and limited support from vendor and top management.

\section{Emerging FOH Operation Technologies}

Advancement in technology is bringing useful tools and applications in daily life as well as the restaurant industry. According to Lorden's (2012) interview, David Lehn, Vice President of Information Technology for Noodles \& Company, stated that a modern restaurant should have digital menu boards and signage, and R.P. Rama, Vice President \& Chief Technology Officer for JHM Hotels, predicts that biometric tools will bring many benefits to the hospitality industry, stating: "[i]t would resolve any issues with stolen or lost credit cards or even getting duplicate cards". Digital signage devices, meantime, can be used as interactive digital menus, and used for promoting special meals and discounts, sharing photos and videos about the restaurants, and informing the guests about forthcoming events (Sonnenshein, 2014). According to the Digital Signage Federation (N.A.), a digital sign can easily be a standard fixture of a restaurant and offers many benefits, such as: cost savings, promoting special and new items, and providing upselling opportunities. A biometric reader is another innovative technology for the restaurant industry. A biometric reader is a device that identifies people by their unique physical traits (such as fingerprints, retina prints, and voice), and stores these identifiers to use for later verification of the same customers based on their profile in the database, which includes their identities linked to their unique makers (Collins and Cobanoglu, 2008). As a result of implementing biometric-enabled POS, Hooters, one of the biggest chains with 452 world restaurants, has accomplished reduction in transaction fraud, payroll fraud, and food costs. Also, 
Hooters got rid of swipe card replacement cost and unauthorized overrides (Hospitality Technology Magazine, 2015).

On an annual Hospitality Technology Magazine review on the latest POS Hardware releases, Mastroberte (2014) reported that some of the vendors released energy efficient POS and barcode scanners/readers integrated with the POS system. A barcode scanner/reader is a device that reads the barcodes and converts them into language-based information such as the product's name, price, and any discounts attached to the item, if available (Kim and Lim, 2011). Barcode readers also provide ease and efficiency in meal coupon redemption. Another recent release is the energy efficient POS system. This is a POS system which uses low energy consumption units in and of itself, as well as in other devices such as handheld devices, and the mobile tablets also connected to the energy efficient POS (Mastroberte, 2014).

\section{Back of House (BOH) Operations}

According to AH\&LA (2006), it is difficult to manage a restaurant without measuring and controlling important main performance indicators. With the help of BOH operation systems it is possible to measure and monitor these indicators, such as: cost of food, inventory, financial status, and labor scheduling and productivity (AH\&LA, 2006). Some of the important BOH operations systems are: accounting / financial software, labor management system / labor screening and recruitment tool, customer relationship management system, business intelligence system, inventory management application, company intranet, kitchen management systems (kitchen displays and kitchen printers), integrated cost control systems, cloud-based application, enterprise management system, enterprise reporting system and real-time based reporting, disaster recovery system, and personal digital assistant and intra-day reporting. 


\section{Accounting / Financial Software}

This is a software application connected with POS systems which creates sales transaction reports and economic events (Tesone, 2005). Many BOH operations software programs include a variety of accounting modules but most of them generally include at least: accounts receivable, accounts payable, payroll accounting, inventory accounting, purchasing, and financial reporting modules (Kasavana, 2011). The main reason of using the accounting software is to keep track of all financial transactions which occur among the stakeholders of the company (Collins and Cobanoglu, 2008). Moreover, the main benefits of the accounting applications are "managing cash flow, collecting monies owed by customers, controlling and tracking expenditures, evaluating financial status, and tracking monies owed to creditors" (Collins and Cobanoglu, 2008, p. 225)

\section{Labor Management System/Labor Screening and Recruitment Tool}

Labor management systems help the restaurant to create working schedules for better and more efficient work force forecasting, and gives the managers better opportunity to analyze the performance of employees, and to control clock-in/clock-out hours (AH\&LA, 2006). According to National Restaurant Association (2014), employee turnover rate in the accommodations and restaurant industry was $62.6 \%$ in 2013 , whereas it was $42.2 \%$ in the overall private industry. Therefore, some of the POS systems provide labor screening, which offers restaurateurs the opportunities to keep track of employee status such as: employee records, tax information, employee benefits, and recruitment tools (AH\&LA, 2006). This offers restaurateurs control over the online new position applicants, to better hire the right employee and to train them effectively (AH\&LA, 2006). As a result, it was aimed to decrease the turnover rate with the help of labor 
management/screening tools.

\section{Customer Relationship Management System}

This is an information technology management system which allows restaurants to mainly focus on customer activities for maintaining a profitable customer loyalty in the long run (Lo, Stalcup and Lee, 2010). With the help of the customer relationship management systems, contact information (e.g., email, mailing address, cell phone numbers etc.) of the restaurant customers can be kept and promotional campaigns can be sent to customers by using this contact information (Collins and Cobanoglu, 2008). Another important feature of this system is that this system provides a record which contains useful information such as name and previous meal

preferences. As a result, costumers can be greeted by the servers with their name, and help them with their meal preferences (DeMicco et al., 2015).

\section{Business Intelligence System}

This is an integrated module with $\mathrm{BOH}$ operation system and provides detailed reports such as: budgets, profit/loss statements, balance sheets and daily reports (e.g., guest counts, food cost, and labor cost) that keep managers' eyes on daily operations (AH\&LA, 2006). The main advantage of the business intelligence system is that it provides the reports in real time. Therefore, restaurant managers can have quicker and more informed decisions (AH\&LA, 2006)

\section{Inventory Management Application}

This is an integrated module with accounting system which provides detailed information on the quantity and price of the products, and has the capability to monitor the replacement 
period of the inventory (Kasavana, 2011). Additionally, inventory management systems make the process of the ordering and receiving the inventories easier for the restaurant operators (Collins and Cobanoglu, 2008). Moreover, with the help of a handheld device which is connected to inventory management software, taking the inventory and organizing the storage will be easier and quicker (Collins and Cobanoglu, 2008).

\section{Company Intranet}

This is an internal network inside the company which requires Internet to communicate among the employees of the company (Collins and Cobanoglu, 2008). Intranet is an important and flexible system for easy "access to operations manuals, discussion forums, company news items, a corporate documents library, e-mail between sites and many other purposes" (AH\&LA, 2006, p. 17). Moreover, intranet provides many benefits such as "rapid transmission of up-todate information, improved communication flows, knowledge enhancement, sharing of best practice in context and encouragement of innovation" (Curry and Stancich, 2000, p. 249).

\section{Kitchen Management Systems}

The Kitchen management system is crucial to the success of service in restaurants (Ansel and Dyer, 1999). The main components, which facilitate the kitchen management system, are: kitchen display systems, and kitchen printers. Kitchen display systems are made of video monitors which "can be used to help the kitchen better manage orders and to ensure that orders are prepared in a timely fashion" (Kimes, 2008, p. 304). Kitchen display systems provide some additional advantages such as keeping track of the preparation times for menu items, therefore, allowing the management to measure and compare the performance of the kitchen staff (Collins 
and Cobanoglu, 2008). In addition, kitchen display systems serve as a communication tool between the kitchen staff and servers. Kitchen printers serve the same purpose as the kitchen display systems but they are used instead if there is a need for paper copies for an internal control system, or if the printed copies are critical for the production operations (Kasavana, 2011). As a result, with the advanced kitchen technologies, restaurants would have a successful service and would not have any service interruption (Oronsky and Chathoth, 2007)

\section{Integrated Cost Control System}

This is an integrated application on the POS, which uses the current prices of the products to calculate the cost of menu items (O’Connor, 1996). Based on each recipe's portion size, cooking or preparation method, and ingredients, which are identified on the system before hand, the selling price can be calculated with a viable profit percentage (O’Connor, 1996). Cobanoglu (2012) stated the benefits of the integrated cost control systems are keeping track of the perpetual inventory, accessing the cost information, and keeping track of the cost instantly and having the ability to make right decisions about cost on time.

\section{Cloud-based Application}

According to Mell and Grange (2011), cloud computing also known as virtual computing is defined as "a model for enabling ubiquitous, convenient, on-demand network access to a shared pool of configurable computing resources (e.g., networks, servers, storage, applications, and services) that can be rapidly provisioned and released with minimal management effort or service provider interaction" (p. 2). The cloud represents the delivery of the software via the Internet (Kasavana, 2011). In other words, the software is distributed to the clients with the help 
of the Internet. The restaurant industry is switching to cloud-based applications. Some examples of them include cloud-based POS, integrated video/IP video for security and back office systems. Integrated video/IP video is used as part of POS in which the transactions are recorded at a unit level (Collins and Cobanoglu, 2008). If an exception rule is achieved (e.g., a server voids orders 3 or more times per shift), this video is sent to management over the cloud systems for additional screening to conclude if the employee is stealing money.

\section{Enterprise Management System (EMS)}

Enterprise management system (EMS) provides the technology infrastructure for multiunit hospitality organizations including restaurant chains (Kasavana, 2011). According to Norton (1999), EMS is "an integrated solution for planning, executing, and controlling business processes horizontally across the value chain" (p. 38). Most of the EMS is based on cloud technology where all information are retained and distributed from central point with the help of Internet and intranet. EMS accesses the data on a real time from different systems that feed the central database. Property level data is fed into the central EMS on a real-time basis or on predetermined intervals for analysis and reporting purposes. For EMS to work, property based systems must integrate to the central database, allowing the data to be consolidated and stored for additional analysis.

\section{Enterprise Reporting System (ERS) and Real-Time based Reporting}

Enterprise Reporting Systems (ERS) distributes the collected by EMS to the authorized users after turning it to information (Kasavana, 2011). This information helps the executives to make timely, well-informed business decisions (Collins and Cobanoglu, 2008). EMS is 
structured to make different analysis on the data collected from property level systems by sorting data by regions, price points, and other variables, implementing some business and financial rules (e.g., occupancy rates, revenue per available seat). Once these analyses are finalized, the ERS reports this information on a dashboard that is designed to present complex data on a simple manner. All information contains "drill down" feature that allow the executive to go in deeper into data form that makes the information. For example, an executive can sort all restaurants based on annual sales amounts company wide, then drill down to a regional basis to a city, and then to a store.

Real-time based reporting is used in ERS as a method to distribute the information to authorized users on a real-time basis (Kasavana, 2008). Real-time based reporting feature is designed to provide immediate feedback to the management team, enabling them to make faster decisions to maximize the revenue or minimize the costs.

\section{Disaster Recovery System}

Restaurants depend on technology systems on a daily basis for operational and managerial level (Collins and Cobanoglu, 2008). These systems are called "mission-critical" systems indicating that restaurants may have a hardship if these systems do not work or function properly. For this reason, restaurant companies employ disaster recovery systems that will enable the restaurant operators to restore their systems in the shortest time possible (Cobanoglu, 2007; Kasavana, 2011). Disaster recovery system employs different tools and techniques such as daily back up and redundant servers. 


\section{Personal Digital Assistant (PDA) and Intra-day Reporting}

PDA provides many useful functions for management. According to Writing (N.A.), PDA can work as an electronic secretary, an electronic notebook, and a voice recorder.

Moreover, using a PDA in the restaurant industry offers many advantages, such as: "increased efficiency, speedier service, better usability and ease of use, enhanced reputation/image and increased accuracy" (Prasad, Scornavacca, and Lehmann, 2005). Additionally, PDA can access the POS system and some of POS functionalities such as intra-day reporting. This function offers hour-by-hour reports about the restaurant sales, guest checks, and guest counts. As a result, restaurant managers can have a better control over their daily tasks and decisions. 


\section{CHAPTER THREE:}

\section{METHODOLOGY}

The purpose of this study was to examine the utilization of Front of House and Back of House technology applications by U.S. restaurants across different types of restaurants along with their level of IT management style, and the importance of these technology applications to the restaurants' operations.

\section{Research Design and Instrument}

The survey had four sections. The first section listed Budgets and Business Strategies where respondents were asked to provide information about their IT budgets and business strategies. The second section listed Point of Sale Front of House (POS FOH) operation technology features where respondents were asked to indicate if they utilize these technologies. If they answered "yes", then it asked the level of the importance of each item for the restaurants. All items concerning the importance of POS FOH operation technology features were rated on a 5-point Likert-scale ranging from $1=$ Not important at all to $5=$ Extremely important. In addition to POS FOH operation technology features in the first section, levels of agreement with perspectives on mobile POS were asked to respondents $(1=$ Strongly disagree, $5=$ Strongly agree, and $6=$ Not sure $^{1}$ ). The third section of the survey included Point of Sale Systems Back of House (POS BOH) tools features and asked the respondents to indicate if they utilize these

\footnotetext{
${ }^{1}$ This option was given to respondents when they could not evaluate the item with certainty and this number was not used in the mean calculation.
} 
technologies. If they answered "yes", then it asked the level of each items importance for the restaurants. All items concerning the importance of POS BOH operation tools features were rated on a 5-point Likert-scale ranging from $1=$ Not important at all to $5=$ Extremely important. Finally, the fourth section asked for levels of agreement on Payment Card Industry Data Security Standard (PCI DSS) compliance in restaurants $(1=$ Strongly disagree, $5=$ Strongly agree, and 6

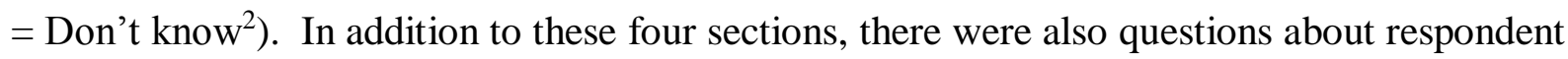
and company information. All of the section questions about the restaurant technology were obtained through extensive review of the literature.

\section{Sample}

The sample consisted of 500 randomly selected restaurant technology managers who are current subscribers of Hospitality Technology Magazine as of January 2013. This study utilized secondary data which was provided by Cobanoglu. Secondary data is useful when it is difficult to find valid and reliable primary data (Cowton, 1998). "It is suggested that secondary data not only offer advantages in terms of cost and effort, as conventionally described in research methods books, but also that in certain cases their use may overcome some of the difficulties that particularly afflict business ethics researchers in the gathering of primary data" (Cowton, 1998, p. 423). After eliminating some of the suspected and incomplete surveys, 136 survey data were processed. These sample groups represented 67,299 restaurant units. Of this number, 57,208 were quick service restaurants, 8,457 were casual/family restaurants, 109 were fine-dining restaurants, and 1,525 were other types of restaurant. All of the sample members had an email address, therefore only an online version of the survey was conducted.

\footnotetext{
2 This option was given to respondents when they could not evaluate the item with certainty and this number was not used in the mean calculation.
} 
Sample size is a hotly debated topic in the literature. Comrey and Lee (1992) suggest that there should be at least 300 participants and each variable in the factor analysis should have 5 to 10 observations. However, Tabachnick and Fidell (2013) stress that 5 observations for each item would be enough in most cases. Adding to debate, Gorsuch (1983) and Hatcher (1994) state that a sample that consists minimum, 100 responses would be adequate for an exploratory factor analysis. The sample size in this study is greater than 100 and there was a 5 to 1 ratio for each variable for the POS FOH, POS BOH, mobile POS perspective and PCI DSS compliance. Consequently, according to the above sample size evaluation, the sample group that is used in this study is acceptable.

\section{Limitations and Assumption}

The limitations of this study are the sampling procedure and sample size. The sample consisted of the IT managers of restaurants who subscribe to Hospitality Technology Magazine; therefore, the results may not able to be generalized beyond this population. Additionally, it was assumed that the respondents had the responsibility for their restaurant companies, including multi-units, and their answers represented the technology outlook of the entire enterprise.

Whenever there is less than 100 percent participation in a survey, there is a question of non-response bias: that is, the likelihood of data being changed if all members of the population would have responded to the survey. We have conducted a non-response analysis using wave analysis (early versus later respondents) to answer (1) whether non-respondents and respondents differed significantly, (2) whether equivalent data from those who did not respond would have significantly altered findings. Rylander, Propst, and McMurtry (1995) suggested that late respondents and non-respondents were alike and wave analysis and respondent/non-respondent 
comparisons yielded the same results. Therefore, we conducted an independent samples t-test on the means of POS BOH and POS FOH technology features' importance to see if early respondents' responses were different from late respondents'. Analysis indicated that there was no significant difference in any of the POS BOH and POS FOH technology features' importance, concluding that this survey did not suffer non-response bias and therefore, was representative of the population that is Hospitality Technology Magazine subscribers who are in charge of information technology in restaurants.

\section{Construct Validity}

Construct validity is a very critical task and one of the most difficult types of validity to establish (Churchill, 1979). Therefore, the instrument in this study was sent to a panel of restaurant technology experts to make sure the questions in the instruments were valid. Based on their suggestions some minor adjustments have been made to the instrument to increase construct validity.

\section{Reliability}

"Reliability concerns the extent to which measurements are repeatable..."(Nunnally and Durham, 1975, p. 10). Cronbach's coefficient alpha is the most known and commonly used test for reliability issues (Pallant, 2013). Grau (2007) cited from Cronbach (1951) that “Cronbach’s alpha is a coefficient that describes how well a group of items focuses on a single idea or construct" (p. 3104). The recommendation of Nunnally (1978) for Cronbach's alpha is a minimum of .70. DeVellis (2012) supports that Cronbach's alpha values between .60 and .65, .65 and $.70, .70$ and .80 , and .80 and .90 are undesirable, acceptable, respectable and very good 
respectively. Reliability scores in this study were: .76, .88, .71, and .76 for POS FOH, POS BOH, Mobile POS Perspective and PCI DSS compliance, respectively. According to DeVellis (2012) and Nunnally (1978), Cronbach's alpha scores of the POS FOH, Mobile POS Perspective and PCI DSS Compliance sections do fit the parameters of an acceptable and/or respectable range for this study. Moreover, Cronbach's alpha score of POS BOS is "very good" (DeVellis, 2012).

\section{Data Analysis}

The data analysis was organized into 3 parts (descriptive, factor analysis and independent samples t-test). The data analyzed with The Statistical Packages for Social Sciences (SPSS, version 21). In the descriptive part of the data analysis, the information about respondents' job functions, company characteristics and companies' IT perspectives are evaluated.

In the second part, factor analysis was used. According to Yong and Pearce (2013), "the broad purpose of factor analysis is to summarize data so that relationships and patterns can be easily interpreted and understood" (p. 79). In this study, 20 variables were used to test the POS FOH systems, 19 variables used to test the POS FOH systems, 13 variables used to test the Mobile POS features and 11 variables used to test the PCI DSS Compliance. Since the factor analysis is a data reduction technique, factor analysis is used to create correlated variable composites and to reduce variables for better interpretation.

Exploratory and confirmatory factor analysis are the two approaches to factor analysis (Pallant, 2013; Thompson, 2004; Yong and Pearce, 2013). Most of the social science researchers have reported their studies with exploratory and/or confirmatory factor analysis (Osborne, Costello, and Kellow, 2008). Costello and Osborne (2005) reported that exploratory factor 
analysis had been used in more than 1700 studies during a two-year period covered by the American Psychological Association (PSYCINFO) database.

Confirmatory factor analysis is used for "confirming previously defined hypotheses concerning the relationships between variables" (Walker and Maddan, 2008, p. 326), whereas exploratory factor analysis is used for exploring the number of components affecting variables and to test the variables which go together (Child, 2006). Since this study was not confirming previously defined hypotheses, exploratory factor analysis was used.

According to Costello and Osborne (2005), other than acceptable sample size, there are three critical issues (extraction method, rotation method, and scores of factor loadings) which researchers have to ensure to have a better result from exploratory factor analysis. In addition to Costello and Osborne, Walker and Maddan (2008) suggested that before starting the factor analysis, it is important to have a univariate analysis for a normal distribution, and also to check the two measures of the univariate analysis: skewness and kurtosis. Furthermore, it is necessary to test reliability issues before factor analysis (Grau, 2007; Yong and Pearce, 2013).

Principal components, principal factors, image factoring, maximum likelihood factoring, alpha factoring, unweighted least squares, and generalized least squares are the extraction methods; however, principal components analysis is the one method generally used by most researchers (Pallant, 2013). Principal components analysis is an effective technique to decrease large items into small components or groups without losing a lot of data (Matsunaga, 2010, Tabachnick and Fidell, 2013). The aim of principal component analysis fit the purpose of this study; therefore it was selected as the extraction method.

Factor analysis requires a rotation method for better interpretation. Yong and Pearce (2013) stated that factors need to be rotated for better understanding since it is difficult to 
interpret them without rotation. Two main techniques for rotation are orthogonal (varimax, quartimax and equamax) and oblique (direct oblimin and promax) (Pallant, 2013). The orthogonal technique presumes that factors are uncorrelated, however; the assumption in the oblique methods is that factors are correlated (Brown, 2009). Varimax is the most popular and commonly used orthogonal technique for rotation (Costello and Osborne, 2005; Pallant, 2013). Yong and Pearce (2013) state "Varimax minimizes the number of variables that have high loadings on each factor and works to make small loadings even smaller" (p. 84). As a result, since the assumptions for factors are correlated, and it is required to minimize the number of variables that have high loadings on each factor, the Varimax technique was used.

According to Matsunaga (2010), the cutoff point of factor loading is one of the common approaches used in deciding the scores of factor loading of items: that is, whether to keep items in the factor loading table or not. Although Costello and Osborne (2005) and Pallant (2013) have suggested 30 to be the set point for factor loading, Matsunaga (2010) reported that the cutoff point is .40 or higher or for liberal estimates and .60 is the minimum cutoff limit for more conservative researchers (2010). Therefore, items with factor loadings of .40 or higher were preferred to cluster variables together. The factors with eigenvalues greater than one were considered as significant based on the recommendation of Yong and Pearce (2013).

In addition to above, skewed and kurtosis variables should also be investigated very carefully, since normal distribution is crucial for the factor analysis (Walker and Maddan, 2008). "Skewness is a measure to what extent a distribution of values deviates from symmetry around the mean, whereas kurtosis is a measure of the peakedness or the flatness of a distribution" (Tijhuis, Brattli, and Sæther, 2002, p. 71). The range for skewness and kurtosis is a controversy in the literature reviewed. George and Mallery (1999) indicate that a value range between +2 to - 
2 for skewness and kurtosis is adequate for a normal univariate distribution. However, Tabachnick and Fidell (2013) stress that the acceptable values for skewness and kurtosis should be between +1.5 and -1.5 . Moreover, values exceeding 3 and 10 for skewness and kurtosis respectively should be considered to be a problem for a normal univariate distribution (Kline, 2005). In light of the literature reviewed, skewness and kurtosis of each item used in the factor analyses was checked and the variables that have values of skewness and kurtosis greater than three were removed from the model.

The third and final stage of the data analysis included testing hypotheses based on factor analysis outcomes by using an independent samples t-test. The main purpose of using an independent samples t-test is to determine whether position, types of restaurant, business leadership and technology leadership differ on the factor attributes. 


\section{CHAPTER FOUR:}

\section{FINDINGS}

The purpose of this study was to examine the utilization of Front of House and Back of House technology applications by U.S. restaurants across different types of restaurants and along with level of IT management style, and the importance of these technology applications to the restaurants' operations. In this section, descriptive statistics, factor analysis results, and independent samples t-test results are reported in order to the answer research questions and test the hypotheses. Sample size of this study was 136 and these sample groups represented 67,299 restaurant units.

\section{Company Characteristics, IT Budgets and Strategies}

In this section, descriptive statistics are demonstrated related to: job function of the respondents, company description, represented number of restaurants and types of restaurants, business metrics comparison, organization preferences from business leadership and technology leadership, IT budget projections of companies as sales percentages, corporate annual IT budget, comparison between capital expenditures versus operating expenditures, reference to IT strategic planning in the mission statement of company, level of IT decision making at the company, IT steering committee and POS system replacement. 
Table 4: Job Function of the Respondents

\begin{tabular}{lr}
\hline Job Function & Valid Percent \\
\hline Information systems/Technology management & 39.0 \\
Owner/Operator & 21.1 \\
Corporate management & 18.7 \\
Food/Beverage management & 4.9 \\
Operations/Property management & 4.1 \\
Financial management & 3.3 \\
Sales/Marketing management & 2.4 \\
Purchasing management & 1.6 \\
Other (including Business developer, IS developer, General manager) & 4.9 \\
Total & 100.0 \\
\hline
\end{tabular}

The highest proportion (39\%) of the respondents hold the "Information systems/Technology management" position in their companies. The second and the third highest proportions of the respondents hold "Owner/Operator" (21.1\%) and "Corporate Management" (18.7\%) positions (See Table 4).

Table 5: Company Description

\begin{tabular}{lr}
\hline Company Description & Valid Percent* \\
\hline National restaurant chain & 30.9 \\
Regional restaurant chain & 20.6 \\
Global restaurant chain & 16.2 \\
Independent restaurant management company without franchised products & 14.7 \\
Franchisor & 14.0 \\
Independent restaurant management company with franchised products & 7.4 \\
Other (including cinema eatery-multi unit, independent single unit operator, & 7.4 \\
sports \& entertainment retail / F\&B/catering and privately owned &
\end{tabular}

More than $60 \%$ of the respondents work for chain restaurants, a category further subdivided into: "National restaurant chain" (30.9\%), "Regional restaurant chain" (20.6\%) and "Global restaurant chain" (16.2\%). Almost 30\% of the respondents work for independent restaurants, a category further subdivided into: Independent restaurant management company without franchised products" (14.7\%), "Independent restaurant management company with 
franchised products" (7.4\%) and other independent types of restaurants (7.4\%). Moreover, $14.0 \%$ of the respondents work for "Franchisors" (See Table 5).

Table 6: Type of the Restaurant

\begin{tabular}{lrr}
\hline Type of Restaurant & Number & Valid Percent \\
\hline Quick Service Restaurant (including fast casual) & 57208 & 85.0 \\
Casual/Family Restaurant (full service) & 8457 & 12.6 \\
Fine Dining Restaurant & 109 & 0.2 \\
Other & 1525 & 2.3 \\
Total & 67299 & 100.0 \\
\hline
\end{tabular}

As indicated in Table 6, in this study, 67,299 individual restaurants were represented by the respondents, including: "Quick service restaurants" (57,208), "Casual/family restaurants" $(8,457)$, "Fine dining restaurants" (209) and other types of restaurants $(1,525)$.

Table 7: Business Metrics Comparison Current Year and Previous Year

\begin{tabular}{lrrrr}
\hline Business Performance: & Decreased & Remained Flat & Increased & Total \% \\
\hline Gross revenue (company-wide) & - & 42.6 & 57.4 & 100.0 \\
Average guest check (per customer) & 2.2 & 41.3 & 56.5 & 100.0 \\
Guest counts (guest volume) & 9.3 & 55.8 & 34.9 & 100.0 \\
Same store sales growth (per location) & - & 46.8 & 53.2 & 100.0 \\
Net profitability (company-wide) & 4.3 & 51.1 & 44.7 & 100.0 \\
\hline
\end{tabular}

The main drivers of restaurant business performance ("Gross revenue", "Average guest check", "Guest counts", "Same store sales growth" and "Net profitability") have been examined (See Table 7). The majority of the restaurants have reported that more than $90 \%$ of the business performance was either flat $(42.6 \%)$ or better $(57.4 \%)$ compared to the previous year. More than $50 \%$ of the attendees reported that "Gross revenue", "Average guest check", and "Same store sales growth" increased but "Average guest check" and "Net profitability" remained flat. Some 
respondents $(9.3 \%)$ have seen a decrease on "Guest counts" compared to the previous years (See Table 7).

Table 8: Organization Preferences: Business Leadership versus Technology Leadership

\begin{tabular}{lrr}
\hline Organization Preferences from & $\begin{array}{r}\text { A business leadership } \\
\text { Valid Percent }\end{array}$ & $\begin{array}{r}\text { A technology leadership } \\
\text { Valid Percent }\end{array}$ \\
\hline An innovator/leader & 53.7 & 31.5 \\
A close follower & 25.9 & 38.9 \\
A distant follower & 9.3 & 22.2 \\
A reactor to industry conditions and competitors moves & 11.1 & 7.4 \\
Total & 100.0 & 100.0 \\
\hline
\end{tabular}

As seen in the Table 8, 53.7\% of the restaurants companies reported that they preferred to be "An innovator in business leadership"; however, only $31.5 \%$ of them preferred to be "An innovator in technology leadership". While $25.9 \%$ of the companies preferred to be "A close follower in business leadership", $38.9 \%$ of the companies preferred to be to be "A close follower in technology leadership". Moreover, $11.1 \%$ of the companies preferred to be "A reactor to industry conditions and competitor moves in business leadership", compared to $7.4 \%$ in technology leadership (See Table 8).

Table 9: IT Budged Projection for Today and in Three Years as a Percentage of Sales

\begin{tabular}{lrr}
\hline IT budget & For $\mathbf{2 0 1 3}$ & Projection in three years \\
\hline Less than 1\% & 31.5 & 16.7 \\
$1 \%$ & 25.9 & 16.7 \\
$2 \%$ & 13.0 & 25.9 \\
$3 \%$ & 7.4 & 13.0 \\
$4 \%$ & 3.7 & 1.9 \\
$5 \%$ & 11.1 & 11.1 \\
$6 \%$ & - & 3.7 \\
$7 \%$ & - & 1.9 \\
$8 \%$ & - & 1.9 \\
I don't know & 7.4 & 7.4 \\
Total & 100.0 & 100.0 \\
\hline
\end{tabular}


In 2013, more than 55\% of the respondents in total have reported that their IT budget consisted of $1 \%(31.5 \%)$ or less than $1 \%(25.9 \%)$ of the total sales (See Table 9). Moreover, as seen from the table above, it is projected that there might be an increase in the IT budgets of the restaurants. For instance, some of the respondents have reported more than $6 \%$ (up to $8 \%$ ) of the total sales will be allocated as IT budget for three years' projection, in contrast to 2013 (See Table 9).

Table 10: Corporate Annual IT Budget in Dollars for 2013

\begin{tabular}{lr}
\hline IT Budget in Dollars in 2013 & Valid Percent \\
\hline More than \$1 Billion & 75.5 \\
\$500 Million - \$1 Billion & 17.0 \\
I prefer not to answer & 7.5 \\
Total & 100.0 \\
\hline
\end{tabular}

More than $75.5 \%$ of the represented restaurant companies had an IT budget of "More than \$1 Billion" in 2013. Additionally, $17 \%$ of the represented companies had an IT budget of “\$500 Million - \$1 Billion” in 2013. A proportion of $7.5 \%$ of the respondents did not prefer to answer this question (See Table 10).

Table 11: Comparison between Capital Expenditures versus Operating Expenditures

\begin{tabular}{lcc}
\hline & $\mathbf{M}^{\mathbf{1}}$ & $\mathbf{S D}^{\mathbf{2}}$ \\
\hline Capital Expenditures & 37.5 & 23.7 \\
Operating Expenditures & 61.8 & 23.4 \\
\hline
\end{tabular}

Notes: ${ }^{1}$ Mean $(\text { Min. }=0 \text {, Max. }=100)^{2}$ Standard Deviation

On average $37 \%$ of the IT budget was allocated to the "Capital expenditures", which includes investing new technology, innovation, etc. On the other hand, on average $61.8 \%$ of the IT budget was allocated to the "Operating expenditures", which include maintaining systems, licensing, and fees (See Table 11). 
Table 12: Reference to IT Strategic Planning in the Mission Statement of Company

\begin{tabular}{lr}
\hline Reference to IT strategic planning in the mission statement of company & Valid Percent \\
\hline Yes & 17.0 \\
No & 71.7 \\
Don't have a mission statement & 9.4 \\
Not sure & 1.9 \\
Total & 100.0 \\
\hline
\end{tabular}

The majority of the respondents $(71.7 \%)$ declared that the mission statement of the company does not point out IT strategic planning (See Table 12). While $17.0 \%$ of the respondents stated that IT strategic planning is part of the mission statement of the companies, entirely $11.3 \%$ of the respondents state that they are not sure $(1.9 \%)$ or that their companies do not have a mission statement $(9.4 \%)$ (See Table 12).

Table 13: Level of IT Decision Making at the Company

\begin{tabular}{lr}
\hline IT decisions are made predominately at the: & Valid Percent \\
\hline Corporate level & 92.2 \\
Unit level & 5.9 \\
Other (including owner/operator) & 2.0 \\
Total & 100.0 \\
\hline
\end{tabular}

Most of the restaurants (92.2\%) predominantly make their IT decisions on "Corporate level". Only $5.9 \%$ of the restaurants companies make their IT decisions on the "Unit level" and $2.0 \%$ of the respondents state that IT decisions are predominately made by the "Owner/operator" (See Table 13).

Table 14: IT Steering Committee

\begin{tabular}{lr}
\hline IT steering committee & Valid Percent \\
\hline Yes & 41.5 \\
No & 54.7 \\
Not sure & 3.8 \\
Total & 100.0 \\
\hline
\end{tabular}


While $41.5 \%$ of the companies have an IT steering committee, $54.7 \%$ of the companies do not, and $3.8 \%$ of the respondents are not sure whether their companies have an IT steering committee or not (See Table 14).

Table 15: POS System Replacement

\begin{tabular}{lr}
\hline Replacement your company's current POS system & Valid Percent \\
\hline Within a year & 12.5 \\
1-2 years & 14.6 \\
3-4 years & 39.6 \\
5-6 years & 12.5 \\
7-8 years & 10.4 \\
More than 10 years & 10.4 \\
Total & 100.0 \\
\hline
\end{tabular}

More than $65 \%$ of the companies replaced their POS System within the last four years or less than four years (12.5\% within a year, 14,6\% within 1-2 years, and 39.6\% within 3-4 years). However, more than $30 \%$ of the respondents state that they replaced their POS system 5 years and/or more than 5 years ago (12.5\% 5-6 years ago, $10.4 \%$ 7-8 years ago and $10.4 \%$ more than 10 years ago) (See Table 15).

\section{Research Questions}

In this section, research questions that proposed for this study are shown and further explained.

1. "What are the main drivers for IT investments in restaurants?"

To be able to answer the first research question, respondents were asked, "Please indicate the approximate distribution of IT budget or spending at your company" and "Please indicate the 
approximate distribution of Technology area budget allocation (not including personnel) in percentages at your company".

Table 16: IT Budget Distribution at the Restaurant Companies

\begin{tabular}{lrr}
\hline & $\mathbf{M}^{\mathbf{1}}$ & $\mathbf{S D}^{\mathbf{2}}$ \\
\hline Hardware & 20.6 & 16.0 \\
Software & 19.2 & 16.0 \\
Internal personnel & 17.5 & 16.7 \\
External service providers & 13.7 & 17.0 \\
Networks \& Telecom & 9.4 & 7.6 \\
Facilities & 4.1 & 7.6 \\
Other & 3.2 & 6.8 \\
\hline Notes: ${ }^{1}$ Mean (Min. = 0, Max. = 100) ${ }^{2}$ Standard Deviation & &
\end{tabular}

As seen in the Table 16, companies allocated on average $20.6 \%$ for "Hardware", $19.2 \%$ for "Software", $17.5 \%$ for "Internal personnel", $13.7 \%$ for "External service providers", 9.4\% "Networks and telecom", 4.1\% for "Facilities" and 3.2\% for other spending of their IT budget.

Table 17: Technology Area IT Budget Distribution

\begin{tabular}{lrr}
\hline & $\mathbf{M}^{\mathbf{1}}$ & SD $^{\mathbf{2}}$ \\
\hline POS solutions & 30.8 & 21.0 \\
Back office solutions & 22.0 & 15.8 \\
Networking & 11.5 & 10.7 \\
Security solutions & 9.3 & 14.3 \\
Mobile/Web technologies & 9.0 & 9.4 \\
Kitchen technology & 6.3 & 9.4 \\
\hline Notes: ${ }^{1}$ Mean (Min. = 0, Max. = 100) ${ }^{2}$ Standard Deviation & &
\end{tabular}

For the technology area IT budget distribution, "POS solutions" (30.8\%) and "Back office solutions" (22.0\%) received the bulk of the funds, which together accounted for more than $52 \%$ of the overall technology area IT budget (See Table 17). Other than POS solutions and Back office solutions, companies spent on average $11.5 \%$ for "Networking", $9.3 \%$ for "Security 
solutions", $9.0 \%$ for "Mobile/Web technologies" and 6.3\% for "Kitchen technology" of their technology area IT budget (See Table 17).

2. "What are the main drivers for restaurants' IT efforts?"

Table 18: Main Drivers the Company's IT Efforts

\begin{tabular}{lc}
\hline Main Drivers for the Company's IT Efforts & Valid Percent* \\
\hline Business efficiency & 30.9 \\
Enhanced guest service & 27.2 \\
Employee productivity & 25.7 \\
Security/compliance (PCI and payments) & 25.0 \\
Cost-saving measures & 22.8 \\
Revenue-generating opportunities & 14.7 \\
Increasing guest loyalty & 14.7 \\
Preserve existing technology investment(s) & 12.5 \\
Competitive pressure & 6.6 \\
Social responsibility (e.g., Green initiatives) & 4.4 \\
Other (including business intelligence and future focus ) & 1.5 \\
\hline *Percentages don't add up to 100\% due to multiple selections allowed.
\end{tabular}

According to the Table 18, "Business efficiency" (30.9\%), "Enhanced guest service" (27.2\%), "Employee productivity" (25.7\%), "Security/Compliance" (25.0\%) and "Cost savings measures" (22.8\%) are the top five main drivers for the company's IT efforts. The other main drivers for the company's IT efforts are "Revenue-generating opportunities" (14.7), "Increasing guest loyalty" (14.7\%), "Preserve existing technology investment" (12.5\%), "Competitive pressure" (6.6\%) "Social responsibility" (4.4\%) and other main drivers including: business intelligence and future focus (1.5\%) (See Table 18). 
3. "What is the top challenge facing restaurant' technology departments?"

Table 19: Top Challenges for the Restaurant Technology Departments

\begin{tabular}{lr}
\hline Top challenges for the technology departments & Valid Percent \\
\hline Insufficient IT budgets to keep pace with needed investments & 33.3 \\
The technology itself is insufficient to meet our needs & 19.6 \\
Guests expect greater technology than we can keep pace with & 15.7 \\
We lack IT talent in our internal team & 13.7 \\
Our company philosophy does not embrace technology innovation & 9.8 \\
Other (including growth in new stores, team bandwidth and difficulties in training) & 7.8 \\
Total & 100.0 \\
\hline
\end{tabular}

As can be seen in the Table 19,33.3\% of the respondents pointed out that "Insufficient IT budget to keep pace with needed investment" is the top challenge of the technology departments. The other main challenges for the restaurant technology departments are "The technology itself is insufficient to meet our needs" $(19.6 \%)$, "Guests expect greater technology than we can keep pace with" (15.7\%) and "We lack IT talent in our internal team" (13.7\%).

4. "What are the point of sale (POS) Front of House (FOH) technology features used in restaurants?”

5. "What is the importance of POS FOH technology features to the restaurants' operations by IT managers?"

Addressing the questions above, respondents were asked: "For each of the POS FOH features/devices, to indicate if their organization is currently using the technology/solution, or if it has plans to add the technology in the coming 12 months. In addition, they were asked to rate the importance of each technology to their organization and the overall restaurant industry." 
Table 20: POS FOH Technology Software/Hardware Utilization and Their Importance

\begin{tabular}{lcccccc}
\hline \multirow{2}{*}{ POS FOH technology software/hardware utilized } & \multicolumn{3}{c}{ Current usage } & \multicolumn{3}{c}{ Importance } \\
\cline { 2 - 6 } & Yes & No & Plan to add & Total \% & M $^{\mathbf{1}}$ & SD $^{\mathbf{2}}$ \\
\hline POS hardware & 95.9 & 4.1 & & 100.0 & 4.4 & 0.9 \\
Touch screen & 93.9 & 2.0 & 4.1 & 100.0 & 4.4 & 0.8 \\
POS software & 93.8 & 6.3 & & 100.0 & 4.6 & 0.8 \\
Gift card integration & 87.8 & 6.1 & 6.1 & 100.0 & 4.4 & 0.8 \\
Integrated credit card swipe into POS & 81.6 & 16.3 & 2.0 & 100.0 & 4.3 & 1.1 \\
Take-out/Delivery system & 44.4 & 35.6 & 20.0 & 100.0 & 3.1 & 1.5 \\
Energy efficient POS & 32.7 & 59.2 & 8.2 & 100.0 & 2.8 & 1.0 \\
POS Integration into online ordering & 32.7 & 38.8 & 28.6 & 100.0 & 3.6 & 1.3 \\
Menu labeling/Nutritional information & 32.7 & 49.0 & 18.4 & 100.0 & 3.2 & 1.1 \\
Wireless credit card authorization & 30.6 & 53.1 & 16.3 & 100.0 & 3.0 & 1.4 \\
Digital signage & 30.6 & 49.0 & 20.4 & 100.0 & 3.1 & 1.3 \\
Table management & 26.5 & 67.3 & 6.1 & 100.0 & 2.3 & 1.4 \\
Reservations & 20.4 & 73.5 & 6.1 & 100.0 & 2.1 & 1.5 \\
Biometrics fingerprint reader & 16.7 & 68.8 & 14.6 & 100.0 & 2.4 & 1.4 \\
Barcode scanners & 16.3 & 59.2 & 24.5 & 100.0 & 2.7 & 1.2 \\
Social media activity integrated into POS and/or & 12.8 & 57.4 & 29.8 & 100.0 & 3.2 & 1.1 \\
CRM platform & 10.6 & 74.5 & 14.9 & 100.0 & 2.3 & 1.5 \\
Tableside payment device & 8.5 & 80.9 & 10.6 & 100.0 & 2.2 & 1.4 \\
Tableside ordering device (tablet, other hardware) & 6.1 & 81.6 & 12.2 & 100.0 & 2.5 & 1.3 \\
Near field communications (NFC) capability & 2.1 & 60.4 & 37.5 & 100.0 & 2.7 & 1.3 \\
Bill pay via customers' mobile phone & Notes: ${ }^{1}$ Mean (1 = Not important at all, 5 = Extremely important) ${ }^{2}$ Standard Deviation & &
\end{tabular}

Based on the Table 20, "POS hardware" (95.9\%), "Touch screen" (93.9\%), "POS software" (93.8\%), "Gift card integration" (87.7\%), and "Integrated credit card swipe into POS" $(81.6 \%)$ are heavily used in the industry. "Bill pay via customers' mobile phone" (37.5\%), "Social media activity integrated into POS and/or CRM platform" (29.8\%), "POS Integration into online ordering" (28.6\%), "Barcode scanners" (24.5\%), "Digital signage" (20.4\%), "Takeout/Delivery system" (20.0\%) are the some of the POS FOH features/devices that companies plan to add in the future. In the restaurant industry, the five most important POS FOH features/devices are "POS hardware", "Touch screen", "POS software", "Gift card integration", and "Integrated credit card swipe into POS" (See Table 20). 
6. "What are the point of sale (POS) Back of House (BOH) technology features used in restaurants?"

7. 'What is the importance of POS BOH technology features to the restaurants' operations by IT managers?"

To be able to answer questions above, respondents were asked: "For each of the POS

$\mathrm{BOH}$ features/devices, to indicate if their organization is currently using the technology/solution, or if it has plans to add the technology in the coming 12 months. In addition, they were asked to rate the importance of each technology to their organization and the overall restaurant industry."

Table 21: POS BOH Technology Software/Hardware Utilization and Their Importance

\begin{tabular}{lcccccc}
\hline \multirow{2}{*}{ POS BOH technology software/hardware utilized } & \multicolumn{3}{c}{ Current usage } & \multicolumn{3}{c}{ Importance } \\
\cline { 2 - 7 } & Yes & No & Plan to add & Total \% & M $^{\mathbf{1}}$ & SD $^{\mathbf{2}}$ \\
\hline Accounting/Financial software & 93.3 & 6.7 & 0.0 & 100.0 & 4.4 & 1.0 \\
Enterprise reporting & 86.7 & 11.1 & 2.2 & 100.0 & 4.3 & 1.0 \\
Inventory management software & 84.1 & 13.6 & 2.3 & 100.0 & 4.3 & 1.1 \\
Kitchen printers & 75.6 & 24.4 & 0.0 & 100.0 & 3.9 & 1.4 \\
Company intranet & 71.1 & 20.0 & 8.9 & 100.0 & 3.7 & 1.1 \\
Labor management & 68.9 & 20.0 & 11.1 & 100.0 & 4.2 & 1.0 \\
Intra-day reporting & 66.7 & 28.9 & 4.4 & 100.0 & 3.8 & 1.2 \\
Disaster recovery plan for technology systems & 57.8 & 26.7 & 15.6 & 100.0 & 4.1 & 1.1 \\
Integrated video / IP video for security & 55.6 & 31.1 & 13.3 & 100.0 & 3.5 & 1.1 \\
Cloud-based applications & 47.7 & 36.4 & 15.9 & 100.0 & 3.4 & 1.3 \\
Kitchen displays & 46.7 & 37.8 & 15.6 & 100.0 & 3.6 & 1.2 \\
Integrated cost control software & 46.7 & 46.7 & 6.7 & 100.0 & 3.6 & 1.2 \\
Business intelligence system & 44.4 & 28.9 & 26.7 & 100.0 & 3.9 & 1.1 \\
Labor screening and recruitment tools & 42.2 & 40.0 & 17.8 & 100.0 & 3.6 & 1.3 \\
Real-time, web-based reporting & 42.2 & 22.2 & 35.6 & 100.0 & 3.8 & 1.2 \\
Kitchen management & 40.0 & 51.1 & 8.9 & 100.0 & 3.5 & 1.1 \\
Customer relationship management system & 33.3 & 48.9 & 17.8 & 100.0 & 3.4 & 1.1 \\
Mobile device for manager use & 28.9 & 51.1 & 20.0 & 100.0 & 3.2 & 1.0 \\
\hline
\end{tabular}

Notes: ${ }^{1}$ Mean $(1=\text { Not important at all, } 5=\text { Extremely important })^{2}$ Standard Deviation

As seen in the Table 21, "Accounting/Financial software" (93.3\%), "Enterprise reporting" (86.7\%), and "Inventory management software" (84.1\%) are the heavily used POS BOH Technology Software/Hardware in the restaurant industry. Moreover, "Kitchen printers" 
(75.6\%), "Company intranet" (71.1\%), "Labor management" (68.9\%), "Intra-day reporting" (66.7\%), "Disaster recovery plan for technology systems" (57.8\%), and "Integrated video / IP video for security" (55.6\%) are the mostly used POS BOH Technology Software/Hardware in the restaurant industry. "Real-time, web-based reporting" (35.6\%), "Business intelligence system" (26.7\%) and "Mobile device for manager use" (20.0\%) are the some of the POS BOH features/devices that companies plan to add in the future. The five most important POS BOH features/devices are "Accounting/Financial software", "Enterprise reporting", "Inventory management software", "Kitchen printers" and "Company intranet" (See Table 21).

\section{8. "What are the perceptions of restaurant IT managers on mobile POS systems?"}

Table 22: Mobile POS Perspectives

\begin{tabular}{lrr}
\hline & $\mathbf{M}^{\mathbf{1}}$ & $\mathbf{S D}^{\mathbf{2}}$ \\
\hline Mobile POS helps serve guests more quickly & 4.0 & 1.0 \\
Mobile POS terminals increase guest satisfaction & 3.9 & 1.1 \\
Mobile credit card terminals reduce credit card skimming & 3.9 & 1.3 \\
Mobile POS devices are easy to break & 3.7 & 1.1 \\
Mobile POS devices are too expensive & 3.7 & 1.1 \\
Mobile POS terminals "wow" guests & 3.5 & 1.1 \\
Mobile POS devices are easy to lose & 3.3 & 1.0 \\
My company has a website that is optimized for mobile devices (i.e. iPhone, Android) & 3.2 & 1.4 \\
My company does not see the value in investing in wireless handheld POS terminals & 2.8 & 1.3 \\
Mobile POS is not a secure method of payment & 2.8 & 1.2 \\
My company has a mobile app & 2.6 & 1.4 \\
\hline Notes: ${ }^{1}$ Mean (1 = Strongly Disagree, 5 = Strongly Agree) ${ }^{2}$ Standard Deviation & &
\end{tabular}

The survey respondents mainly agreed on the following mobile POS perceptions "Mobile POS helps serve guests more quickly", "Mobile POS terminals increase guest satisfaction", "Mobile credit card terminals reduce credit card skimming", "Mobile POS devices are easy to break" and "Mobile POS devices are too expensive" (See Table 22). 


\section{9. "What are the perceptions of restaurant IT managers on Payment Card Industry Data Security Standard (PCI DSS) practices in restaurants?"}

Table 23: PCI Compliance Trends and Challenges

\begin{tabular}{lcc}
\hline & $\mathbf{M}^{\mathbf{1}}$ & $\mathbf{S D}^{\mathbf{2}}$ \\
\hline Card brands should take greater responsibility in ensuring payment technology is secure & 4.6 & 0.9 \\
Merchants have an unreasonable burden associated with protecting cardholders & 4.4 & 1.2 \\
Our organization plans to upgrade devices and procedures by the April 2015 EMV & 4.2 & 1.1 \\
deadline for merchant compliance & 3.9 & 1.1 \\
PCI Standards are too complex & 3.6 & 1.6 \\
Our franchisees lack commitment to compliance efforts & 3.5 & 1.3 \\
We are fully aware of changes necessary to implement EMV technology & 3.5 & 1.4 \\
We have deployed the PCI council's best practices for mobile payments & 3.0 & 1.4 \\
We lack vendor support for PCI compliance efforts & 2.9 & 1.3 \\
We lack the budget necessary to implement payment security technologies & 2.8 & 1.3 \\
We lack knowledgeable staff at a senior-level to oversee payment security measures & 2.4 & 1.3 \\
\hline We have limited commitment from top management for payment security &
\end{tabular}

Notes: ${ }^{1}$ Mean $(1=\text { Strongly Disagree, } 5=\text { Strongly Agree })^{2}$ Standard Deviation

$\mathrm{M}>3.5$ is considered as "Agree"

The survey respondents mainly agreed on the following PCI compliance and challenges,

"Card brands should take greater responsibility in ensuring payment technology is secure", "Merchants have an unreasonable burden associated with protecting cardholders", "Our organization plans to upgrade devices and procedures by the April 2015 EMV deadline for merchant compliance", "PCI Standards are too complex" and "Our franchisees lack commitment to compliance efforts" (See Table 23). 
10. "To what extent are U.S. restaurants compliant with PCI DSS requirements?"

Table 24: Payment Card Industry Data Security Standards

\begin{tabular}{lcccc}
\hline & Yes & No & $\begin{array}{c}\text { Don't } \\
\text { know }\end{array}$ & Total \\
\hline $\begin{array}{lccc}\text { Install and maintain a firewall configuration to protect } \\
\text { cardholder data }\end{array}$ & $95.3 \%$ & $2.3 \%$ & $2.3 \%$ & $100.0 \%$ \\
$\begin{array}{l}\text { Use and regularly update anti-virus software or programs } \\
\text { Restrict access to cardholder data by business need-to- }\end{array}$ & $95.3 \%$ & $2.3 \%$ & $2.3 \%$ & $100.0 \%$ \\
know & $93.0 \%$ & $2.3 \%$ & $4.7 \%$ & $100.0 \%$ \\
$\begin{array}{l}\text { Assign a unique ID to each person with computer access } \\
\text { Protect stored cardholder data }\end{array}$ & $93.0 \%$ & $4.7 \%$ & $2.3 \%$ & $100.0 \%$ \\
$\begin{array}{l}\text { Encrypt transmission of cardholder data across open, } \\
\text { public networks }\end{array}$ & $90.7 \%$ & $4.7 \%$ & $4.7 \%$ & $100.0 \%$ \\
$\begin{array}{l}\text { Track and monitor all access to network resources and } \\
\text { cardholder data }\end{array}$ & $86.0 \%$ & $11.6 \%$ & $2.3 \%$ & $100.0 \%$ \\
$\begin{array}{l}\text { Regularly test security systems and processes } \\
\text { Develop and maintain secure systems and applications }\end{array}$ & $85.7 \%$ & $9.5 \%$ & $4.8 \%$ & $100.0 \%$ \\
$\begin{array}{l}\text { Maintain a policy that addresses information security for } \\
\text { all personnel }\end{array}$ & $81.4 \%$ & $11.6 \%$ & $7.0 \%$ & $100.0 \%$ \\
$\begin{array}{l}\text { Do not use vendor-supplied defaults for system } \\
\text { passwords and other security parameters }\end{array}$ & $76.7 \%$ & $20.9 \%$ & $2.3 \%$ & $100.0 \%$ \\
Use of point-to-point encryption (P2PE) & $51.2 \%$ & $25.6 \%$ & $23.3 \%$ & $100.0 \%$ \\
$\begin{array}{l}\text { Outsource PCI compliance efforts } \\
\text { Our organization has invested in PCI compliance }\end{array}$ & $46.5 \%$ & $44.2 \%$ & $9.3 \%$ & $100.0 \%$ \\
insurance & $38.1 \%$ & $45.2 \%$ & $16.7 \%$ & $100.0 \%$ \\
Use of tokenization at the card swipe & $32.6 \%$ & $46.5 \%$ & $20.9 \%$ & $100.0 \%$ \\
\hline
\end{tabular}

PCI data security standards are used by the restaurant companies in the range of $81.4 \%$ to 95.3\%, except for the "Use original passwords (non-vendor-supplied defaults) for system passwords and other security parameters" which $76.7 \%$ of the respondents answered "yes" and $20.9 \%$ of the respondents answered "no". Additionally, practices such as "Use of point-to-point encryption (P2PE)", "Outsource PCI compliance efforts", "Our organization has invested in PCI compliance insurance" and "Use of tokenization at the card swipe" were not preferred by majority of the respondents (See Table 24). 
11. "What is the level of PCI DSS compliance in restaurants?"

Table 25: Level of Payment Card Industry Compliance

\begin{tabular}{lrr}
\hline & $\mathbf{M}^{\mathbf{1}}$ & SD $^{\mathbf{2}}$ \\
\hline Level of PCI compliance & 87.0 & 15.7 \\
\hline Notes: ${ }^{1}$ Mean $(\text { Min. }=0, \text { Max. }=100)^{2}$ Standard Deviation & &
\end{tabular}

On average, the level of payment card industry compliance is $87 \%$ in the represented restaurant companies (See Table 25).

\section{Exploratory Factor Analyses}

In this study, exploratory factor analyses (EFA) were utilized to identify the proposed factors of Point of Sales Front of House (POS FOH) operation technology features, Point of Sale Systems Back of House (POS BOH) tools features, mobile POS perspectives, and Payment Card Industry Data Security Standard (PCI DSS) compliance statements.

From literature reviewed and the advice of restaurant technology experts, 20 significant software/hardware items were captured for POS FOH operations, whereas 19 significant software/hardware items were captured for POS BOH operation. The respondents were asked to indicate if they utilize POS FOH and POS BOH technology. Besides the "yes" and "no" option to this question, the option "have plan to add" was also given to respondents. If they answered, affirmatively, then it asked the level of each item's importance for the restaurants. All items the concerning importance of POS FOH and POS BOH operation technology features were rated on a 5-point Likert-scale ranging from $1=$ Not important at all to $5=$ Extremely important. 
For the mobile POS perspectives and PCI DSS, 13 and 11 items, respectively, captured and asked the level of each item's importance for the restaurants on a 5-point Likert-scale ranging from $1=$ Strongly disagree to $5=$ Strongly agree .

Before starting the EFA, due Walker and Maddan's (2008) suggestion, two measures of univariate analysis (skewness and kurtosis) of each item in each section were checked as a first step. Although, the majority of items in each section had a skewness and kurtosis value between +1.5 and -1.5 , there were some items that had a skewness and kurtosis value greater than 3 . According to Kline (2005), the values exceeding 3 were considered to be a problem for a normal univariate distribution. Therefore, the items which had a skewness and/or kurtosis value greater than 3 were removed from the model.

- In the POS FOH section, since the kurtosis of the survey items: "POS Hardware" (3.088) and "POS Software" (7.431) were greater than 3; they were removed from further analysis.

- In the POS BOH section, since the kurtosis of the survey item: "Enterprise Reporting" (3.342) was greater than 3; it was removed from the further analysis.

- In the PCI DSS section, since the kurtosis of the survey items: "Card brands should take greater responsibility in ensuring payment technology is secure" (9.058) and "Merchants have an unreasonable burden associated with protecting cardholders" (3.189) were greater than 3; they were removed from the further analysis.

As a second step, the reliability scores of each section were calculated, and are demonstrated in the Table 26. According to DeVellis (2012) and Nunnally (1978), Cronbach's Alpha scores of the POS FOH, Mobile POS Perspective and PCI DSS Compliance sections are 
within parameters considered to be acceptable and/or respectable for this study. Moreover, a Cronbach's alpha score of POS BOS is considered "very good" (DeVellis, 2012).

Table 26: Reliability Scores

\begin{tabular}{|l|l|}
\hline Survey Sections & Cronbach's Alpha \\
\hline POS FOH & 0.76 \\
\hline POS BOH & 0.88 \\
\hline Mobile POS Perspective & 0.71 \\
\hline PCI DSS Compliance & 0.76 \\
\hline
\end{tabular}

After removing the items that did not distribute normally and/or did not have acceptable reliability scores, as the following step EFA with principal components analysis and Varimax rotation was conducted on the each section's remaining items. After exploratory factor analysis was utilized, according to suggestion of Yong and Pearce (2013), table of correlation matrix, Bartlett's test of sphericity and the Kaiser-Meyer-Olkin measure of sampling adequacy (KMO), as well as anti-image correlation matrix, eigenvalues, communalities and percentage of the nonredundant residuals, total variance explained, and rotated factor matrix were checked for each section.

To be able to interpret an exploratory factor analysis there should be some correlations of .30 or greater (Pallant, 2013). Yong and Pearce (2013) stressed that correlations among the variables greater than $+/-.90$ should be removed from the model. Therefore, for each item and section, it was ensured that the majority of the item correlations were .30 or greater and there was not a correlation among the variables greater than $+/-.90$.

After the correlation matrix test, it is a requirement to check the significance level of Bartlett's test of sphericity and the Kaiser-Meyer-Olkin measure of sampling adequacy (KMO), to be able to determine the factorability of the data (Pallant, 2013). Bartlett's test of sphericity 
should also demonstrate a significance level of $\mathrm{p}<0.05$ to be able to continue the exploratory factor analysis (Yong and Pearce, 2013). Although Yong and Pearce (2013) states that the cutoff for the Kaiser-Meyer-Olkin measure of sampling adequacy (KMO) should be greater than .50, Pallant (2013) states that the value for KMO should be .60 or above. As a result, due to the fact that all of the four sections' values of the Kaiser-Meyer-Olkin measure of sampling adequacy was higher than the recommend value of .60 and Bartlett's test of sphericity was significant at a level of $\mathrm{p}<0.05$, an anti-image correlation matrix was checked for supporting the Kaiser-MeyerOlkin measure of sampling adequacy (KMO) and Bartlett's test of sphericity.

Anti-image correlation "matrices contain measures of sampling adequacy for each variable along the diagonal and the negatives of the partial correlation/covariance on the offdiagonals" (Field, 2013, p. 287). According to Yong and Pearce (2013), the value on the diagonal element of the anti-image correlation matrix should be above .50 , and if the value is below the cutoff point (.50), more data should be collected or the item that has a value below the cutoff should be removed from the model. As a result, it was realized that there were some items in each section that had an anti-image correlation value of less that .50. Therefore, items with a value of less than .50 anti-image correlations were removed from the model. Since there were few items with a value of less than .50 anti-image correlations in some of the sections, as a first step, the item with the lowest value was removed from the model and the model tested again. After trying few different variations to select the item to be removed, it was decided that items should be removed one by one from lowest value to highest value, which are less than .50 .

\section{Consequently;}

- In the POS FOH section, the survey items "Integrated credit card swipe into POS" (.224), "Touch screen" (.380), "Menu labeling/nutritional information" (.462) and 
"Gift card integration" (.487) were removed from the model respectively.

- In the POS BOH section, the survey items "Kitchen printers" (.201), "Mobile device for manger use" (.481) and "Customer relationship management system" (.456) were removed from the model respectively.

- In the Mobile POS perspective section, the survey item "My company does not see the value in investing in wireless handheld POS terminals" (.406) was removed from the model.

- In the PCI DSS section, the survey item "We have deployed the PCI council's best practices for mobile payment" (.456) was removed from the model.

Before evaluating the table of total variance explained and rotated factor matrix, communalities and percentage of the non-redundant residuals were checked. According to Walker and Maddan (2008), it is important to inspect the communality, of which is "represented by the sum of the squared loadings for a variable across factors" (p. 333). The lowest, moderate and highest values of communalities in the social sciences are considered to be $.40, .70$, and .80 or greater respectively, and if the communality of the item is below .40, it can be removed from the model (Costello and Osborne, 2005). Another critical test in the exploratory factor analysis is residuals. Yong and Pearce (2013) point out that "a model that is a good fit will have less than $50 \%$ of the non-redundant residuals with absolute values that are greater than $.05 \%$ (p. 90). As a result of the communalities check, all four sections had less than $50 \%$ of the non-redundant residuals with absolute values that are greater than .05 . However, some of the items had a value lower than .50 in communalities table:

- In the POS FOH section, since the "Digital signage" (.483) had a value lower than .50 in the communalities table, it was removed from the model. 
- In the mobile POS Perspective section, "Mobile POS is not a secure method of payment" $(.242)$ had a value lower than .50 in the communalities table so it was removed from the model.

By successfully completing all of the above tests, the significance level of Bartlett's test of sphericity, the Kaiser-Meyer-Olkin measure of sampling adequacy (KMO), table of total variance explained and rotated factor matrix were checked and the results are demonstrated below.

Table 27: Bartlett's Test of Sphericity and the Kaiser-Meyer-Olkin Measure of Sampling Adequacy (KMO)

\begin{tabular}{llrrrr}
\hline & & POS & POS BOH & $\begin{array}{r}\text { Mobile POS } \\
\text { Perspectives }\end{array}$ & $\begin{array}{r}\text { PCI DSS } \\
\text { Compliance }\end{array}$ \\
\hline $\begin{array}{ll}\text { Kaiser-Meyer-Olkin Measure } \\
\text { of Sampling Adequacy. }\end{array}$ & & .644 & .763 & .703 & .695 \\
Bartlett's Test of Sphericity & Approx. Chi-Square & 268.949 & 326.908 & 205.170 & 136.954 \\
& df & 78 & 105 & 36 & 28 \\
& Sig. & .000 & .000 & .000 & .000 \\
\hline
\end{tabular}

As seen in the table above, all of the four sections' values of the Kaiser-Meyer-Olkin measure of sampling adequacy were higher than the recommend value of .60 (Pallant, 2013) and Bartlett's test of sphericity was significant at a level of $\mathrm{p}<0.05$ (Yong and Pearce, 2013).

To be able to assess the total number of significant factors, it is required to find the table of total variance explained and check the initial eigenvalues that are 1 or greater (Yong and Pearce, 2013). This is the most commonly used technique and is known as the Kaiser-Guttman criterion (Matsunaga, 2010). In the table of total variance explained, the initial eigenvalues equal to 1 or greater show the total variance explained as components and as a cumulative percent of variance (Pallant, 2013). 
A rotated factor matrix is used to name factors and interpret them (Yong and Pearce, 2013). On the rotation matrix, the minimum loading of an item should be at least .32 to be considered statistically meaningful (Tabachnick and Fidell, 2013).

Table 28: Rotated Component Matrix for POS FOH Operation Features

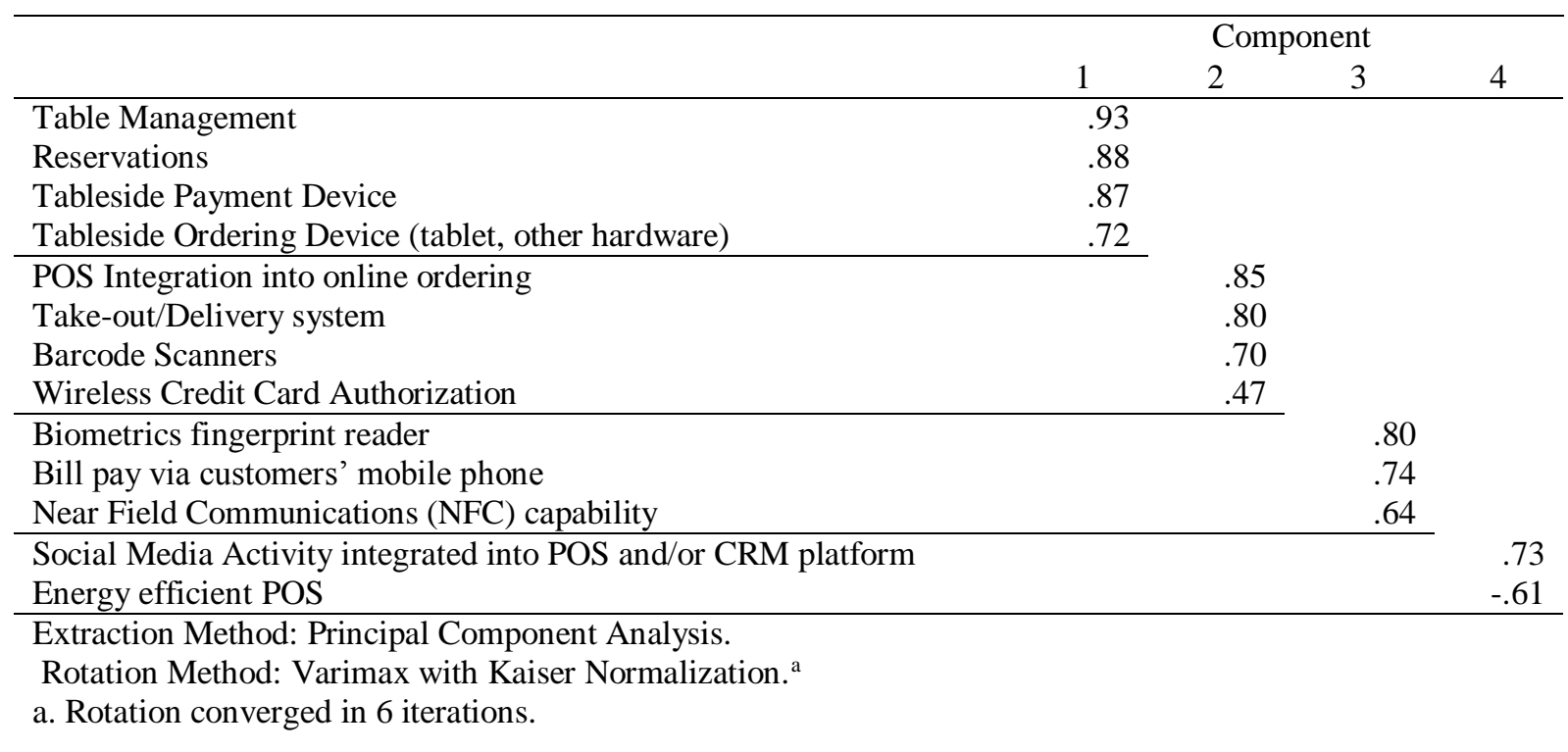

EFA resulted in four factors with eigenvalues greater than 1.0 that cumulatively explain $71.27 \%$ of the entire variance for POS FOH. All of the communalities were within acceptable limits. Except for the Barcode scanners (.51), communalities of all the other items were between .63 to .90 . As can be seen in Table 28 , factor loading of items ranged .47 to .93 . Based on the characteristics of the rotated component matrix for POS FOH operation features, the following names were assigned to factors, respectively: Table management features, Online/ordering features, Mobile payment features and Emerging applications. As a first factor, Table management features captured $31.07 \%$ of the variance consisting of 4 items ("Table management", "Reservations", "Tableside payment device" and "Tableside ordering device”). Online/ordering features, which a created second factor, captured $21.74 \%$ of the variance 
consisting of 4 items ("POS integration into online ordering", "Take-out/delivery system", "Barcode scanners", and "Wireless credit card authorization"). Mobile payment features, as the third factor, captured $10.29 \%$ of the variance consisting of 3 items ("Biometrics fingerprint reader", "Bill pay via customers' mobile phone" and "Near field communications capability"). As a last factor, Emerging applications captured 8.18\% of variance consisting of 2 items ("Social media activity integrated into POS and/or CRM platform" and "Energy efficient POS").

Table 29: Rotated Component Matrix for POS BOH Operation Features

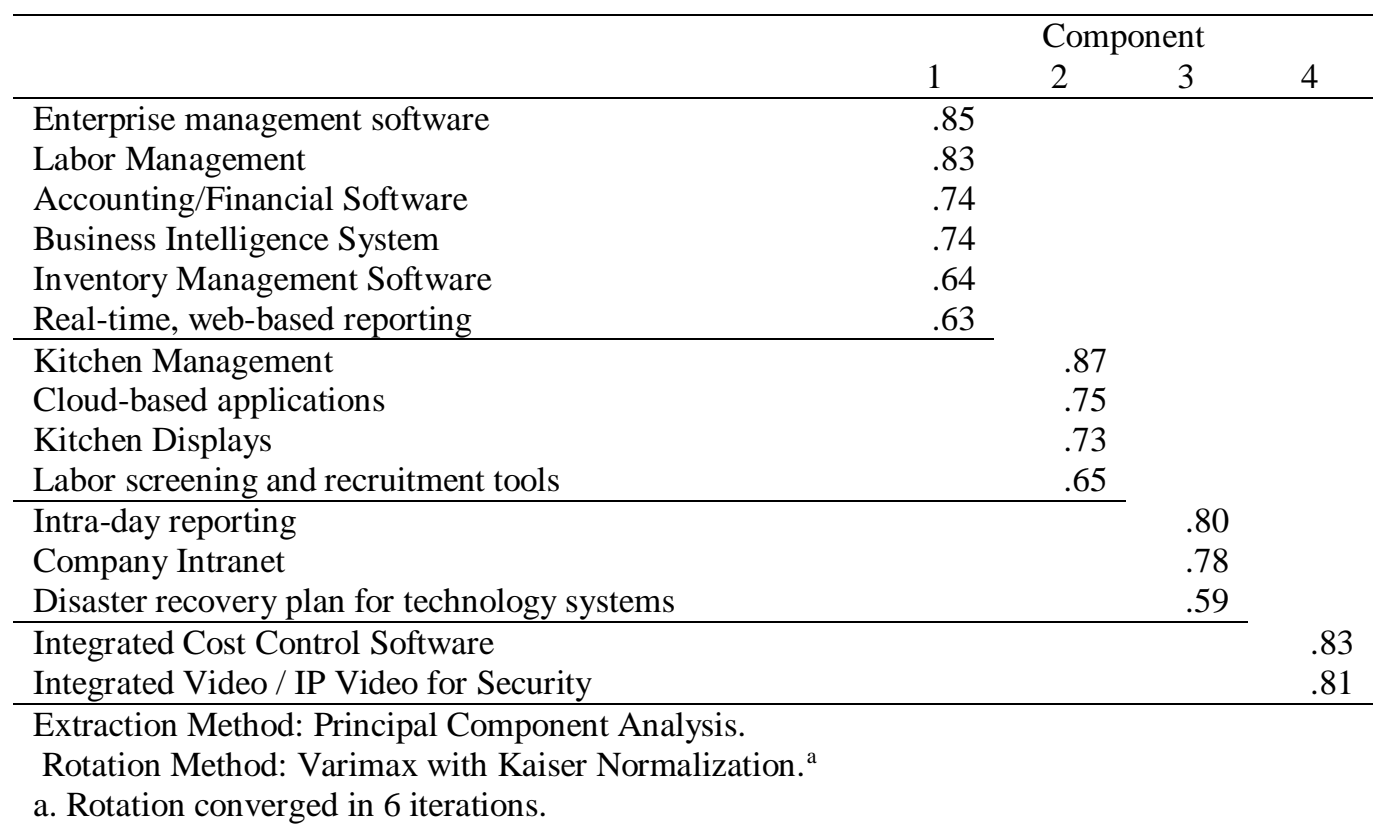

EFA for POS $\mathrm{BOH}$ resulted in four factors with eigenvalues greater than 1.0 that cumulatively explain $71.28 \%$ of the entire variance. All of the communalities were within acceptable limits. Other than the "Disaster recovery plan for technology systems" $(.50)$, communalities ranged from .65 to .87 . As is clearly shown in the Table 29 , factor loading of items ranged .59 to .87 , suggesting a high correlation of the items. Following names, Essential functions, Cloud applications, Enterprise systems and Integrated systems were assigned to 
factors respectively, based on the characteristics of the rotated component matrix for POS BOH operation features. Essential functions, as the first factor, captured 39.66\% of the variance consisting of 6 items ("Enterprise management software", "Labor management", “Accounting/financial software", "Business intelligence system", "Inventory management software" and "Real-time, web-based reporting"). Cloud applications, as the second factor, captured $15.75 \%$ of the variance consisting of 4 items ("Kitchen management", "Cloud-based applications", "Kitchen displays", and "Labor screening and recruitment tools"). Enterprise systems, as the third factor, captured $8.28 \%$ of the variance consisting of 3 items ("Intra-day reporting", "Company intranet" and "Disaster recovery plan for technology systems"). As the last factor, Integrated systems captured 7.58\% of the variance consisting of 2 items ("Integrated cost control software" and "Integrated video / IP video for security").

Table 30: Rotated Component Matrix for Mobile POS Perspectives

\begin{tabular}{|c|c|c|c|}
\hline & & pon & \\
\hline & 1 & 2 & 3 \\
\hline Mobile POS helps serve guests more quickly & .87 & & \\
\hline Mobile POS terminals increase guest satisfaction & .84 & & \\
\hline Mobile credit card terminals reduce credit card skimming & .81 & & \\
\hline Mobile POS terminals "wow" guests & .78 & & \\
\hline Mobile POS devices are easy to break & & .86 & \\
\hline Mobile POS devices are easy to lose & & .84 & \\
\hline Mobile POS devices are too expensive & & .78 & \\
\hline My company has a mobile app & & & .84 \\
\hline $\begin{array}{l}\text { My company has a website that is optimized for mobile } \\
\text { devices (i.e. iPhone, Android) }\end{array}$ & & & .84 \\
\hline $\begin{array}{l}\text { Extraction Method: Principal Component Analysis. } \\
\text { Rotation Method: Varimax with Kaiser Normalization. }{ }^{a}\end{array}$ & & & \\
\hline
\end{tabular}

EFA for Mobile POS revealed the presence of three components with eigenvalues higher than 1 , explaining $45.06 \%, 17.81 \%$, and $12.94 \%$ of the variance respectively and explaining the total $75.81 \%$ of the entire variance. All of the communalities were acceptable with a range from 
.67 to .83 . As is clearly shown Table 30 , factor loading of items ranged from .78 to .87 , suggesting a high correlation of the items. Based on the characteristics of the rotated component matrix for Mobile POS perspectives, following names were assigned to factors respectively: Advantages of Mobile POS, Disadvantages of Mobile POS, and Web-enabled mobile POS

Features. As the first factor, Advantages of Mobile POS captured $45.06 \%$ of the variance consisting of 4 items ("Mobile POS helps serve guests more quickly", "Mobile POS terminals increase guest satisfaction", "Mobile credit card terminals reduce credit card skimming" and "Mobile POS terminals "wow" guests"). Disadvantages of Mobile POS, as the second factor, captured $17.81 \%$ of the variance consisting of 3 items ("Mobile POS devices are easy to break", "Mobile POS devices are easy to lose" and "Mobile POS devices are too expensive"). As the last factor, Web-enabled mobile POS Features captured $12.94 \%$ of the variance consisting of 2 items ("My company has a mobile app" and "My company has a website that is optimized for mobile devices").

Table 31: Rotated Component Matrix for PCI DSS Compliance

\begin{tabular}{lcc}
\hline & \multicolumn{2}{c}{ Component } \\
& 1 & 2 \\
\hline We lack knowledgeable staff at a senior-level to oversee payment security & .84 \\
measures & .81 \\
We lack the budget necessary to implement payment security technologies & .72 \\
We have limited commitment from top management for payment security & \multicolumn{2}{|}{.90} \\
\hline We lack vendor support for PCI compliance efforts & .86 \\
Our franchisees lack commitment to compliance efforts & \\
\hline Our organization plans to upgrade devices and procedures by the April 2015 EMV & .86 \\
deadline for merchant compliance & \\
PCI Standards are too complex & .64 \\
We are fully aware of changes necessary to implement EMV technology & .64 \\
\hline Extraction Method: Principal Component Analysis. & \\
Rotation Method: Varimax with Kaiser Normalization. ${ }^{\text {a }}$ & \\
a. Rotation converged in 6 iterations. & \\
\end{tabular}

EFA for PCI DSS compliance revealed the presence of three components with 
eigenvalues higher than 1, explaining $42.02 \%, 19.33 \%$, and $15.38 \%$ of the variance respectively and explaining $76.73 \%$ of the entire variance. All of the communalities were acceptable with a range from .67 to .84 . As can be clearly seen Table 31, factor loading of items ranged from .64 to .86 suggesting a high correlation of the items. Based on the characteristics of the rotated component matrix for PCI DSS compliance, the following names were assigned to factors respectively: Barriers to PCI DSS, Lack of support, and Emerging Features. As the first factor, Barriers to PCI DSS captured $42.02 \%$ of the variance consisting of 3 items ("We lack knowledgeable staff at a senior-level to oversee payment security measures", "We lack the budget necessary to implement payment security technologies", and "We have limited commitment from top management for payment security"). Lack of support, as the second factor, captured $19.33 \%$ of the variance consisting of 2 items ("We lack vendor support for PCI compliance efforts" and "Our franchisees lack commitment to compliance efforts"). As the last factor, Emerging Features captured $12.94 \%$ of the variance consisting of 3 items (“Our organization plans to upgrade devices and procedures by the April 2015 EMV deadline for merchant compliance", "PCI Standards are too complex" and "We are fully aware of changes necessary to implement EMV technology").

\section{Hypotheses Testing}

Based on the job function, respondents were divided into two groups, named IT and NonIT position holder, respectively. Additionally, based on the company descriptions, companies were also divided into two groups: chain and independent restaurants. Finally, according to companies' reported preferences from business and technology perspectives, companies were 
grouped under two categories (Business Leadership and Technology Leadership): either “innovator" or "follower".

\section{Hypotheses Related to POS FOH Technology Features}

An independent samples t-test was conducted to compare factors of POS FOH technology features for restaurant types ("Chain" and "Independent”), business leadership perspective ("Innovator" and "Follower"), technology leadership perspective ("Innovator" and "Follower"), and job function ("IT" and "Non-IT"), and to test the hypotheses below:

1. $\mathrm{H}_{\mathrm{A} 1}=$ There is a significant difference in $\mathrm{POS} F O H$ technology features between chain restaurants and independent restaurants.

2. $\mathrm{H}_{\mathrm{A} 2}=$ There is a significant difference in $\mathrm{POS} F O H$ technology features between restaurants which identify themselves as innovators versus followers from a business perspective.

3. $\mathrm{H}_{\mathrm{A} 3}=$ There is a significant difference in POS FOH technology features between restaurants which identify themselves as innovators versus followers from a technology perspective.

4. $\mathrm{H}_{\mathrm{A} 4}=$ There is a significant difference in POS FOH technology features between restaurants with IT educated IT managers versus non-IT educated IT managers. 
Table 32: Hypothesis Testing for POS FOH Technology Features

\begin{tabular}{|c|c|c|c|c|c|c|}
\hline Business Leadership & \multicolumn{2}{|c|}{ Innovator } & \multicolumn{2}{|c|}{ Follower } & \multirow[b]{2}{*}{$\mathbf{t}^{3}$} & \multirow[b]{2}{*}{ Sig. ${ }^{4}$} \\
\hline & $\mathbf{M}^{1}$ & SD $^{2}$ & $\mathbf{M}^{1}$ & SD $^{2}$ & & \\
\hline Table management features & 2.24 & 1.30 & 2.05 & 0.88 & 0.54 & 0.59 \\
\hline Online/ordering features & 3.23 & 0.93 & 2.78 & 1.33 & 1.23 & 0.23 \\
\hline Mobile payment features & 2.79 & 0.97 & 1.88 & 1.02 & 2.68 & 0.01 \\
\hline Emerging applications & 3.16 & 0.67 & 2.41 & 0.77 & 3.11 & 0.00 \\
\hline Technology Leadership & \multicolumn{2}{|c|}{ Innovator } & \multicolumn{2}{|c|}{ Follower } & & \\
\hline & $\mathbf{M}^{1}$ & $\mathbf{S D}^{2}$ & $\mathbf{M}^{1}$ & $\mathbf{S D}^{2}$ & $\mathbf{t}^{3}$ & Sig. ${ }^{4}$ \\
\hline Table management features & 2.09 & 1.21 & 2.45 & 1.23 & -0.92 & 0.37 \\
\hline Online/ordering features & 3.31 & 0.94 & 2.73 & 1.14 & 1.76 & 0.08 \\
\hline Mobile payment features & 2.81 & 1.03 & 2.09 & 0.94 & 2.27 & 0.03 \\
\hline Emerging applications & 3.13 & 0.64 & 2.69 & 0.89 & 1.95 & 0.05 \\
\hline
\end{tabular}

There is not a statistically significant difference between the chain and independent restaurants' mean for factors of POS FOH technology features:

- Table management features; $\mathrm{t}=-1.16, \mathrm{p}=0.25$

- Online/ordering features; $\mathrm{t}=1.23, \mathrm{p}=0.23$

- Mobile payment features; $\mathrm{t}=1.25, \mathrm{p}=0.22$

- Emerging applications; $\mathrm{t}=-1.00, \mathrm{p}=0.32$

Therefore, hypothesis $\mathrm{H}_{\mathrm{Al}}$ ("There is a significant difference in POS FOH technology features between chain restaurants versus independent restaurants") was rejected.

Due to the fact that there is a statistically significant difference between restaurants which identify themselves as innovators or followers from a Business Leadership perspective for POS FOH technology features on "Mobile payment features", $t=2.68, p=0.01$ and "Emerging applications", $\mathrm{t}=3.11, \mathrm{p}=0.00$ but not a statistically significant difference on "Table management features", $\mathrm{t}=0.54, \mathrm{p}=0.59$ and "Online/ordering features", $\mathrm{t}=1.23, \mathrm{p}=0.23$, hypothesis $\mathrm{H}_{\mathrm{A} 2}$ was partially supported, at $\alpha \leq 0.05$. 
Although there is a statistically significant difference between restaurants which identify themselves as innovators or followers from a Technology Leadership perspective for POS FOH technology features on "Mobile payment features", $\mathrm{t}=2.27, \mathrm{p}=0.03$ and "Emerging applications", $\mathrm{t}=1.95, \mathrm{p}=0.05$, there is not a statistically significant difference on "Table management features", $\mathrm{t}=-0,92, \mathrm{p}=0.37$ and "Online/ordering features", $\mathrm{t}=1.76, \mathrm{p}=0.09$. Therefore, hypothesis $\mathrm{H}_{\mathrm{A} 3}$ was partially supported, at $\alpha \leq 0.05$.

There is not a statistically significant difference between the IT educated IT managers and non-IT educated IT managers mean for factors of POS FOH technology features:

- Table management features; $\mathrm{t}=-0.42, \mathrm{p}=0.68$

- Online/ordering features; $\mathrm{t}=0.40, \mathrm{p}=0.69$

- Mobile payment features; $\mathrm{t}=-1.32, \mathrm{p}=0.20$

- Emerging applications; $\mathrm{t}=-0.20, \mathrm{p}=0.84$

Therefore, hypothesis $\mathrm{H}_{\mathrm{A} 4}$ ("There is a significant difference in POS FOH technology features between restaurants with IT educated IT managers versus non-IT educated IT managers") was rejected.

\section{Hypotheses Related to POS BOH Technology Features}

To compare factors of POS BOH technology features for restaurant types ("Chain" and "Independent”), business leadership perspective ("Innovator" and "Follower"), technology leadership perspective ("Innovator" and "Follower"), and job function ("IT" and "Non-IT"), and to test the hypotheses below, an independent samples t-test was conducted and results are demonstrated below: 
1. $\mathrm{H}_{\mathrm{B} 1}=$ There is a significant difference in $\mathrm{POS} \mathrm{BOH}$ technology features between chain restaurants versus independent restaurants.

2. $\mathrm{H}_{\mathrm{B} 2}=$ There is a significant difference in $\mathrm{POS} \mathrm{BOH}$ technology features between restaurants which identify themselves as innovators versus followers from a business perspective.

3. $\mathrm{H}_{\mathrm{B} 3}=$ There is a significant difference in POS BOH technology features between restaurants which identify themselves as innovators versus followers from a technology perspective.

4. $\mathrm{H}_{\mathrm{B} 4}=$ There is a significant difference in $\mathrm{POS} \mathrm{BOH}$ technology features between restaurants with IT educated IT managers versus non-IT educated IT managers.

Table 33: Hypothesis Testing for POS BOH Technology Features

\begin{tabular}{|c|c|c|c|c|c|c|}
\hline Restaurant Types & \multicolumn{2}{|c|}{ Chain } & \multicolumn{2}{|c|}{ Independent } & \multirow[b]{2}{*}{$\mathbf{t}^{3}$} & \multirow[b]{2}{*}{ Sig. ${ }^{4}$} \\
\hline & $\mathbf{M}^{1}$ & $\mathbf{S D}^{2}$ & $\mathbf{M}^{1}$ & $\mathrm{SD}^{2}$ & & \\
\hline Essential functions & 4.28 & 0.80 & 3.67 & 0.97 & 2.05 & 0.05 \\
\hline Cloud applications & 3.66 & 0.89 & 2.97 & 1.03 & 2.00 & 0.05 \\
\hline Enterprise systems & 1.44 & 0.50 & 1.47 & 0.39 & -0.17 & 0.87 \\
\hline Integrated systems & 1.53 & 0.47 & 1.80 & 0.71 & -1.13 & 0.28 \\
\hline Business Leadership & \multicolumn{2}{|c|}{ Innovator } & \multicolumn{2}{|c|}{ Follower } & & \\
\hline & $\mathbf{M}^{1}$ & $\mathbf{S D}^{2}$ & $\mathbf{M}^{1}$ & SD $^{2}$ & $\mathbf{t}^{3}$ & Sig. ${ }^{4}$ \\
\hline Essential functions & 4.19 & 0.88 & 3.96 & 0.83 & 0.70 & 0.49 \\
\hline Cloud applications & 3.69 & 0.94 & 2.95 & 0.79 & 2.25 & 0.03 \\
\hline Enterprise systems & 1.47 & 0.49 & 1.37 & 0.43 & 0.58 & 0.56 \\
\hline Integrated systems & 1.54 & 0.51 & 1.75 & 0.63 & -1.08 & 0.29 \\
\hline
\end{tabular}

\begin{tabular}{lrrrrrr}
\hline Technology Leadership & \multicolumn{7}{c}{ Innovator } & \multicolumn{2}{c}{ Follower } & & \\
\hline & $\mathbf{M}^{\mathbf{1}}$ & $\mathbf{S D}^{\mathbf{2}}$ & $\mathbf{M}^{\mathbf{1}}$ & SD $^{\mathbf{2}}$ & $\mathbf{t}^{\mathbf{3}}$ & Sig. $^{\mathbf{4}}$ \\
\cline { 2 - 7 } Essential functions & 4.38 & 0.57 & 3.63 & 1.16 & 2.30 & 0.04 \\
Cloud applications & 3.67 & 0.96 & 3.20 & 0.88 & 1.56 & 0.13 \\
Enterprise systems & 1.43 & 0.53 & 1.47 & 0.37 & -0.22 & 0.83 \\
Integrated systems & 1.50 & 0.44 & 1.77 & 0.68 & -1.39 & 0.18 \\
\hline
\end{tabular}

Notes: ${ }^{1}$ Mean $(1=$ Not important at all, $5=$ Extremely Important $)$

${ }^{2}$ Standard Deviation ${ }^{3} \mathrm{t}$ statistics (independent samples t-test) ${ }^{4}$ Significance 
Although there is a statistically significant difference between chain restaurants and independent restaurants mean for POS BOH technology features on "Essential functions", $\mathrm{t}=$ 2.05, $\mathrm{p}=0.05$ and "Cloud applications", $\mathrm{t}=2.00, \mathrm{p}=0.05$, there is not a statistically significant difference on "Enterprise systems", $\mathrm{t}=-0,17, \mathrm{p}=0.87$ and "Integrated systems", $\mathrm{t}=-1.13, \mathrm{p}=$ 0.28. Therefore, hypothesis $\mathrm{H}_{\mathrm{B} 1}$ was partially supported, at $\alpha \leq 0.05$.

Due to the fact that there is a statistically significant difference between restaurants which identify themselves as innovators or followers from a Business Leadership perspective for POS $\mathrm{BOH}$ technology features on "Cloud applications", $\mathrm{t}=2.25, \mathrm{p}=0.03$ but not a statistically significant difference on "Essential functions", $\mathrm{t}=0.70, \mathrm{p}=0.49$, "Enterprise systems", $\mathrm{t}=0.58$, $\mathrm{p}=0.57$, and "Integrated systems hypothesis", $\mathrm{t}=-1.08, \mathrm{p}=0.29, \mathrm{H}_{\mathrm{B} 2}$ was partially supported, at $\alpha \leq 0.05$.

There is a statistically significant difference between restaurants which identify themselves as innovators or followers from a Technology Leadership perspective mean for POS $\mathrm{BOH}$ technology features on "Essential functions", $\mathrm{t}=2.30, \mathrm{p}=0.04$. However, there is not statistically significant difference between restaurants which identify themselves as innovators or followers from a Technology Leadership perspective on "Cloud applications", $\mathrm{t}=1.56, \mathrm{p}=0.13$, "Enterprise systems", $\mathrm{t}=-0.22, \mathrm{p}=0.83$, and "Integrated systems hypothesis", $\mathrm{t}=-1.39, \mathrm{p}=$ 0.18. As a result, $\mathrm{H}_{\mathrm{B} 3}$ was partially supported, at $\alpha \leq 0.05$.

There is not a statistically significant difference between the IT educated IT managers and non-IT educated IT managers mean for factors of POS BOH technology features:

- $\quad$ Essential functions; $\mathrm{t}=1.75, \mathrm{p}=0.09$

- Cloud applications; $\mathrm{t}=0.12, \mathrm{p}=0.90$

- $\quad$ Enterprise systems; $\mathrm{t}=-0.76, \mathrm{p}=0.45$ 
- Integrated systems; $\mathrm{t}=0.80, \mathrm{p}=0.42$

Therefore, hypothesis $\mathrm{H}_{\mathrm{B} 4}$ ("There is a significant difference in POS BOH technology features between restaurants with IT educated IT managers versus non-IT educated IT managers.”) was rejected.

\section{Hypotheses Related to Mobile POS Perspectives}

An independent samples t-test was conducted: to compare factors of mobile POS perspectives for restaurant types ("Chain" and "Independent"), business leadership perspective (“Innovator" and "Follower”), technology leadership perspective (“Innovator" and "Follower"), and job function ("IT" and "Non-IT"), and to test the hypotheses below:

1. $\mathrm{H}_{\mathrm{C} 1}=$ There is a significant difference in mobile POS perspectives between chain restaurants versus independent restaurants.

2. $\mathrm{H}_{\mathrm{C} 2}=$ There is a significant difference in mobile POS perspectives between restaurants which identify themselves as innovators versus followers from a business perspective.

3. $\mathrm{H}_{\mathrm{C} 3}=$ There is a significant difference in mobile POS perspectives between restaurants which identify themselves as innovators versus followers from a technology perspective.

4. $\mathrm{H}_{\mathrm{C} 4}=$ There is a significant difference in mobile POS perspectives between restaurants with IT educated IT managers versus non-IT educated IT managers. 
Table 34: Hypothesis Testing for Mobile POS Perspectives

\begin{tabular}{|c|c|c|c|c|c|c|}
\hline Technology Leadership & \multicolumn{2}{|c|}{ Innovator } & \multicolumn{2}{|c|}{ Follower } & \multirow[b]{2}{*}{$\mathbf{t}^{3}$} & \multirow[b]{2}{*}{ Sig. ${ }^{4}$} \\
\hline & $\mathbf{M}^{1}$ & SD $^{2}$ & $\mathbf{M}^{1}$ & SD $^{2}$ & & \\
\hline Advantages of mobile POS & 4.06 & 0.77 & 3.28 & 1.18 & 2.33 & 0.03 \\
\hline Disadvantages of mobile POS & 3.60 & 0.79 & 3.44 & 1.13 & 0.56 & 0.58 \\
\hline Web enabled mobile POS features & 3.11 & 1.33 & 2.47 & 0.90 & 1.95 & 0.05 \\
\hline \multirow[t]{2}{*}{ Job Functions } & \multicolumn{2}{|c|}{ IT } & \multicolumn{2}{|c|}{ Non-IT } & & \\
\hline & $\mathbf{M}^{1}$ & $\mathbf{S D}^{2}$ & $\mathbf{M}^{1}$ & SD $^{2}$ & $\mathbf{t}^{3}$ & Sig. ${ }^{4}$ \\
\hline Advantages of mobile POS & 3.95 & 0.68 & 3.69 & 1.20 & 0.91 & 0.37 \\
\hline Disadvantages of mobile POS & 3.81 & 0.77 & 3.31 & 0.97 & 1.98 & 0.05 \\
\hline Web enabled mobile POS features & 3.22 & 1.17 & 2.60 & 1.25 & 1.74 & 0.09 \\
\hline
\end{tabular}

There is not a statistically significant difference between the chain and independent restaurants mean for factors of mobile POS perspectives:

- Advantages of mobile POS; $\mathrm{t}=0.25, \mathrm{p}=0.81$

- Disadvantages of mobile POS; $\mathrm{t}=-0.22, \mathrm{p}=0.83$

- Web enabled mobile POS features; $\mathrm{t}=0.96, \mathrm{p}=0.34$

Therefore, hypothesis $\mathrm{H}_{\mathrm{Cl}}$ ("There is a significant difference in mobile POS perspectives between chain restaurants versus independent restaurants.”) was rejected.

There is not a statistically significant difference between restaurants which identify themselves as innovators or followers from a Business Leadership perspective mean for factors of mobile POS perspectives:

- Advantages of mobile POS; $\mathrm{t}=1.43, \mathrm{p}=0.16$

- Disadvantages of mobile POS; $\mathrm{t}=0.34, \mathrm{p}=0.74$

- Web enabled mobile POS features; $\mathrm{t}=0.88, \mathrm{p}=0.39$

Therefore, hypothesis $\mathrm{H}_{\mathrm{C} 2}$ ("There is a significant difference in mobile POS perspectives between restaurants which identify themselves as innovators versus followers from a business perspective.") was rejected. 
There is a statistically significant difference between restaurants which identify themselves as innovators or followers from a Technology Leadership perspective for mobile POS perspectives on "Advantages of mobile POS", $\mathrm{t}=2.33, \mathrm{p}=0.03$ and "Web enabled mobile POS features", $\mathrm{t}=1.95, \mathrm{p}=0.05$. However, there is not statistically significant difference between restaurants which identify themselves as innovators or followers from a Technology Leadership perspective on "Disadvantages of mobile POS", $\mathrm{t}=0.56, \mathrm{p}=0.58$. As a result, $\mathrm{H}_{\mathrm{C} 3}$ was partially supported, at $\alpha \leq 0.05$.

Due to the fact that there is a statistically significant difference between restaurants with IT educated IT managers and non-IT educated IT managers on "Disadvantages of mobile POS", $\mathrm{t}=1.98, \mathrm{p}=0.05$ but not a statistically significant difference on "Advantages of mobile POS", $\mathrm{t}$ $=0.91, \mathrm{p}=0.37$ and "Web enabled mobile POS features", $\mathrm{t}=1.74, \mathrm{p}=0.09$, hypothesis $\mathrm{H}_{\mathrm{C} 4}$ was partially supported, at $\alpha \leq 0.05$.

\section{Hypotheses Related to PCI DSS Compliance}

To compare factors of PCI DSS compliance for restaurant types ("Chain" and “Independent”), business leadership perspective (“Innovator" and "Follower”), technology leadership perspective (“Innovator" and "Follower"), and job function (“IT" and "Non-IT"), and to test the hypotheses below, an independent samples t-test was conducted and results are demonstrated below:

1. $\mathrm{H}_{\mathrm{D} 1}=$ There is a significant difference in PCI DSS compliance between chain restaurants versus independent restaurants. 
2. $\mathrm{H}_{\mathrm{D} 2}=$ There is a significant difference in PCI DSS compliance between restaurants which identify themselves as innovators versus followers from a business perspective.

3. $\mathrm{H}_{\mathrm{D} 3}=$ There is a significant difference in PCI DSS compliance between restaurants which identify themselves as innovators versus followers from a technology perspective.

4. $\mathrm{H}_{\mathrm{D} 4}=$ There is a significant difference in PCI DSS compliance between restaurants with IT educated IT managers versus non-IT educated IT managers.

Table 35: Hypothesis Testing for PCI DSS Compliance

\begin{tabular}{|c|c|c|c|c|c|c|}
\hline Business Leadership & \multicolumn{2}{|c|}{ Innovator } & \multicolumn{2}{|c|}{ Follower } & \multirow[b]{2}{*}{$\mathbf{t}^{3}$} & \multirow[b]{2}{*}{ Sig. ${ }^{4}$} \\
\hline & $\mathbf{M}^{1}$ & $\mathbf{S D}^{2}$ & $\mathbf{M}^{1}$ & $\mathbf{S D}^{2}$ & & \\
\hline Barriers to PCI DSS & 2.62 & 1.04 & 3.03 & 1.43 & -1.02 & 0.31 \\
\hline Lack of support & 3.07 & 1.27 & 4.05 & 1.59 & -2.03 & 0.05 \\
\hline Emerging features & 3.90 & 0.80 & 3.73 & 1.00 & 0.57 & 0.57 \\
\hline Technology Leadership & \multicolumn{2}{|c|}{ Innovator } & \multicolumn{2}{|c|}{ Follower } & & \\
\hline & $\mathbf{M}^{1}$ & $\mathbf{S D}^{2}$ & $\mathbf{M}^{1}$ & $\mathbf{S D}^{2}$ & $\mathbf{t}^{3}$ & Sig. ${ }^{4}$ \\
\hline Barriers to PCI DSS & 2.64 & 1.00 & 2.84 & 1.38 & -0.55 & 0.58 \\
\hline Lack of support & 2.97 & 1.11 & 3.93 & 1.69 & -2.01 & 0.05 \\
\hline Emerging features & 3.97 & 0.66 & 3.67 & 1.12 & 0.96 & 0.35 \\
\hline
\end{tabular}

Notes: ${ }^{1}$ Mean $(1=$ Strongly disagree, $5=$ Strongly agree $)$

${ }^{2}$ Standard Deviation ${ }^{3} \mathrm{t}$ statistics (independent samples t-test) ${ }^{4}$ Significance

There is not a statistically significant difference between the chain and independent restaurants mean for factors of PCI DSS compliance:

- Barriers to PCI DSS; $\mathrm{t}=0.99, \mathrm{p}=0.33$

- Lack of support; $\mathrm{t}=0.74, \mathrm{p}=0.46$

- Emerging features; $\mathrm{t}=-0.28, \mathrm{p}=0.78$

Therefore, hypothesis $\mathrm{H}_{\mathrm{D} 1}$ ("There is a significant difference in PCI DSS compliance between chain restaurants versus independent restaurants.”) was rejected. 
Due to the fact that there is a statistically significant difference between restaurants which identify themselves as innovators or followers from a Business Leadership perspective for PCI DSS compliance on "Lack of support", $\mathrm{t}=-2.03, \mathrm{p}=0.05$ but not a statistically significant difference on "Barriers to PCI DSS", $\mathrm{t}=-1.02, \mathrm{p}=0.31$ and "Emerging features", $\mathrm{t}=0.57, \mathrm{p}=$ $0.58, \mathrm{H}_{\mathrm{D} 2}$ was partially supported, at $\alpha \leq 0.05$.

Although there is a statistically significant difference between restaurants which identify themselves as innovators or followers from a Technology Leadership perspective for PCI DSS compliance on "Lack of support", $\mathrm{t}=-2.01, \mathrm{p}=0.05$, there is not a statistically significant difference on "Barriers to PCI DSS", $\mathrm{t}=-0.55, \mathrm{p}=0.58$ and "Emerging features", $\mathrm{t}=0.96, \mathrm{p}=$ 0.35. Therefore, hypothesis $\mathrm{H}_{\mathrm{D} 3}$ was partially supported, at $\alpha \leq 0.05$.

There is not a statistically significant difference between restaurants with IT educated IT managers versus non-IT educated IT managers mean for factors of PCI DSS compliance:

- Barriers to PCI DSS; $\mathrm{t}=0.35, \mathrm{p}=0.73$

- Lack of support; $\mathrm{t}=1.04, \mathrm{p}=0.30$

- Emerging features; $\mathrm{t}=0.97, \mathrm{p}=0.34$

Therefore, hypothesis $\mathrm{H}_{\mathrm{D} 4}$ ("There is a significant difference in PCI DSS compliance between restaurants with IT educated IT managers versus non-IT educated IT managers.”) was rejected. 


\section{CHAPTER FIVE:}

\section{CONCLUSIONS AND RECOMMENDATIONS}

Based on the findings of this study, the following conclusions may be made.

Among all respondents who are responsible for information technology (IT) management in their companies, only about $40 \%$ have IT as their sole job function. A majority of the respondents have IT as their secondary job function. This supports the previous studies' findings that IT is still not a major job function in restaurant companies (Cobanoglu, 2007). With the increased dependence on IT and other compliance requirements such as Payment Card Industry Data Security Standards (PCI DSS), restaurateurs may view their IT management policy and create a formal IT structure that supports the entire operation. This finding is also in line with another finding in the study: Business Leadership versus Technology Leadership. A majority of the respondents identified their companies as an innovator from a business perspective while only one third of the companies identified themselves as a leader from a technology perspective.

On average $37 \%$ of companies' IT budgets were allocated to capital expenditures, which include investing in new technology, innovation, etc. On the other hand, on average $61.8 \%$ of the IT budget was allocated to operating expenditures, which include maintaining systems, licensing, and fees. This finding is somewhat in line with results found by the Info Tech Research Group (Johnston, 2015) that “a company's total percentage of all expenditures should be 33 percent for capital assets and 67 percent for operating expenses”. Additionally, it can easily be observed that IT budgets in restaurants are increasing. Findings of the study indicated 
that Point of Sale Systems (Front of House and Back of House features) continue to dominate the IT spending in respondents' restaurants. The spending for mobile technologies continues to increase even though these technologies constitute only nine percent of the total spending currently.

The top five main drivers for company's IT efforts are: "Business efficiency", "Enhanced guest service”, “Employee productivity”, "Security/compliance (PCI and payments)”, and “Costsaving measures”. These drivers are in line with Kasavana' (2011) and Ansel and Dyer (1999).

The main three challenges for restaurant technology companies are "Insufficient IT budgets to keep pace with needed investments", "The technology itself is insufficient to meet our needs", and "Guests expect greater technology than we can keep pace with". This finding is also supported by Fellah (2015). This may be explained with the fact that restaurateurs do not see IT as a major job function, rather as a cost-center. A problem of insufficient investments in IT may disappear, as technology becomes an integral part of business operations and its positive impact to the bottom line becomes clearer. Additionally, according to National Restaurant Association (2015a), "technology rapidly is becoming an expectation rather than a novelty when dining out". As a result, $25 \%$ of the consumers state that technology is an important decision making for choosing a restaurant. Therefore, restaurants may allocate more budgets to meet customer expectations in this area, and consider IT as a major job function.

Top five used POS FOH technology features are "POS hardware", "Touch screen", "POS software", "Gift card, integration", and "Integrated credit card swipe into POS". The five least used technology features are "Social media activity integrated into POS and/or CRM platform", "Tableside payment device", "Tableside ordering device (tablet, other hardware)", "Near field communications capability", and "Bill pay via customers' mobile phone". This finding makes 
sense as the least utilized technologies are emerging technologies. As these technologies develop further, one can predict that they will be used by more restaurants. This is supported by another finding in this study. Restaurant managers have plans to implement "Bill pay via customers' mobile phone", and "Social media activity integrated into POS and/or CRM platform" technology features into their FOH operation technology systems in the future. Additionally, "POS Integration into online ordering", "Barcode scanners", "Digital signage" and "Take-out/Delivery system" are the some other technology features that managers plans to add into the $\mathrm{FOH}$ operations' technology systems in their restaurants.

Top five used POS BOH technology features are "Accounting/Financial software", "Enterprise reporting", "Inventory management software", "Kitchen printers", and "Company intranet". The five least used technology features are "Labor screening and recruitment tools", "Real-time, web-based reporting", "Kitchen management", "Customer relationship management system" and "Mobile device for manager use". These underutilized hardware/software may bring potential benefits of cost savings and enhanced productivity. Some of the restaurant managers have realized their importance and have plan to implement "Real-time, web-based reporting" and "Mobile device for manager use" technology feature to their restaurant in the future. Additionally, "Business intelligence system" is another POS BOH features that restaurant managers wish to have in the future.

There is a positive point of view about Mobile POS devices among the restaurant managers. Respondents agreed with the statements: "Mobile POS helps serve guests more quickly", "Mobile POS terminals increase guest satisfaction", and "Mobile credit card terminals reduce credit card skimming." 
Restaurateurs may do well by developing mobile app for their restaurants, or, at the very least, optimizing their websites for mobile phones. Alternatively, restaurants may utilize existing apps, such as Yelp, to make sure that the restaurant is reaching target customers and their feedbacks or reviews. Finally, the reviews in these different apps need to be monitored on a continuing basis by management.

The findings indicated that the restaurants comply with $87 \%$ of PCI DSS on average. Even though this appears a high percentage, normally PCI DSS compliance should be $100 \%$ among the restaurants that accept, process, and transmit credit card information. PCI DSS requirements do not accommodate a partial compliance. A restaurant may deem "not compliant" even if one of the PCI DSS standards is not met. Restaurants may do well by allocating resources on PCI DSS compliance as a data breach can cost restaurants significant resources as fines. The average cost of a data breach in 2010 was $\$ 7.2$ Million (Stepleton, 2012). About $21 \%$ of the respondents indicated that they use vendor supplied default passwords. This represents a significant potential risk for restaurants as these passwords are highly known publicly and hackers use them widely in data breaches.

There is no statistically significant difference between the Chain and Independent restaurants mean for factors of POS FOH technology features. In addition, there is no statistically significant difference between the IT educated IT managers and non-IT educated IT managers' opinions with regard to the factors of POS FOH technology features. These findings are expected due to the fact that these features are the mission critical of any restaurant. Mission critical systems are defined as systems that are integral to the operation of a restaurant (Collins, Cobanoglu and Bilgihan, 2013). The means of mobile payment features and emerging applications for POS FOH technology features differ significantly between innovators and 
followers. This finding is expected as innovator restaurant companies are expected to invest in emerging and new technologies earlier than follower restaurant companies.

The means of essential functions and cloud applications differ significantly for POS BOH technology features for chain and independent restaurants. Essential functions factor consisted of the following variables: "Enterprise management software", "Labor management", “Accounting/financial software”, "Business intelligence system”, "Inventory management software" and "Real-time, web-based reporting". This finding may be attributed to the necessity of the essential functions in the chain restaurants. Due to the fact that chain restaurants are composed of multiple units, they may need these functions more than independent restaurants which are usually have one or few units.

In terms of mobile POS perspectives, innovator restaurants from technology leadership perspective agree significantly more in advantages of mobile POS ("Mobile POS helps serve guests more quickly", "Mobile POS terminals increase guest satisfaction", "Mobile credit card terminals reduce credit card skimming" and "Mobile POS terminals "wow" guests") and webenabled mobile POS features ("My company has a mobile app" and "My company has a website that is optimized for mobile devices"). Innovator companies are expected to experiment with new technologies before follower companies. Therefore, this is another expected finding. Additionally, IT educated managers realize the disadvantages of mobile POS features significantly more than non-IT educated managers.

In terms of PCI DSS compliance, there are some significant differences between innovator and follower restaurant companies and between IT educated managers and non-IT educated managers. Followers need more support from vendors and franchisors in PCI DSS compliance. As expected, there is no significant difference between chain and independent 
restaurants, as well as between IT educated restaurant managers and non-IT educated restaurant managers with regard to their opinions on PCI DSS compliance.

Future research may include the replication of this study every other year to keep track of the trends in restaurant technology. In addition, the impact of technology on restaurant customers' satisfaction is another future research topic. Finally further research is needed in emerging technology from both operators and customers' perspectives. 


\section{REFERENCES}

American Hotel \& Lodging Association. (2006). Food and Beverage Systems. Retrieved from http://www.ahla.com/uploadedFiles/AHLA/Members_Only/_Common/technology_prime rs_pdf/88126NEI01ENGE.pdf

Andaleeb, S., \& Conway, C. (2006). Customer satisfaction in the restaurant industry: an examination of the transaction-specific model. Journal of Services Marketing, 20(1), 311.

Ansel, D., \& Dyer, C. (1999). A framework for restaurant information technology. The Cornell Hotel and Restaurant Administration Quarterly, 40(3), 74-4.

Barney, J. (2015). 15 Firm resources and sustained competitive advantage.International Business Strategy: Theory and Practice, 283.

Barua, A., Kriebel, C. H., \& Mukhopadhyay, T. (1995). Information technologies and business value: An analytic and empirical investigation. Information systems research, 6(1), 3-23.

Berezina, K., Cobanoglu, C., Miller, B. L., \& Kwansa, F. A. (2012). The impact of information security breach on hotel guest perception of service quality, satisfaction, revisit intentions and word-of-mouth. International journal of contemporary hospitality management, 24(7), 991-1010.

Bienstock, C. C., Stafford, M. R., \& Stafford, T. F. (2015). The Role of Technology in Industrial Customers' Perceptions of Logistics Service Quality and Their Future Purchase Intentions. In Revolution in Marketing: Market Driving Changes (pp. 122-122). Springer International Publishing.

Binkley, J. K. (2006). The effect of demographic, economic, and nutrition factors on the frequency of food away from home. Journal of Consumer Affairs, 40(2), 372-391.

Bosworth, B. P., \& Triplett, J. E. (2001). What's New About the New Economy? IT, Economic Growth and Productivity. International Productivity Monitor, 2, 19-30.

Brown, J. D. (2009). Choosing the right type of rotation in PCA and EFA. JALT Testing \& Evaluation SIG Newsletter, 13(3), 20-25.

Bryjolfsson, E., \& Hitt, L. M. (1998). Beyond the productivity Paradox: Computers are the catalyst for bigger changes. Communication of the ACM.

Brynjolfsson, E., \& Hitt, L. M. (2000). Beyond computation: Information technology, organizational transformation and business performance. The Journal of Economic Perspectives, 23-48.

Buhalis, D. (1998). Information technologies in tourism: Implications for the tourism curriculum (pp. 289-297). Springer Vienna.

Buhalis, D. (2003). eTourism: Information technology for strategic tourism management. Pearson Education.

Byrne, P. J., Capps, O., \& Saha, A. (1998). Analysis of quick-serve, mid-scale, and up-scale food away from home expenditures. The International Food and Agribusiness Management Review, 1(1), 51-72. 
Child, D. (2006). The essentials of factor analysis. ( $3^{\text {rd }}$ ed.). New York, NY: Continuum International Publishing Group.

Cho, W., \& Olsen, M. D. (1998). A case study approach to understanding the impact of information technology on competitive advantage in the lodging industry. Journal of Hospitality \& Tourism Research, 22(4), 376-394.

Churchill Jr, G. A. (1979). A paradigm for developing better measures of marketing constructs. Journal of marketing research, 64-73.

Clemons, E. K. (1986). "Information Systems for Sustainable Competitive Advantage." Information \& Management, 11 (3): 131-36.

Cobanoglu, C. (2007). A critical look at restaurant network security: Attacks, prevention tools, and practices. Journal of Foodservice Business Research, 10 (1). 31-50.

Cobanoglu, C. (2012). New Management Technologies Fill Missing Tech Links. Hospitality Technology Magazine. Retrieved from http://hospitalitytechnology.edgl.com/columns/New-Management-Technologies-FillMissing-Tech-Links79439

Cobanoglu, C., Erdem, M., Nusair, K.K., \& Berezina, K. (2012). 14 ${ }^{\text {th }}$ Annual Restaurant Technology Study. Hospitality Technology. Retrieved from http://www.hospitalityit.com/pdfs/2012resttechstudy.pdf

Collins, G. R., \& Cobanoglu, C. (2008). Hospitality information technology: Learning how to use it $\left(6^{\text {th }}\right.$ ed.). Dubuque, IA: Kendall/Hunt

Collins, G., Cobanoglu, C., \& Bilgihan, A. (2013). Hospitality Information Technology: Learning How to Use it ( $7^{\text {th }}$ Ed.) Kendall Hunt.

Collins, G., Cobanoglu, C., \& Malik, T (2003). Hospitality Information Technology: Learning How to Use it $\left(5^{\text {th }} \mathrm{Ed}\right)$. Kendall Hunt.

Comrey, L.A. \& Lee, H.B. (1992). A first course in factor analysis ( $2^{\text {nd }}$ ed.). Hillside, NJ: Lawrence Erlbaum Associates.

Connolly, D. J., Haley, M. G., (2008). PCI DSS Compliance: Just Whose Responsibility is It? Hospitality Technology. Retrieved from http://www.htmagazine.com/ME2/dirmod.asp?sid=\&nm=\&type=MultiPublishing \&mod= PublishingTitles\&mid=3E19674330734FF1BBDA3D67B50C82F1\&tier=4\&id=D70138 F32BB54C2ABED5EFDB27ACB157

Costello, A. B., \& Osborne, J. (2005). Best practices in exploratory factor analysis: four recommendations for getting the most from your analysis. Practical Assessment Research \& Evaluation, 10(7)

Cowton, C. J. (1998). The use of secondary data in business ethics research. Journal of Business Ethics, 17(4), 423-434.

Creamer, D., \& Lorden, A.A (2014). POS software trend report 2015. Hospitality Technology. Retrieved from http://hospitalitytechnology.edgl.com/news/POS-Software-Trend-Report201597065

Curry, A., \& Stancich, L. (2000). The intranet - an intrinsic component of strategic information management?. International journal of information management, 20(4), 249-268.

Czesany, S. (2006). Hospodarsky cyklus. Linde Praha, Praha.

David, J. S., Grabski, S., \& Kasavana, M. (1996). The productivity paradox of hotel-industry technology. The Cornell Hotel and Restaurant Administration Quarterly, 37(2), 64-70. 
Debackere, K., Verbeek, A., Luwel, M., \& Zimmermann, E. (2002). Measuring progress and evolution in science and technology-II: The multiple uses of technometric indicators. International Journal of Management Reviews, 4(3), 213-231.

Dedrick, J., Gurbaxani, V., \& Kraemer, K. L. (2003). Information technology and economic performance: A critical review of the empirical evidence. ACM Computing Surveys (CSUR), 35(1), 1-28.

DeMicco, F., Cobanoglu, C., Dunbar, J., Grimes, R., Chen, C., \& Keiser, J. R. (2015). Restaurant Management: A Best Practices Approach. Dubuque, IA: Kendall/Hunt.

Devaraj, S., \& Kohli, R. (2003). Performance impacts of information technology: Is actual usage the missing link?. Management science, 49(3), 273-289.

DeVellis, R. F. (2012). Scale development: Theory and applications ( $3^{\text {rd }}$ ed.). Thousand Oaks, CA: Sage Publications, Inc.

Digital Signage Federation. (N.A.). Primary benefits of digital signage/menu boards for restaurants and QSR locations. Retrieved from http://www.digitalsignagefederation.org/Resources/Documents/Articles\%20and\%20Whit epapers/Primary_Benefits_DSMenuBoards.pdf

Federal Trade Commission. (2014). Consumer sentinel network data book for JanuaryDecember 2013. Retrieved from https://www.ftc.gov/system/files/documents/reports/consumer-sentinel-network-databook-january-december-2013/sentinel-cy2013.pdf

Fellah, A. (2015, February 3). Meeting Guest Expectations is an Ongoing Challenge. Retrieved from http://www.wi-fi360.com/hotels-increase-tech-spending-2015/

Field, A. (2013). Discovering statistics using IBM SPSS statistics. Sage.

George, D. \& Mallery, P. (1999). SPSS for Windows Step by Step. A simple Guide and Reference. Allyn and Bacon, Boston, 359 pp.

Goch, L. (1999). The 51\% niche market. Best's Review; Life/Health Edition. Vol. 99, pp. 40-3.

Gorsuch, R. L. (1983). Factor analysis (2 ${ }^{\text {nd }}$ ed.) Hillsdale, NJ: LEA.

Grau, E. (2007). Using Factor Analysis and Cronbach's Alpha to Ascertain Relationships Between Questions of a Dietary Behavior Questionnaire. In Proceedings of the Survey Research Methods Section, ASA.

Ham, S., Kim, W. G., \& Jeong, S. (2005). Effect of information technology on performance in upscale hotels. International Journal of Hospitality Management, 24(2), 281-294.

Hatcher, L. (1994). A step-by-step approach to using the SAS system for factor analysis and structural equation modeling. Cary, NC:SAS Institute, Inc.

Hayes, J., 2002. Industry execs: best customer feedback info is 'real' thing. Nation's Restaurant News March 18, 36(11)

Horovitz, B. (2012, December 10). Consumers demanding more mobile meal options. USA Today. Retrieved from http://www.usatoday.com/story/money/business/2012/12/10/mobile-meal-orderingrestaurants/1759007/

Hospers, G. J. (2005). Joseph Schumpeter and his legacy in innovation studies. Knowledge, Technology \& Policy, 18(3), 20-37.

Hospitality Technology Magazine. (2015, February 26). Increasing profits and reducing theft with biometric-enabled POS. Retrieved from http://hospitalitytechnology.edgl.com/news/Increasing-Profits-and-Reducing-Theft-withBiometric-Enabled-POS98547 
Hua, N., \& Templeton, A. (2010). Forces driving the growth of the restaurant industry in the USA. International Journal of Contemporary Hospitality Management, 22(1), 56-68.

Hua, N., Morosan, C., \& DeFranco, A. (2015). The other side of technology adoption: Examining the relationships between e-commerce expenses and hotel performance. International Journal of Hospitality Management, 45, 109-120.

Huo, Y. H. (1998). Information technology and the performance of the restaurant firms. Journal of Hospitality \& Tourism Research, 22(3), 239-251.

Johnston, K. (2015). Differences and Similarities of Capital and Operational Budgeting. Retrieved from http://smallbusiness.chron.com/differences-similarities-capitaloperational-budgeting-33149.html

Jorgenson, D. W. (2001). Information technology and the U.S. economy (Presidential address to the American Economic Association). American Econ. Rev. 91, 1, 1-32.

Jorgenson, D. W., \& Stiroh, K. J., (2000). Raising the speed limit: US economic growth in the information age. Brookings papers on economic activity, 125-235.

Jorgenson, D. W., \& Vu, K. (2005). Information Technology and the World Economy. The Scandinavian Journal of Economics, 107(4), 631-650.

Kasavana, M. L. (2011). Managing Technology in the Hospitality Industry (6th ed.). Lansing, MI: The American Hotel \& Lodging Educational Institute.

Kauffman, R. J., \& Walden, E. A. (2001). Economics and Electronic Commerce: Survey and Directions for Research. International Journal of Electronic Commerce (5:4), pp. 5-116.

Kim, H., \& Gu, Z. (2003). Risk-adjusted performance: a sector analysis of restaurant firms. Journal of Hospitality \& Tourism Research, 27(2), 200-216.

Kim, T. G., Lee, J. H., \& Law, R. (2008). An empirical examination of the acceptance behaviour of hotel front office systems: An extended technology acceptance model. Tourism Management, 29(3), 500-513.

Kim, Y. G., \& Lim, J. (2011). A POS system based on the remote client-server model in the small business environment. Management Research Review,34(12), 1334-1350.

Kimes, S. E. (2008). The role of technology in restaurant revenue management. Cornell Hospitality Quarterly, 49(3), 297-309.

Kimes, S. E., \& Collier, J. (2014). Customer-facing payment technology in the U.S. restaurant industry. Cornell Hospitality Reports, 14(12), 6-17.

Kinsey, J. (1983). Working wives and the marginal propensity to consume food away from home. American Journal of Agricultural Economics, 65(1), 10-19.

Kline, R. B. (2005). Principles and practice of structural equation modeling (2nd ed.). New York, NY: Guilford.

Korotayev, A. V. \& Tsirel, S. V. (2010). A Spectral Analysis of World GDP Dynamics: Kondratieff Waves, Kuznets Swings, Juglar and Kitchin Cycles in Global Economic Development, and the 2008-2009 Economic Crisis. Structure and Dynamics. 4(1): 3-57.

Kulatilaka, N. H., \& Venkatraman, N. (2001). Strategic Options in the Digital Era. Business Strategy Review (12:4), pp. 7-15.

Lam, T., Cho, V., \& Qu, H. (2007). A study of hotel employee behavioral intentions towards adoption of information technology. International Journal of Hospitality Management, 26(1), 49-65.

Lang, J. (2006). Is the Web Really a Sales Builder?. Restaurant Business, 105(5), 11-12.

Laudon, K. C., and J. P. Laudon. (2010). Management Information Systems: Managing the Digital Firm. 11th ed. Upper Saddle River, NJ: Pearson Prentice Hall. 
Law, R., Buhalis, D., \& Cobanoglu, C. (2014). Progress on information and communication technologies in hospitality and tourism. International Journal of Contemporary Hospitality Management, 26(5), 727-750.

Law, R., Leung, R., \& Buhalis, D. (2009). Information technology applications in hospitality and tourism: A review of publications from 2005 to 2007. Journal of Travel \& Tourism Marketing, 26(5-6), 599-623.

Leung, R., \& Law, R. (2013). Evaluation of hotel information technologies and EDI adoption the perspective of hotel IT managers in Hong Kong. Cornell Hospitality Quarterly, 54(1), 25-37.

Liang, T. P., \& Tang, M. J. (1992). VAR analysis: a framework for justifying strategic information systems projects. ACM SIGMIS Database, 23(1), 27-35.

Liddle, A.J. (2002). NRA tech poll bolsters think-tank's 2010 forecast. Nation's Restaurant News November 26, 36(47)

Lo, A. S., Stalcup, L. D., \& Lee, A. (2010). Customer relationship management for hotels in Hong Kong. International Journal of Contemporary Hospitality Management, 22(2), 139-159.

Lorden, A.A., (2012, February 21). Industry outlook. Hospitality Technology. Retrieved from http://hospitalitytechnology.edgl.com/news/Industry-Outlook--78720

Lucas, P. (2003, November 1). Wireless Gets a New Lease on Life. Credit Card Management Retrieved from http://business.highbeam.com/137021/article-1G1-110621368/wirelessgets-new-lease-life

Madhavaram, S., \& Appan, R. (2015, January). Deconstructing Research on Information Technology (IT) Capabilities: Implications for Marketing Strategy. InProceedings of the 2010 Academy of Marketing Science (AMS) Annual Conference (pp. 25-25). Springer International Publishing.

Manion, C., \& DeMicco, F. J. (2005). Handheld wireless point of sale systems in the restaurant industry. Journal of Foodservice Business Research, 7(2), 103-111.

Mastroberte, T. (2014, September 5). What's new in POS hardware for 2014. Hospitality Technology. Retrieved from http://hospitalitytechnology.edgl.com/news/What-s-New-inPOS-Hardware-for-201495084

Matsunaga, M. (2010). How to factor-analyze your data right: Do's, don'ts, and howto's. International Journal of Psychological Research, 3(1), 97-110.

McCall, M., \& Belmont, H. J. (1996). Credit card insignia and restaurant tipping: Evidence for an associative link. Journal of Applied Psychology, 81(5), 609.

McCracken, V. A., \& Brandt, J. A. (1987). Household consumption of food-away-from-home: total expenditure and by type of food facility. American Journal of Agricultural Economics, 69(2), 274-284.

McFarlan, F. W. (1984). "Information Technology Changes the Way You Compete." Harvard Business Review, 62 (3): 98-103.

Mell, P., \& Grance, T. (2011). The NIST definition of cloud computing.

Melville, N., Kraemer, K., \& Gurbaxani, V. (2004). Review: Information technology and organizational performance: An integrative model of IT business value. MIS quarterly, 28(2), 283-322.

Mihalic, T., \& Buhalis, D. (2013). ICT as a new competitive advantage factor-case of small transitional hotel sector. Economic and Business Review, 15(1), 33-56. 
Mithas, S., Tafti, A. R., Bardhan, I., \& Goh, J. M. (2012). Information technology and firm profitability: mechanisms and empirical evidence. Mis Quarterly, 36(1), 205-224.

Mogelonsky, M. (1998). Food on demand. American Demographics, Vol. 20 No. 1, p. 57.

Mogotlhwane, T., Khosrowshahi, F., \& Underwood, J. (2006, April). Information technology productivity paradox. In 6th International Postgraduate Research Conference.

National Restaurant Association. (2013). 2013 Restaurant Industry Pocket Factbook. Retrieved from http://www.restaurant.org/Downloads/PDFs/NewsResearch/Factbook2013_LetterSize.pdf

National Restaurant Association. (2014). Economist's notebook: Hospitality employee turnover rose slightly in 2013. Retrieved from http://www.restaurant.org/NewsResearch/News/Economist-s-Notebook-Hospitality-employee-turnover

National Restaurant Association. (2015a). 2015 Restaurant Industry Forecast. Retrieved from http://www.restaurant.org/Downloads/PDFs/NewsResearch/research/ForecastExecSummary2015-FINAL.pdf

National Restaurant Association. (2015b). 2015 Economic Engine. Retrieved from http://www.restaurant.org/Industry-Impact/Employing-America/Economic-Engine

Norton, D. (1999). SAP Strategic Enterprise Management: Translating Strategy into Action: The Balanced Scorecard. SAP AG.

Nunnally, J. C. (1978). Psychometric theory (2nd ed.). New York: McGraw-Hill

Nunnally, J. C., \& Durham, R. L. (1975). Validity, reliability, and special problems of measurement in evaluation research. In E. L. Struening \& M. Guttentag (Eds.), Handbook of evaluation research. Beverly Hills, CA: Sage.

Nyheim, P. D., McFadden, F. M., \& Connolly, D. J. (2005). Technology Strategies for the Hospitality Industry. Upper Saddle River, NJ: Prentice Hall.

O'Connor, P. (1996). Using computers in hospitality. Cassell plc.

Olsen, M. D. \& Connolly, J. D. (2000). Experienced-based Travel. Cornell Hotel and Restaurant Administration Quarterly, 41, 30.

Oronsky, C. R., \& Chathoth, P. K. (2007). An exploratory study examining information technology adoption and implementation in full-service restaurant firms. International Journal of Hospitality Management, 26(4), 941-956.

Osborne, J. W., Costello, A. B., \& Kellow, J. T. (2008). Best Practices in Exploratory Factor Analysis. In J. W. Osborne (Ed.), Best Practices in Quantitative Methods (pp. 205-213). Thousand Oaks, CA: Sage Publishing.

Oz, E. (2005). Information technology productivity: in search of a definite observation. Information \& Management, 42(6), 789-798.

Pallant, J. (2013). SPSS survival manual. (5th ed.) McGraw-Hill International.

Patil, S., \& Wongsurawat, W. (2015). Information Technology (IT) Outsourcing by Business Process Outsourcing/Information Technology Enabled Services (BPO/ITES) Firms in India--A Strategic Gamble. Journal of Enterprise Information Management, 28(1).

PCI Security Standards Council. (2011). PCI DSS Tokenization Guidelines. Retrieved from https://www.pcisecuritystandards.org/documents/Tokenization_Guidelines_Info_Supple ment.pdf

PCI Security Standards Council. (2012). Point-to-Point Encryption (P2PE), Retrieved from https://www.pcisecuritystandards.org/documents/P2PE_v1_1_FAQs_Aug2012.pdf

PCI Security Standards Council. (2013). PCI DSS v3.0. Retrieved from www.pcisecuritystandards.org/documents/pci_dss_v2.pdf 
Pizam, A. (Ed.). (2005). International encyclopedia of hospitality management. Routledge.

Porter, M. E. (1985). Competitive Advantage: Creating and Sustaining Superior Performance. New York: Free Press.

Prasad, M., Scornavacca, E., \& Lehmann, H. (2005). Using wireless personal digital assistants in a restaurant: impact and perceived benefits. InMobile Business, 2005. ICMB 2005. International Conference on (pp. 69-74). IEEE.

Prochaska, F. J., \& Schrimper, R. A. (1973). Opportunity cost of time and other socioeconomic effects on away-from-home food consumption. American Journal of Agricultural Economics, 55(4 Part 1), 595-603.

Redman, B. J. (1980). The impact of women's time allocation on expenditure for meals away from home and prepared foods. American Journal of Agricultural Economics, 62(2), 234237.

Rehman, S., \& Coughlan, J. (2013). An efficient mobile payment system based on NFC technology. Int. Sci. Index, 7, 1702-1706.

Riggs, N. (2013). Social media and your POS: The search for Bigfoot. Fast Casual. Retrieved from http://www.fastcasual.com/blogs/social-media-and-your-pos-the-search-for-bigfoot/

Rosenberg, N., \& Frischtak, C. R. (1984). Technological innovation and long waves. Cambridge Journal of Economics, 7-24.

Ruggless, R., (2003). Industry execs, educators seek ways to boost customer counts. Nation's Restaurant News December 15, 37(50)

Ruth, D., Brush, T. H., \& Ryu, W. (2015). The use of information technology in the provision of HR compensation services and its effect on outsourcing and centralization. Journal of Purchasing and Supply Management, 21(1), 25-37.

Rylander, R. G., Propst, D. B., \& McMurtry, T. R. (1995). Nonresponse and recall biases in a survey of traveller spending. Journal of Travel Research, 33 (4), 39-45.

Sambamurthy, V., Bharadwaj, A., \& Grover, V. (2003). Shaping Agility through Digital Options: Reconceptualizing the Role of Information Technology in Contemporary Firms. MIS Quarterly (27:2), pp. 237 - 263.

Satran, J. (2013, January 23). Credit Cards And Restaurants: Industries Mull 'Cashless' Dining Consequences. Retrieved from http://www.huffingtonpost.com/2013/01/23/credit-cardsrestaurants-cashless-dining_n_2482242.html

Schumpeter, J. A. (1934). The theory of economic development. Cambridge, MA: Harvard University Pres.

Schumpeter, J. A. (1939). Business cycles (Vol. 1, pp. 161-74). New York: McGraw-Hill.

Scornavacca, E., Prasad, M., \& Lehmann, H. (2006). Exploring the organisational impact and perceived benefits of wireless Personal Digital Assistants in restaurants. International Journal of Mobile Communications, 4(5), 558-567.

Siguaw, J., Enz, C., \& Namasivayam, K., (2000). Adaptation of information technology in US Hotels: Strategically driven objectives. Journal of Travel Research 39(2), 192-201.

Sledzik, K. (2013). Schumpeter's View on Innovation and Entrepreneurship.Management Trends in Theory and Practice,(ed.) Stefan Hittmar, Faculty of Management Science and Informatics, University of Zilina \& Institute of Management by University of Zilina.

Sonnenshein, M., (2014, October 06). Digital signs in restaurants offer surprising benefits. Gourmet Marketing. Retrieved http://www.gourmetmarketing.net/digital-signsrestaurants-offer-surprising-benefits/ 
Sood, A. \& Tellis, G. J. (2005). Technological Evolution and Radical Innovation. Journal of Marketing,152-168.

Stepleton, T. (2012). Data Breach Cost. Retrieved from http://www.zurichna.com/internet/zna/sitecollectiondocuments/en/products/securityandpr ivacy/data $\% 20$ breach $\% 20$ costs $\% 20 \mathrm{wp} \% 20$ part $\% 201 \% 20 \% 28$ risks, $\% 20$ costs $\% 20$ and $\% 20$ mitigation\%20strategies\%29.pdf

STR Analytics. (2014). HOST Almanac Highlights 2014. Retrieved from http://www.str.com/Media/Default/Samples/HOSTAlmanac_Highlights.pdf

Tabachnick, B. G., \& Fidell, L. S. (2013). Using multivariate statistics (6th ed.). Boston, MA: Allyn and Bacon.

Tanning, L., \& Tanning, T. (2013). How the Baltic States Transportation Companies Survived the Economic Crisis: The Lessons of Crisis. International Journal of Operations and Logistics Management, 2(4), 14-32.

Tanning, T., Saat, M., \& Tanning, L. (2013). Kondratiev wave: overview of world economic cycles. Global Business and Economics Research Journal, 2(2), 1-11.

Tesone, D. V. (2005). Hospitality information systems and e-commerce. John Wiley \& Sons, Inc. Thompson, B. (2004). Exploratory and confirmatory factor analysis: Understanding concepts and applications. American Psychological Association.

Thompson, S., Ekman, P., Selby, D., \& Whitaker, J. (2014). A model to support IT infrastructure planning and the allocation of IT governance authority.Decision Support Systems, 59, 108-118.

Tichy, O. (2011). Schumpeterian business cycles: past, present and future. Economics \& Management, 16.

Tijhuis, L., Brattli, B., \& Sæther, O. M. (2002). A geochemical survey of topsoil in the city of Oslo, Norway. Environmental Geochemistry and Health, 24(1), 67-94.

Trustwave. (2014). 2014 Trustwave Global Security Report. Retrieved from https://www2.trustwave.com/rs/trustwave/images/2014_Trustwave_Global_Security_Rep ort.pdf

U.S. Bureau of Economic Analysis. (2014a). Personal Consumption Expenditures by Type of Product. Retrieved from

http://www.bea.gov/iTable/iTable.cfm?ReqID=9\&step $=1$ \#reqid $=9 \&$ step $=3 \& i$ suri $=1 \& 90$ $3=70$

U.S. Bureau of Economic Analysis. (2014b). U.S. Bureau of Economic Analysis, Annual InputOutput Tables. Retrieved from

http://www.themanufacturinginstitute.org/ /media/A3407E22FF1D4177B3AA203227E0 C841.ashx

U.S. Bureau of Economic Analysis. (2015). Gross Domestic Product. Retrieved from http://www.bea.gov/iTable/iTable.cfm?ReqID=9\&step $=1$ \#reqid $=9 \&$ step $=3 \&$ isuri $=1 \& 90$ $3=5$

U.S. Bureau of Labor Statistics. (2012). Travel expenditures, 2005-2011: spending slows during recent recession. Beyond the Numbers, Vol. 1 No. 20, p. 1. Retrieved from http://www.bls.gov/opub/btn/volume-1/pdf/travel-expenditures-2005-2011-spendingslows-during-recent-recession.pdf

U.S. Department of Agriculture. (2014). Food Expenditures. Retrieved from http://www.ers.usda.gov/topics/food-choices-health/food-consumption-demand/foodaway-from-home.aspx 
U.S. Department of Labor. (2014). Women in the Labor Force: A Databook. Retrieved from http://www.bls.gov/cps/wlf-databook-2013.pdf

Walker, J., \& Maddan, S. (2008). Statistics in criminology and criminal justice: analysis and interpretation. Jones \& Bartlett Learning.

Walker, J.R., (2014) The restaurant: From concept to operation (7th ed.). Hoboken, NJ: John Wiley \& Sons, Inc.

Weill, P. (1992). The relationship between investment in information technology and firm performance: A study of the valve manufacturing sector. Information systems research, 3(4), 307-333.

Wester, J. (2013, January 28). Starbucks still feeling a buzz from mobile payments. Retrieved from http://www.fastcasual.com/news/starbucks-still-feeling-a-buzz-from-mobilepayments/

World Travel Organization Tourism Highlights. (2014). UNWTO Tourism Highlights 2014 Edition. Retrieved from http://dtxtq4w60xqpw.cloudfront.net/sites/all/files/pdf/unwto_highlights14_en_hr_0.pdf

Writing, A. (N.A.). Organizational uses of a PDA. Small Business. Retrieved from http://smallbusiness.chron.com/organizational-uses-pda-455.html

Wyckoff, D.D., \& Sasser, W.E. (1978) The Chain Restaurant Industry. Lanham, MD: Lexington Books.

Xiong, W., \& Luo, Y. J. (2012). A Study of IT Productivity Paradox in Luxury Hotels: A Case Study in Guangzhou [J]. Tourism Tribune, 4, 015.

Yen, S. T. (1993). Working wives and food away from home: the Box-Cox double hurdle model. American Journal of Agricultural Economics, 75(4), 884-895.

Yong, A. G., \& Pearce, S. (2013). A beginner's guide to factor analysis: Focusing on exploratory factor analysis. Tutorials in Quantitative Methods for Psychology, 9(2), 79-94. 


\section{APPENDIX A:}

\section{Letter of Permission from the Current Holder of the Data}

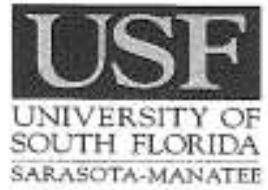

February 2, 2015

Muhittin Cavusoglu

8350 N. Tamiami Trail

Sarasota, FL 34243

Dear Mr. Cavusoglu

I hereby glve you permission to use my data set for the Restaurant Technology study for your thesis. Please let me know if you need any further documentation

Sincerely.

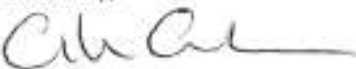

Dr. Cihan Cobanogiu

Dean \& Professor 